\title{
Recent Trends in Producing Ultrafine Grained Steels
}

\author{
Hossam Halfa \\ Steel Technology Department, Central Metallurgical Research and Development Institute (CMRDI), Helwan, \\ Egypt \\ Email: hossamhalfa@cmrdi.sci.eg, hossamhalfa@gmail.com
}

Received 3 May 2014; revised 23 June 2014; accepted 3 July 2014

Copyright @ 2014 by author and Scientific Research Publishing Inc.

This work is licensed under the Creative Commons Attribution International License (CC BY). http://creativecommons.org/licenses/by/4.0/

(c) (i) Open Access

\begin{abstract}
Ultrafine grained steels with grain sizes below about $1 \mu \mathrm{m}$ offer the prospect of high strength and high toughness with traditional steel compositions. These materials are currently the subject of extensive research efforts worldwide. Alloy design is one of the first considered issues, while designing new steel with targeted mechanical properties. However, the alloying content of steel does not fully determine the mechanical properties, but manufacturing procedure, hot rolling and cooling parameters, heat treatment parameters etc. are also of vital importance. For instance, same steel with different processing conditions can exhibit rather large variations in properties. To be precise, chemical composition with the processing parameters determines the microstructure, which in turn determines the properties of the steel. Steel is defined as an iron alloy containing $\mathrm{C}$, Mn and Si that are generally used as alloying elements in steel. Micro-alloying elements such as $\mathrm{Nb}$, $\mathrm{Ti} \mathrm{V}$, and $\mathrm{B}$, are considered to be effective, causing strengthening as well as microstructural refinement in small quantities below $0.1 \mathrm{wt} \%$ (therefore these are called micro-alloy elements) and are quite generally used in ultrafine grain steel. Substitution alloying elements, such as $\mathrm{Mo}, \mathrm{Ni}, \mathrm{Cr}$ and $\mathrm{Cu}$ are alloyed to suppress phase transformation temperatures, i.e. for reaching certain level of strengthening, since the strength of steel structures strongly depends on the phase transformation temperature. Accordingly, the alloy design of ultrafine grains steels with different structures generally relies on: i) carbon levels, ii) sufficient alloying to obtain the desired transformation temperature and iii) micro-alloying technology in conjunction with Thermo Mechanical Controlled Processes (TMCP). Also, both advanced thermo-mechanical processes and severe plastic deformation strategies are used to produce ultrafine grained steels. Both approaches are suited to produce submicron grain structures with attractive mechanical properties. This overview describes the various techniques to fabricate ultrafine grained steels.
\end{abstract}

\section{Keywords}

Ultrafine, Thermomechanical, Severe Plastic Deformation, Structure 


\section{Strengthening Mechanisms of Steel}

In principle, the strength of steel is contributed by a number of strengthening mechanisms as follows [1] [2]:

-Intrinsic strength of ferritic iron;

-Solid solution strengthening;

-Precipitation strengthening;

-Grain size strengthening;

-Dislocation strengthening.

The yield strength $\left(\Delta \sigma_{y}\right)$ can then be expressed as:

$$
\sigma_{y}=\Delta \sigma_{F e}+\Delta \sigma_{s s}+\Delta \sigma_{g s}+\Delta \sigma_{d i s}+\Delta \sigma_{p p t}
$$

In Equation (1), the strength has been expressed as a simple linear sum of individual strengthening mechanisms and has been applied in many cases extracting the different strengthening mechanisms in steels with bainitic microstructures [2].

Charleux et al. [3] have discussed the validity of the summing of the strengthening components in expressing the degree of strengthening in the case of Nb-Ti low carbon bainitic (LCB) steels. According to them, it is necessary to consider the relative length scales and strength of the strengthening obstacles. If they are significantly different, a linear addition would be appropriate. For instance, strength of ferrous alloys is derived from the solid solution strengthening (including base strength of iron) and grain size strengthening. On the other hand, precipitation and dislocation strengthening arise from a similar density and strength of obstacles, which dislocate sample on the glide plane. For example, Foreman and Makin [4] obtained a Pythagorean flow stress addition law for discrete obstacles on the slip plane in the case where a similar density of relatively strong discrete obstacles (i.e. forest dislocations) and relatively weak obstacles (i.e. precipitates) are present. Therefore an alternative way to express the yield strength as a function of individual strengthening mechanisms is a sum equation where precipitation and dislocation strengthening obey a Pythagorean law:

$$
\sigma_{y}=\Delta \sigma_{F e}+\Delta \sigma_{s s}+\Delta \sigma_{g s}+\left(\Delta \sigma_{d i s}^{2}+\Delta \sigma_{p p t}^{2}\right)^{1 / 2}
$$

In the following sections different strengthening mechanism will be presented and discussed in detail.

\subsection{Intrinsic Strength of Iron}

The strength of ferritic iron without significant impurities has been estimated to be 85 - 88 MPa [5] in a low carbon ferritic steel and this can be considered as the base strength to which the other components will be added to estimate the overall yield strength.

\subsection{Solid Solution Strengthening}

Solid solution strengthening arises because the size differences between the solute and solvent atoms and the strain field that interferes with the dislocations as they move through the lattice causing plastic flow. The most significant factor behind the solid solution seems to be the size difference between solvent (in steels, Fe) and solute atoms, but there are also evidences that differences in shear modulus and the relative chemical differences contribute to solid solution strengthening. Although many of the factors, which contribute to the energetics of dislocation movement, are known and have been assessed in experimental studies, there is, as yet, no complete theory and, therefore it is not yet possible to predict the strengthening effect for a particular element from the first principles [6].

Most practical approach to assess the solid solution strengthening is to use empirical relationships between alloying additions and tensile properties of steels. These equations are in form:

$$
\Delta \sigma_{s s}=\Sigma A_{i} * \mathrm{wt} \%
$$

where $A_{i}=$ factor for strengthening resulting from $1.0 \mathrm{wt} \%$ addition of element $i$. Table 1 shows $A_{i}$ values for some alloying elements generally used in LCB steels [2] [5] [7].

A reasonable assumption for aforementioned elements is that a major portion of these element is in solid solution and available for solid solution strengthening, since with exception of Mo, these elements do not have a great tendency to precipitate out of solid solution as carbides, nitrides or other complex precipitates in steels. In 
Table 1. Values $\mathrm{A}_{i}$ for some alloying elements generally used in LCB steels [2] [5] [7].

\begin{tabular}{cccccccc}
\hline Element & $\mathrm{Cr}$ & $\mathrm{Si}$ & $\mathrm{Ni}$ & $\mathrm{Al}$ & $\mathrm{Man}$ & $\mathrm{Cu}$ & Mo \\
\hline Amount/MPa/1 Weight\% & 0 & 84 & 33 & 30 & 32 & 38 & 11 \\
\hline
\end{tabular}

the case of Mo, the possible precipitation of MoC does not cause significant underestimation of solid solution strengthening, since the Mo content of investigated steels and the factor of Mo are both low. The very significant solid solution strengthening of $\mathrm{N}$ that is often reported in the literature is assumed to be zero, since the presence of strong nitride formers renders it unlikely that any significant levels of $\mathrm{N}$ will remain in solid solution. Carbon in solid solution would also be expected to provide a high level of solid solution strengthening with coefficient of a similar order to that of nitrogen. However, the solubility of carbon in ferrite and steels contain strong carbide formers, such as $\mathrm{Nb}$, Mo and $\mathrm{Ti}$ at ambient temperatures is very low, so that the contribution from carbon to solid solution strengthening is assumed to be negligible. In the B treated steels, Ti is added to bind $\mathrm{N}$, so that the B addition can remain in solid solution and be in the form such that it can be effective for the transformation hardening. However, any significant contribution from solid solution strengthening from B, although being an interstitial atom, is not expectable since it tends to occupy the sites on prior austenite boundaries rather than interstitial sites in grain interiors [2]. Solid solution strengthening can be obtained from $\mathrm{Si}, \mathrm{Mn}$, Mo and $\mathrm{Ni}$ alloying. Siwecki et al. [8] observed the increase of strength by $30 \mathrm{MPa}$ due to addition of $0.2 \mathrm{wt} \%$ of Mo in microalloyed steels, and also the change of yielding from discontinuous to continuous and improved heat affected zone toughness in Ti-V steels. According to Misra et al. [9], simultaneous additions of $0.3 \% \mathrm{Cu}$ and $0.15 \% \mathrm{Ni}$ can further enhance yield strength by $32.4 \mathrm{MPa}$ in a $690 \mathrm{MPa}$ grade steel.

\subsection{Precipitation Strengthening}

Strengthening effect by the precipitates relies on their interaction with dislocations. Essentially, precipitation strengthening is achieved by producing a particulate dispersion of obstacles to dislocation movement, which are produced by the second phase precipitation process. The degree of strengthening is not only dependent upon the nature of the interaction of precipitates with dislocations, but also on the volume fraction and the size of particles. In general, there are several mechanisms that can contribute to increase in strength by the precipitation. These mechanisms include chemical hardening arising from the development of antiphase boundaries, when dislocation cuts through a particle, coherency strengthening, which relates to coherency strains developed in the matrix around a coherent precipitate and dispersion hardening due to looping of dislocations around the precipitates in so-called Orowan manner [10].

\section{Strengthening of Steels by Microalloy Precipitates}

Three microalloy elements, namely $\mathrm{Ti}, \mathrm{Nb}$ and $\mathrm{V}$, are widely used as combinations to improve the mechanical properties of steels. A common feature of aforementioned microalloy elements is their tendency to react with $\mathrm{C}$ and $\mathrm{N}$ to form microalloy carbides, nitrides and carbonitrides, which can contribute to precipitation strengthening. Ti forms an extremely stable nitride, which is virtually insoluble in austenite and may be used for restricting grain grow growth during processing and removing nitrogen. Excess Ti can precipitate at lower temperatures as carbides, which contribute to precipitation strengthening [11]. Nb forms carbonitrides, which can precipitate quite readily in austenite under deformation (so called strain-induced precipitation) and resist recrystallization of austenite. Further precipitation of the remaining $\mathrm{Nb}$ in ferrite gives rise to precipitation strengthening [12]. $\mathrm{V}$ is the most soluble of the three microalloying and does not readily precipitate in austenite. VN is considerably stable compared to its carbides, so that their precipitation hardening is markedly enhanced with increasing $\mathrm{N}$ content in steel [12]. When precipitation of TiC, $\mathrm{NbC}$ or $\mathrm{V}(\mathrm{C}, \mathrm{N})$ takes place during cooling after the hot rolling it may occur in two different ways. During the inter-phase precipitation, where nucleation occurs on the austenite-ferrite phase boundary, producing a particle-rich sheet at the location, where the boundary is temporarily halted. Alternatively, homogeneous nucleation and growth of carbonitrides may occur in the newly formed ferrite [13]. Classically, it was believed that total C in steel could not influence homogenous precipitation in ferrite due to low equilibrium solubility.

\subsection{Grain Size Refinement Strengthening}

Grain size refinement is one of the best-established strengthening methods in steels, as well as in other metals. 
The well-known Hall-Petch equation describes the relation between ferrite grain size and the yield strength.

$$
\sigma_{y}=\sigma_{o}+k_{y} d^{-1 / 2}
$$

where $\sigma_{y}=$ yield strength, $\sigma_{o}=$ friction stress, $k_{y}=$ grain boundary resistance and $d=$ grain size.

According to Equation (4) the yield strength is dependent on the reciprocal of square root of the grain size. This type of relationship has been shown to be valid for grain sizes down to about $1 \mu \mathrm{m}$ [14].

\subsection{Dislocation Strengthening}

An increase in dislocation density results in a strength increment, because further motion and production of dislocations becomes more difficult. Bainitic ferrite contains a higher dislocation density than polygonal ferrite, for a part of the dislocation substructure of the deformed parent austenite can be inherited by bainite (plastic relaxation) and the growth of bainite may be accompanied by the formation of dislocations in and around bainite (plastic accommodation) leading to additional strengthening [15]. The relationship between dislocation density and strength increment can be described by:

$$
\Delta \sigma=\beta G b(\rho)^{1 / 2}
$$

where $\Delta \sigma=$ the increase in yield strength, $\beta=$ a constant, $b=$ Burgers vector, $G=$ shear modulus and $\rho=$ dislocation strengthening.

According to Takahashi and Bhadeshia [16], it might be assumed that for low alloy steels the dislocation density depends mainly on transformation temperature via the influence of latter on the strength of the parent and product phases. It should then be possible to treat all of the displacive transformations, such as martensite, bainite and Widmanstätten ferrite together. They have derived an empirical equation between the phase transformation and dislocation density (in $\mathrm{m}^{-2}$ ), which is valid over the range $570-920 \mathrm{~K}$ :

$$
\log \rho=9.2880+6880 / T-1780360 / T^{2}
$$

where $T=$ temperature in Kelvin.

Transmission electron microscopy has revealed a dislocation density of about $4 \times 10^{14} \mathrm{~m}^{-2}$ for an alloy with bainite starting temperature, Bs around $650^{\circ} \mathrm{C}$. This compares with allotriomorphic ferrite obtained in same steel at $800^{\circ} \mathrm{C}$ with a dislocation density of about $0.5 \times 10^{14} \mathrm{~m}^{-2}$. Edmonds and Cochrane [17] reported a value of $10^{14}$ $\mathrm{m}^{-2}$ for the dislocation density, attributing to the yield strength by approximately $145 \mathrm{MPa}$. Hulka and Heisterkamp [18] gave a value of about $1.5 \times 10^{14} \mathrm{~m}^{-2}$. The dislocation density seems to increase with decreasing transformation temperature. Irregular nature and high dislocation density are typical of low temperature transformation products (bainitic ferrite, acicular ferrite) formed under continuous cooling.

\subsection{Total Strengthening}

In total, the contributions of five strengthening mechanisms on yield strength (YS) level of 700 MPa strip are shown in Figure 1 [19]. However, even higher yield strengths of the order of 1030 MPa may be possible in HSLA steels with a fully bainitic structure. Simple summation is a simplistic case, marked deviations of the linearity in strengthening have been observed for mixtures of lower bainite/martensite [15] [20].

\section{Grain Refinement as a Unique Mechanism for Improving Strength and Toughness}

\subsection{Strength}

The yield stress for bcc steels processed by different methods is plotted in Figure 2 as a function of the inverse square root of the grain size for grain sizes ranging from 45 to $0.2 \mu \mathrm{m}$. The ultrafine microstructures (grain size less than $2 \mu \mathrm{m}$ ) were produced by various techniques: the open symbols display the results from the severe plastic deformation (SPD) methods; the full symbols in gray represent the results from the advanced thermomechanical process routes (ATP); the full symbols in black show the results from the conventional route (Conv).

The lower yield strength of the 0.13C-0.67Mn-0.14Si (wt\%) steel sheet produced by cold rolling and annealing [21] is shown by the solid diamond in Figure 2 where the grain size varied from 1.6 to $30 \mu \mathrm{m}$. The friction stress $\sigma_{i}$ is about $100 \mathrm{MPa}$ and the grain boundary resistance $k_{y}$ is $551 \mathrm{MPa} \mu \mathrm{m}^{1 / 2}$ [21], according to the 


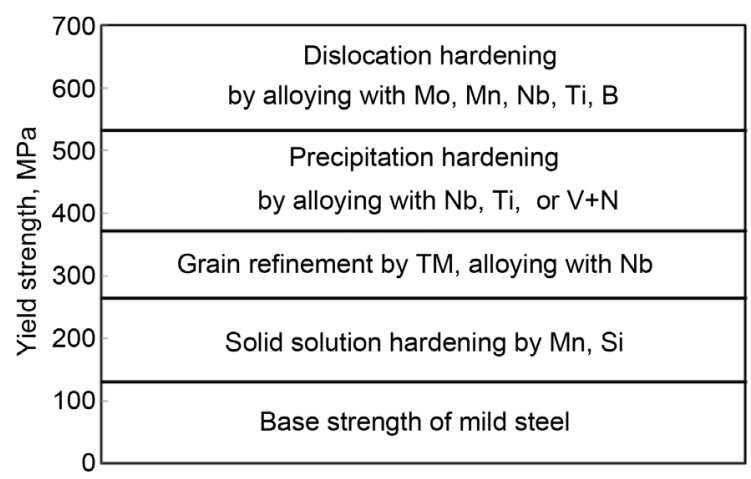

Figure 1. Strengthening mechanisms yielding to the YS level of $700 \mathrm{MPa}$ [19].

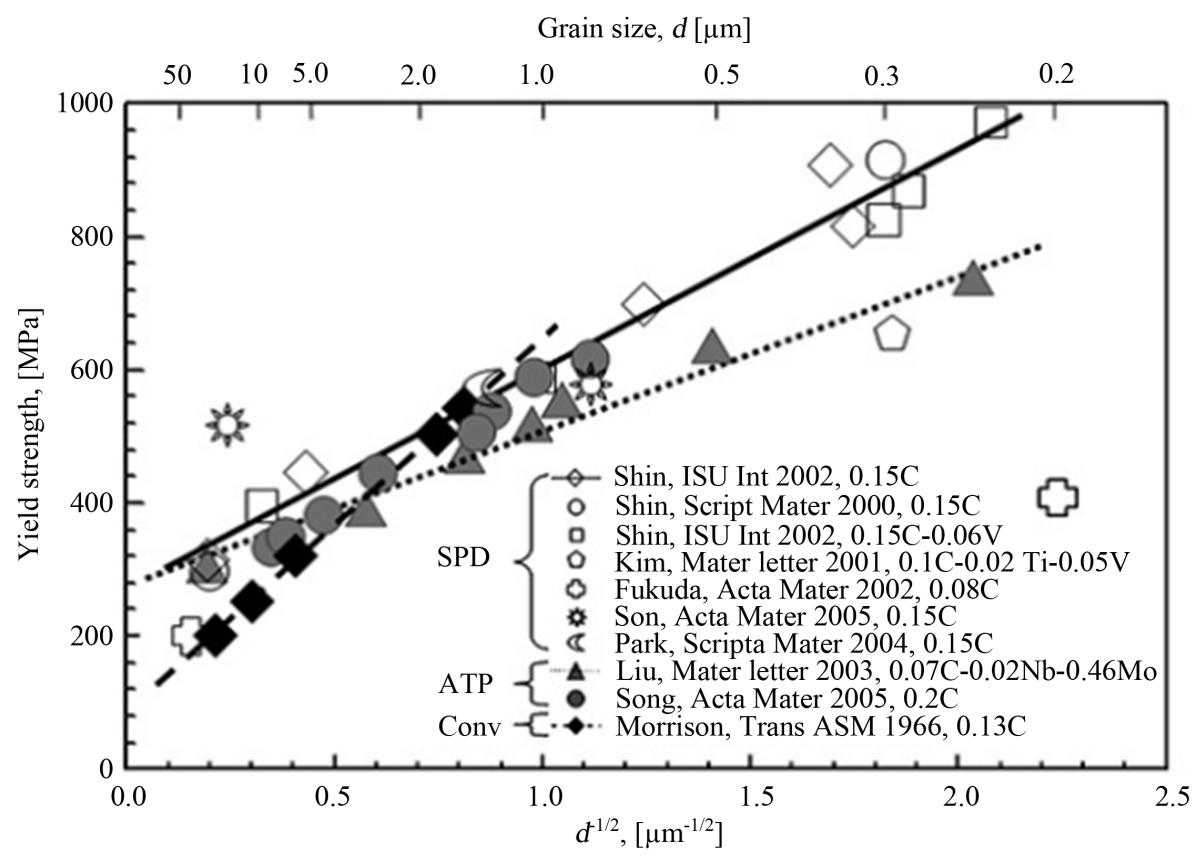

Figure 2. Hall-Petch relationship in ultrafine grained bcc steels [22]-[26]. The open symbols display the results from the SPD methods; the full symbols in gray represent the results from the advanced thermomechanical process routes (ATP); the full symbols in black show the results from the conventional route (Conv). The straight lines show the Hall-Petch relation for different steels.

work of Morrison. Equal-channel angular pressing (ECAP) (at $623 \mathrm{~K}$ ) followed by annealing at temperatures between 373 and $873 \mathrm{~K}$ produced steels with grain sizes ranging from about 0.23 to $10 \mu \mathrm{m}$ in a low carbon (0.15C-1.1Mn-0.25Si, wt\%) and a low alloy steel (0.15C-1.1Mn-0.25Si-0.06V, wt\%) [22]. The $k_{y}$ value in Figure 2 (slope of bold line) is smaller in the steel processed by ECAP compared with the results of Morrison (dashed bold line). The yield stress for a grain size of $30 \mu \mathrm{m}$ before ECAP is above the value predicted by Morrison, while the yield stress after ECAP is below the line. This phenomenon also reappears in other studies from both SPD and advanced thermomechanical processes [23]-[29]. That is, while the Hall-Petch relationship in steels may extend to the submicron range, the parameter $k_{y}$ may decrease. For steels with submicron grain sizes produced by ECAP, the yield stress for steels with a carbon content less than $0.1 \mathrm{wt} \%$ [23] [26] is notably smaller than for the steels with $0.15 \mathrm{wt} \%$ carbon [22] for a given grain size. The reason for this behavior is not fully understood, but could result from differences in grain size measurement. The data for samples with a dual phase microstructure (displayed by the sun symbol in Figure 2) [24] do not follow the line predicted by the Hall-Petch relationship as mentioned above. It seems that a smaller increment in stress is achieved in the dual 
phase steel when the ferrite grain size is refined from 19.4 to $0.8 \mu \mathrm{m}$. It is not clear whether this is related to some variation in the amount and morphology of the second phase after grain refinement.

It should be stressed that in early investigations by Morrison [21], as shown in Figure 2, the different grain sizes were produced by cold rolling and subsequent annealing at different temperatures. This offered the advantage to alter only one parameter - the grain size. In the investigation by Song [29], (where the initial motivation was not to measure the value of $k_{y}$ and $\sigma_{i}$ in the Hall-Petch equation), the coarse microstructure consisted of conventional ferrite and pearlite. When refined into the ultrafine microstructure, however, it comprised ferrite and fine spheroidized cementite. A smaller $k_{y}$ value was found by Shin et al. [27], which might also be attributed to the change in overall microstructure (along with grain size) in their study. By use of the ECAP technique, the initial coarse grained ferrite-pearlite microstructure was severely deformed. After four deformation passes, a microstructure with finer ferrite and a partially spheroidized pearlite was obtained. Thus, the smaller $k_{y}$ value in some studies on ultrafine ferrite might be the result of a reduction in the yield strength by replacing harder pearlite with softer ferrite and spheroidized cementite in the ultrafine microstructure. The presence of low misorientations between some grains in the ultrafine ferrite may also contribute to the reduced $k_{y}$ value in comparison to conventional "coarse" ferrite with high misorientations. It should be mentioned that most of the submicron microstructures measured for the SPD technique consist of large quantities of low-angle grain boundaries, and grain dimensions measured refer to the thickness of stretched microbands, which is not the same as average grain diameter. Further consideration of grain morphologies and appropriate characterization methods may be worthwhile to define the Hall-Petch relationship more accurately.

Unfortunately, the estimation of the contribution of the grain size in bainitic structures is more complicated than in simple ferritic steels. The nature of bainite, lath size and shape as well as carbide size and distribution, vary systematically with the temperature of transformation. All features are refined at low transformation temperatures. Furthermore, situation becomes far more complicated due to the fact that in bainitic structures, boundaries can be present with both low and high angle misorientations [2]. However in lath type, rather than polygonal structures, several publications suggest that the strength is related to reciprocal of some characteristic scale in microstructures, rather than $d^{-1 / 2}$ type relationship in the Hall-Petch equation [2] [15] [28]. Hence, yield strength can be expressed as:

$$
\sigma_{y}=\sigma_{o}+k_{y} d^{-1}
$$

where $\sigma_{y}, \sigma_{o}$ and $k_{y}$ have identical meanings to Equation (4), but these have different values. The microstructural factor relating to grain size $\mathrm{d}$ in Equation (7) is not completely clear. Brozzo et al. [30], in their studies on the low $\mathrm{C}$ bainitic steels, found a clear relationship between lath width and strength but only a weak correlation with packet size. This would indicate that slip across laths is the controlling factor.

\subsection{Impact Toughness}

Steel is still one of the traditional engineering materials widely used in industry. The high strength and high toughness steel is the most desirable product. However, in fact, strength and toughness are normally contrary. If the strength of steel increase its toughness normally decreases and vice versa. The composition and microstructure of the steel are primary factors controlling the strength and the toughness. Thus the grain refinement is a highly effective method to improve both the strength and the toughness [31]-[33].

Toughness is conveniently characterized by the Charpy impact test [34]-[36] in terms of (i) the Charpy Transition Temperature (CTT), and (ii) the ductile-to-brittle transition appearance temperature, DBTT. CTT is evaluated, from the Charpy absorbed energy transition curve, as the absorbed energy corresponding to half the value of the upper shelf energy. The DBTT is defined as the temperature for $50 \%$ cleavage on the fracture surfaces of the Charpy impact specimens [37] [38]. Conventional coarse grain ferrite/pearlite (CGF/P) steels often show a close similarity of these two measures of transition temperature, that is CTT-DBTT. The high absorbed energy in the upper shelf region is associated with ductile fracture by micro-void coalescence (i.e. dimple rupture) whereas the low absorbed energy in the lower shelf region is associated with brittle cleavage fracture. In contrast, UGF/C steels had a DBTT was much lower than the CTT, attributed to the fact that the fracture mechanism of the ductile to brittle transition was caused by a different fracture mechanism: the decreased energy absorption by ductile fracture [38].

For conventionally processed low carbon steels with ferrite grain sizes greater than $10 \mu \mathrm{m}$, Pickering's clas- 
sical work indicated that the ductile-to-brittle transition temperature (DBTT) is a function of strengthening mechanism [38]. For a yield strength increase of 9.8 MPa, if the strengthening is by dislocation, the DBTT will increase by $6 \mathrm{~K}$; if by dispersion strengthening, the DBTT will increase by $4 \mathrm{~K}$; if by grain-size refinement, however, the DBTT will decrease by $10 \mathrm{~K}$. The effect of grain size on DBTT is characterized by Hall-Petch style formula:

$$
D B T T=A-k d^{-1 / 2}
$$

and

$$
D B T T=A-k \ln d^{-1 / 2}
$$

where constants $A$ and $K$ depend on metallurgical factors other than the grain size, and $d$ is grain size. With these relationships, it is expected that ultrafine grained steels would have improved impact toughness.

The reported impact toughness data from ultrafine grained steels are still limited, partly due to the difficulty in obtaining large enough specimens from the laboratory-scale samples. Figure 3 shows a set of recent results, comparing the DBTT of two steels with ferrite sizes of 6.8 and $1.3 \mu \mathrm{m}$, respectively. The upper shelf energy of the ultrafine grained steel is lower, and the transition region occurs over a wider range of temperature, compared with the coarser grained steel. The DBTT for the ultrafine grained steel is lower than the coarser grained steel. A detailed explanation of the DBTT curves is provided in references [39] [40].

The DBTT results reported by Hanamura et al. [38] also confirm that the low-carbon steel with ultrafine grained ferrite/cementite microstructure has a much lower DBTT than that of the conventional ferrite/pearlite, quench/tempered, or quenched microstructure. Unlike results of Song et al., results of Hanamura et al. show the upper shelf energy of the ultrafine grained microstructure is as high as that of the coarser grained ferrite/pearlite microstructure for the same steel (Figure 4).

The effective grain size $\left(\mathrm{d}_{\mathrm{eff}}\right)$ is a useful measurement to characterize the effect of grain size on impact toughness. Instead of using the directly measured grain size, Hanamura et al. [38] have proposed to use the effective grain size as the variable to measure the impact toughness. The $\mathrm{d}_{\mathrm{eff}}$ is defined as the unit crack path in which a cleavage crack goes through in a straight fashion to form a facet, corresponding to the microstructural unit having a specific crystallographic orientation and bounded by large-angle grain boundaries. The $\mathrm{d}_{\mathrm{eff}}$ can be experimentally measured from the fractography. Using the $\mathrm{d}_{\text {eff }}$ concept, the four types of microstructure are ranked as $\mathrm{d}_{\text {eff }}=8 \mu \mathrm{m}$ for the ultrafine grained ferrite/cementite (UF-F/C) microstructure, $20 \mu \mathrm{m}$ for the ferrite/pearlite (F/P) microstructure, $25 \mu \mathrm{m}$ for the quenched and tempered (Q/T) microstructure, and $100 \mu \mathrm{m}$ for the as-quenched (Q) microstructure. This ranking is the same as the DBTT ranking, with smaller $\mathrm{d}_{\text {eff }}$ having a lower DBTT. Further,

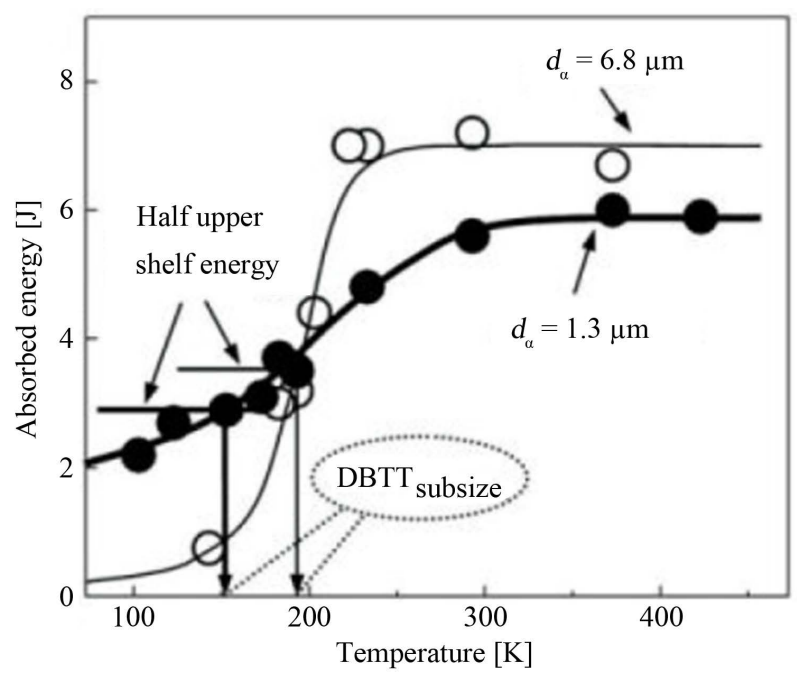

Figure 3. Effect of test temperature on Charpy impact energy of two steels with different ferrite grain sizes [40]. The symbol $\mathrm{d} \alpha$ indicates the average ferrite grain diameter. DBTT subsize refers to ductile-to-brittle transition temperature measured with sub-sized specimen (ligament size of $3 \times 4 \mathrm{~mm}^{2}$ ). 


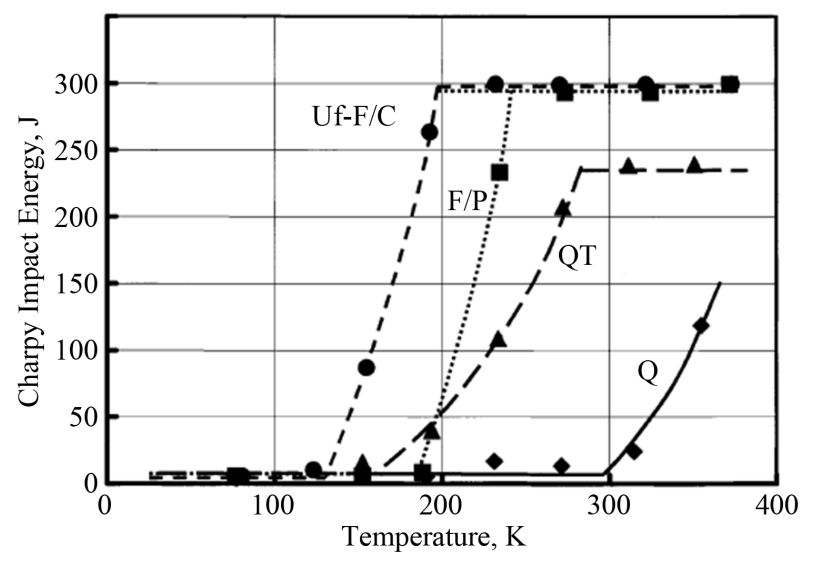

Figure 4. Charpy impact energy as a function of test temperature for ferrite/pearlite (F/P), ultrafine ferrite/cementite (UF-F/C), as quenched $(\mathrm{Q})$, and quench and tempered $(\mathrm{Q} / \mathrm{T})$ steels [38].

it is found that the $\mathrm{d}_{\text {eff }}$ number is determined by the ferrite grain size for $\mathrm{F} / \mathrm{P}$, by the prior austenite grain size for $\mathrm{Q}$, by the martensite packet size for $\mathrm{Q} / \mathrm{T}$, and by the ferrite grain size for UF-F/C microstructure. With such knowledge, the impact toughness can be tailored by the microstructure design. Statistically, the impact toughness for low-alloy steels follows an inverse trend against the yield strength, as shown in Figure 5, in which the shaded region on the left side of figure indicates the data distribution. Conventional quench and tempering (QT) can significantly increase the yield strength, but greatly decreases the impact energy. Ultrafine grained steels, as processed with the "tempforming" (TF) process, however, can have 16 times higher impact toughness than the conventional quench and tempered steel.

The extremely high impact toughness for this "tempformed" steel is owing to the ultrafine, elongated, fibrous ferrite grains with $<110>$ crystalline orientation along the rolling direction, interspersed with nanometer-sized carbides. With such a microstructure, the fractured specimens showed fibrous delamination that is thought to relax the triaxial stress conditions ahead of the advancing crack tip, thus leading to high impact energy [41].

\section{Grain Refinement for Saving Materials and Saving Energy}

Nowadays, the structural materials for aerospace, shipbuilding and offshore steels, pressure vessels and automotive applications and any other applications that are tied to power consumption are increasingly required to be energy efficient. The development of high-strength steel is an important way of reducing vehicle weight, amount of material used (reducing material cost) and achieving the purpose of energy saving and emission reduction.

The demand to produce automobiles which fulfill the requirements like, passenger safety, vehicle performance and fuel efficiency, has been the biggest challenge faced by the steel industry for the last couple of decades [42] [43]. In response the steel industry has developed advanced high strength steels (AHSS) including dual phase (DP), transformation induced plasticity (TRIP), complex phase (CP) and martensitic steels (MART). These steels are characterized by improved formability and crash worthiness compared to conventional steel grades, such as pearlitic steels. Currently, advanced high strength steels (AHSS) are extensively used in the auto industry and the projections are that the weight percentage of AHSS steel will increase to 35\% by 2015, here as mild steel decrease from $55 \%$ to $29 \%$ in bodies and closures of light vehicles [44]. The rationales for increased use of the AHSS in the automotive industry are as follows: (1) the reduction of the car weight resulting from the use of high strength thinner gauge sheet steel, reducing the fuel consumption; (2) Increased passenger safety by an improved crash worthiness; (3) The strong competition from the light-weight materials, such as $\mathrm{Al}$ and $\mathrm{Mg}$ alloys and plastics. Figure 6 is a schematic of Volvo-2009 model [45], showing the different classes of materials used for designing the car body.

Riding the trend, there is considerable effort to develop nanostructured steels that will meet such demands. But current effort has been focused on ultrafine-grain (UFG) ferrite single-phase steels, multi-phase steels, and nanostructured Bainite steels. Among various methods of strengthening steel, grain refinement is a method that can enhance strength with no deterioration in toughness [46]. In recent years, a variety of methods have been 


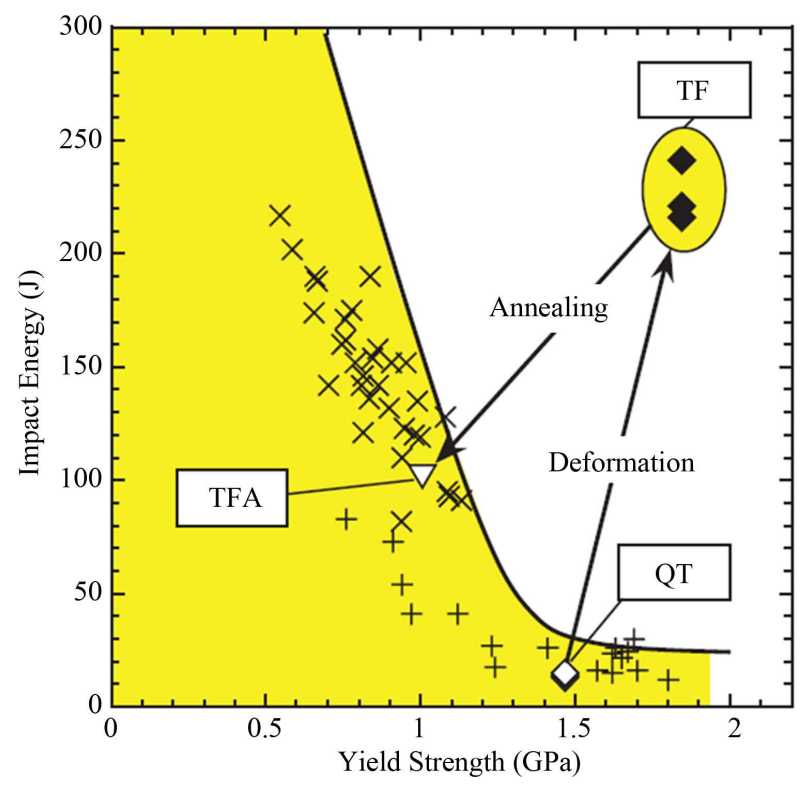

Figure 5. Charpy V-notch impact energy absorption of the low-alloy steel as a function of yield strength at room temperature [41]. The steel that was "tempformed" at $500^{\circ} \mathrm{C}$ (TF) shows large impact energy as compared to that of the steel that was conventionally quenched and tempered (QT), also at $500^{\circ} \mathrm{C}$. Annealing of TF steel at $700^{\circ} \mathrm{C}$ degraded the impact energy to conventionally processed steels.

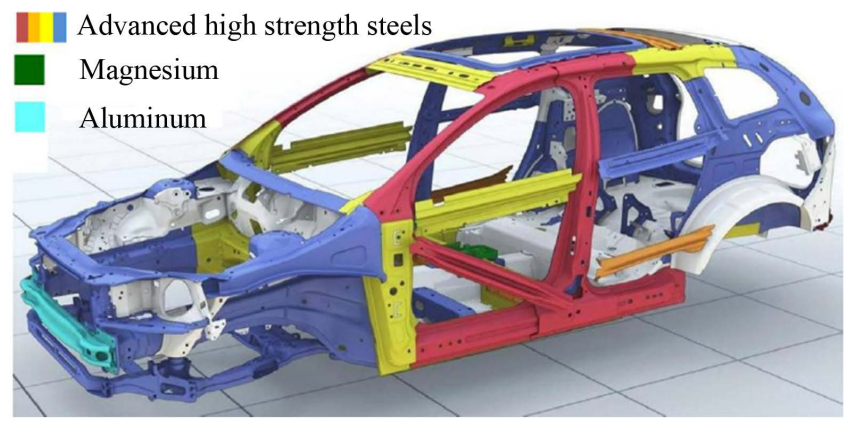

Figure 6. A schematic of Volvo-2009 model, showing the different class of materials used for designing the car body [45].

developed to produce ultrafine-grained steels, including strain-induced ferrite transformation, large-strain warm deformation, intercritical hot rolling, multi-directional rolling and cold-rolling plus annealing of martensitic steel. The grain size is refined to $1-3 \mu \mathrm{m}$ [47]-[49]. But in commercial hot-rolled Nb-Ti and Ti-Mo microalloyed strip steel, the grain size could be controlled within only 5 - $10 \mu \mathrm{m}$ [1] [50].

\section{Methods of Producing Ultrafine Grained Steels}

\subsection{Production Ultrafine Grained Steels by Micro-Alloying}

High-strength low-alloy (HSLA) steels are a class of steels developed to achieve properties superior to those of the ferritic + pearlitic steel and comparable to those of low alloy quenched and tempered martensitic steels. HSLA steels are designed to achieve their desired mechanical properties by the development of microstructures through controlled thermomechanical processing (TMP) and the steel is produced in its final form by a continuous hot deformation process, rolling, or forging, which comprise the TMP. Most HSLA steels are microalloyed with small additions $(0.1 \mathrm{wt} \%)$ of niobium, vanadium, and titanium which control microstructural evolu- 
tion during TMP through the formation of carbonitride precipitates.

With the development of the micro-alloying technology the elements of $\mathrm{Nb}, \mathrm{Ti}$, and $\mathrm{V}$ are used widely in the production to produce ultrafine grain steels (UFG-steels). During solidification from melt, they combine with C and/or $\mathrm{N}$ to form carbide, nitride and/or carbonitride precipitates. Figure 7 shows the correlation between the micro-alloying content and the solubility temperature for the precipitate present in steel $16 \mathrm{MnNi} 4$ [51]. The solubility temperatures for the precipitates present in the steel are $1045^{\circ} \mathrm{C}$ for the $\mathrm{VC}, 1130^{\circ} \mathrm{C}$ for the $\mathrm{VN}, 1168^{\circ} \mathrm{C}$ for the TiC, $1682^{\circ} \mathrm{C}$ for the $\mathrm{TiN}, 1338^{\circ} \mathrm{C}$ for the $\mathrm{NbC}$ and $1073^{\circ} \mathrm{C}$ for the $\mathrm{NbN}$ [51].

These fine precipitates play an effective role by retarding recrystallization (and therefore, increasing the recrystallization stop temperature) that usually follows deformation and thus, helps to retain the accumulated strain and deformed structures of austenite grains. There have been several studies on the recrystallization of carbon steels and Nb microalloyed steel [52]-[55], and various models have been proposed for predicting the recrystallization of austenite.

\subsection{Role of V Micro-Alloying}

In high strength low alloy steels (HSLA), it is common practice to make additions of elements such as $\mathrm{Ti}, \mathrm{Nb}, \mathrm{V}$ for austenite grain size control [56] [57]. These elements have a high chemical affinity for $\mathrm{N}$ and $\mathrm{C}$ and form compounds, carbonitrides, which can control austenite grain growth. Special attention has to be paid to vanadium microalloying addition. Vanadium is a useful microalloying element which improves the mechanical properties of HSLA steels. In quenched and tempered steels, vanadium increases their hardenability and mechanical properties after tempering [58]. It can be used in dual role. Because of the high chemical affinity to nitrogen and carbon it forms carbonitrides $\mathrm{V}(\mathrm{C}, \mathrm{N})$ which controls the austenite grain size. Dissolved vanadium decreases the rate of austenite decomposition and thus increases the hardenability. In high strength low alloy steels, an increase of hardenability at low austenite grain size was observed contrary to the effect of austenite grain size on the hardenability of common steels. This effect is explained by the Garbarz and Pickering hypothesis [59] that pinning the austenite grain boundaries by undissolved carbonitrides particles creates the possibility for segregation of dissolved alloying element atoms on immobile grain boundaries. The resulting decrease in the grain boundary energy reduces their potential for the nucleation of non-martensitic products as was observed in boron steels [60].

\subsection{Role of $\mathrm{Nb}$ Micro-Alloying}

The use of niobium as microalloy element in steel for grain refinement is widespread. NbC usually precipitates after deformation of austenite, can pin dislocations so that recovery and recrystallization of deformed austenite can be intensively retarded [60]-[62].

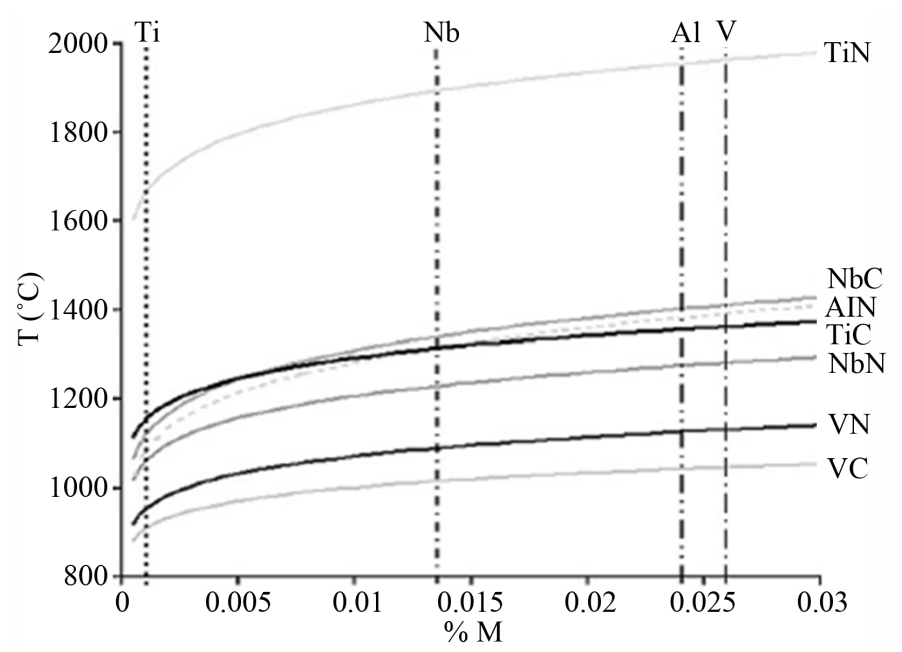

Figure 7. Correlation between the micro-alloying contents (M\%) and the solubility temperature for the precipitates present in the steel 16 MnNi4 [51]. 
Nowadays, most of ferritic-perlitic precipitation hardening steel grades are microalloyed steel. These steels after rolling or forging process would be cooled as completely controlled. The properties of these steel grades would be affected by solidification microstructures, thermomechanical process and cooling process after rolling [60]. Niobium has a three-fold influence on the mechanical properties of steel which are as grain size refinement during thermomechanical hot forming, precipitation hardening and lowering the $\gamma$ to $\alpha$ transition temperature. Grain refinement is the only mechanism that simultaneously increases strength, toughness and ductility. Niobium-microalloyed steel has become a standard material in plate and strip for line pipe, automotive and construction use. Until now, the high potential of microalloyed high strength steel has not been used to the same extent in long products.

$\mathrm{Nb}(\mathrm{C}, \mathrm{N})$ precipitates that have formed and grown at high temperature and in austenite phase prevent from grain coarsening in the subsequent stage of hot deformation. Other diffusion controlled process that occur with solution of niobium in austenite are retarding of austenite $(\gamma)$ to ferrite $(\alpha)$ transformation that cause to increase nucleation of ferrite and reduce grain growth rate, forming of quasi-equivalence structures like bainite and finally appearance very fine $\mathrm{Nb}(\mathrm{C}, \mathrm{N})$ precipitates during transformation that being coherent interface cause to increase strength with precipitation hardening mechanism [61] [62].

\subsection{Role of Ti Micro-Alloying}

In modern industry, obtaining excellent combination of high strength and high toughness is a target for steel. It is well known that $\mathrm{Nb}, \mathrm{V}$ and Ti microalloying elements play important roles in it [63]-[65]. While the microalloying elements precipitate as carbides or nitrides in austenite, the precipitates can lower the grain growth rate by pinning the grain boundaries [66] [67]. The obtained fine grain microstructure can enhance the strength and toughness of steels obviously [68]-[70]. Due to the high price of niobium and vanadium, the development of titanium microalloyed steels are attracted much more attention recently [71]-[74]. There are some researches of precipitation effects on microstructure and mechanical properties in Ti-bearing steels [74]-[76]. But steel alloyed with titanium alone is seldom studied especially in low carbon medium manganese martensitic steel. According to the thermodynamic analyses [77] [78], the main forms of titanium precipitate are $\mathrm{TiN}, \mathrm{Ti}_{4} \mathrm{C}_{2} \mathrm{~S}_{2}$ and $\mathrm{TiC}$ or $\mathrm{Ti}(\mathrm{C}, \mathrm{N})$ composite particles. The role of TiN particles in austenite grain size control is well known and the mechanism by which they exert this influence may be explained by Zener and Gladman's expressions for pinning forces [1] [79], which relate the size and fraction of precipitates. However, the precipitation temperatures for TiN, $\mathrm{Ti}_{4} \mathrm{C}_{2} \mathrm{~S}_{2}$ and $\mathrm{TiC}$ particles are above $1500^{\circ} \mathrm{C}, 1200^{\circ} \mathrm{C}$ and $1000^{\circ} \mathrm{C}$, respectively. Due to the higher precipitation temperatures of TiN and $\mathrm{Ti}_{4} \mathrm{C}_{2} \mathrm{~S}_{2}$ particle, they tend to grow to larger particles, and this is disadvantageous for the mechanical properties. Consequently, TiCs may have the most important effect on steel properties for their smaller size.

\subsection{Role of Nb-Ti Micro-Alloying}

The use of niobium and titanium as microalloy elements in steel for grain refinement is widespread. TiN precipitates, forming during solidification, can powerfully inhibit motion of austenite grain boundaries while NbC, which usually precipitates after deformation of austenite, can pin dislocations so that recovery and recrystallization of deformed austenite can be intensively retarded [80] [81]. It is generally believed that, when steels are heated up to austenite region, the TiN precipitates are the most stable and are known to have a dissolution temperature above the iron liquidus temperature but $\mathrm{NbC}$ precipitates dissolve away rapidly [82] [83]. However, when $\mathrm{Nb}$ and Ti co-existed in the same microalloyed steel, the effect of their interaction of formation and thermo-stability of precipitates, especially during solidification and austenization, was frequently neglected. The approximately solubility temperatures for the precipitates present in the produced steels are shown in Figure 7.

The different precipitates present in the steel due to Ti-Nb micro-alloying were analyzed in terms of size, morphology, and chemistry. They can be classified into types I - IV based on the size and morphology of the precipitates, and are summarized in Table 2. Type I are rod-like intergranular $(\mathrm{Fe}, \mathrm{Mn})_{3} \mathrm{C}$ precipitates. The type II precipitates are TiN containing small amounts of $\mathrm{Nb}$ and are of the size range $120-500 \mathrm{~nm}$. The type III precipitates identified as ( $\mathrm{Nb}, \mathrm{Ti}) \mathrm{C}$ are $\approx 10-200 \mathrm{~nm}$ size and randomly distributed in the matrix, and type IV are spherical or needle-shaped (Nb, Ti)C precipitates $(3-5 \mathrm{~nm})$ that nucleated preferentially on sub-boundaries and dislocations in ferrite. Type I and II are generally undesirable from the viewpoint of toughness since they are known to promote cleavage fracture, while type III and IV are strengthening precipitates. 
Table 2. Precipitate observed in $770 \mathrm{MPa}$ Nb-Ti hot rolled steels [1].

\begin{tabular}{cccc}
\hline Type & Size & Morphology & Precipitate \\
\hline I & $1-1.5 \mu \mathrm{m}$ in length & Intergranular rod-like & $(\mathrm{Fe}, \mathrm{Mn})_{3} \mathrm{C}$ \\
II & $120-400 \mathrm{~nm}$ & Cuboid, round, oblong, ellipsoidal & $(\mathrm{Ti}, \mathrm{Nb}) \mathrm{N}$ \\
III & $10-120 \mathrm{~nm}$ & Spherical, plate & $(\mathrm{Nb}, \mathrm{Ti}) \mathrm{C}$ \\
IV & $3-5 \mathrm{~nm}$ & Needle-like & $(\mathrm{Ni}, \mathrm{Ti}) \mathrm{C}$ \\
\hline
\end{tabular}

\subsection{Role of Boron}

Boron (B) can be an effective element in enhancing the hardenability of the steel and in obtaining a bainite and/or martensite dominant structure. As a typical feature of B is its alloying of trace amounts; the controlled concentration of B is ranging from $10 \mathrm{ppm}$ to $30 \mathrm{ppm}$. B alloying is not indispensable in low carbon bainitic (LCB) steels and it is not always used in steels with yield strength from $500 \mathrm{MPa}$ to700 MPa [84]. On the other hand, for the LCB steels with yield strengths above $700 \mathrm{MPa}$ [85], such as X120 line-pipe steels, B alloying is found to be crucial in order to promote required lower bainitic microstructures for high strength and toughness, besides improving the weldability and maintaining alloying cost at low levels. The hardenability-enhanced effect of B is based on its non-equilibrium segregation at grain boundaries. There are several explanations, how this type of segregation improves the hardenability of steels [86]:

- The non-equilibrium segregation to austenite grain boundaries reduces the grain boundary energy and prevents nucleation of ferrite.

- B can reduce the coefficient of self-diffusion of iron at grain boundaries, thereby reducing the nucleation sites for ferrite. Since the grain boundaries are preferential nucleation sites for ferrite, when B segregates to grain boundaries, these sites will become ineffective.

-Fine borides form along the grain boundaries. Being coherent with the matrix, ferrite is difficult to nucleate at the interface between boride and matrix. (This explanation contradicts with the assumption of atomistic B being effective in enhancing the hardenability).

In general, low carbon micro-alloyed steels have $0.05 \mathrm{wt} \% \mathrm{C}$ and $1.5 \mathrm{wt} \% \mathrm{Mn}$ and utilize micro-alloying concepts to attain a fine-grained microstructure. The fundamental basis for the development of ultra-high strength $770 \mathrm{MPa}$ hot rolled steel is to obtain ferrite-bainite microstructure in the hot rolled product through controlled rolling and alloy design. The two main elements considered for obtaining a bainitic microstructure were boron and molybdenum. Boron retards the nucleation of ferrite by segregating to austenite-ferrite boundaries, where it inhibits ferrite nucleation through strong interaction with lattice defects such as dislocations and vacancies [87] [89]. Thus, boron effectively moves the ferrite C-curve to longer times.

\subsection{Role of Vanadium-Nitrogen Micro-Alloying}

The mechanism of grain refinement caused by addition of nitrogen has been extensively investigated. Ochi et al. [90] suggested that $\mathrm{N}$ promote the formation of intragranular ferrite, and refine the grain in vanadium steel. Wang et al. [91] further confirmed that the addition of $\mathrm{N}$ to $\mathrm{V}$ microalloyed steel could make more vanadiumcontaining precipitates in the form of carbonitrides which acted as nucleus of ferrite formation, and raised the nucleation rate of ferrite, as well as resulted in grain refinement of ferrite. It well known that, vanadium carbides did not take part in pinning process. On the contrary, vanadium carbonitrides can be assumed to have a higher solution temperature than pure vanadium carbides, between $1000^{\circ} \mathrm{C}$ and $1200^{\circ} \mathrm{C}$, depending on the vanadium and nitrogen content [57].

Zhao et al. [92] indicated that, in ferritic-pearlitic microalloyed steel, the area fraction of ferrite increased from $21 \%$ to $38 \%$, and the averaged grain size decreased from $10.3 \mu \mathrm{m}$ to $6.2 \mu \mathrm{m}$, when the nitrogen content was enhanced from $30 \mathrm{ppm}$ to $210 \mathrm{ppm}$ and normalization was performed at $930^{\circ} \mathrm{C}$. An increase in reheating temperature brought elevated strength at an expense of toughness. Improved combination of yielding strength in $650 \mathrm{MPa}$ and toughness in $48 \mathrm{~J}$ at $-20^{\circ} \mathrm{C}$ can be obtained in $33 \mathrm{Mn} 2 \mathrm{~V}$ stee1 with nitrogen content of $140 \mathrm{ppm}$ at reheating temperature of around 930' $\mathrm{C}$ [92].

On the other hand, the higher silicon contents in SiV and SiVN steels increase the activity of carbon in these 
alloys thus stabilizing carbides and carbonitrides [93]. Therefore, the austenitizing temperature of $1200^{\circ} \mathrm{C}$ (heat treatment temperature of investigated HSLA steels) is necessarily not high enough to dissolve all VN or V(C, N) particles and some of them likely restricted the austenite grain growth during the heat treatment. This was, further, confirmed by IDS calculation which gave the following temperatures for the start of precipitation of VN: $1085^{\circ} \mathrm{C}$ for $38 \mathrm{MnSiV5}, 1120^{\circ} \mathrm{C}$ for $\mathrm{SiV}$ and $1265^{\circ} \mathrm{C}$ for $\mathrm{SiVN}$, respectively [93]. Another explanation for the finer ferritic grain size in vanadium containing steels is the inter-phase precipitation of vanadium carbonitrides which slows down the austenite-ferrite transformation giving more time for ferrite nucleation [94] [95]. According to the results of this study it is not excluded that also a high silicon ( $\mathrm{Si}>1 \%$ ) causes a smaller ferritic grain size, e.g. through higher $\mathrm{A}_{\mathrm{R} 3}$ temperature since the nucleation of ferrite starts earlier.

\subsection{Summary}

In practice, more than one microalloying element is often added, each for a different purpose. Hence, the low solubility of TiN makes it a good choice to restrain grain growth during reheating. $\mathrm{Nb}(\mathrm{C}, \mathrm{N})$ is only sparingly soluble below $1000^{\circ} \mathrm{C}$, and it is a good choice if one wishes either to restrain grain growth below this temperature or more importantly to precipitate in deformed austenite. Excess $\mathrm{Ti}, \mathrm{Nb}$ can precipitate at lower temperatures as carbides, which contribute to precipitation strengthening. VC, on the other hand, is much more soluble and is added so that it can remain in solution and precipitate later, forming a fine hardening dispersion in the ferrite. The presence of more than one alloying element can result in the precipitation of complex multi-component carbonitrides such as $(\mathrm{Nb}, \mathrm{V})(\mathrm{C}, \mathrm{N})$ or $(\mathrm{Nb}, \mathrm{Ti})(\mathrm{C}, \mathrm{N})$. The solubility of those complex carbonitrides can be found to a first approximation from the solubility of the individual carbides and nitrides. Finally, $\mathrm{Nb}$ and $\mathrm{Ti}$ can be added to low alloy steels to form carbides and nitrides with a totally different purpose. In the "interstitial free" steels, $\mathrm{Nb}$ and Ti are added to act as "scavengers" for $\mathrm{C}$ and $\mathrm{N}$. They form low-solubility precipitates that result in an almost interstitial free ferrite.

\subsection{Production Ultrafine Grained Steels by Heat Treatment}

Grain refinement is an effective way to improve both strength and toughness. Since the grain size of austenite decomposition products decreases with decreasing austenite grain size, many efforts have been made to refine austenite grains. In the Thermo Mechanical Controlled Processes (TMCP), recrystallization andnon-recrystallization rolling are used to refine austenite grain, of which the minimum size or thickness is $10-20 \mu \mathrm{m}$ in C-Mn steels and $5-10 \mu \mathrm{m}$ in steels microalloyed with $\mathrm{Ti}$ and $\mathrm{Nb}$ [96]. Controlled austenitization is another effective way to obtain ultrafine grained austenite in heat treatment steels, such as rapid cyclic transformation, reversion from tempered and cold rolled martensite. The former, which includes 2 - 4 cycles of rapid austenite-martensite transformation, was employed to obtain austenite grain of 1 - $10 \mu \mathrm{m}$ [97]-[99]. The latter including tempering and further heavily cold rolling was attempted to refine austenite grain size to 1 - $5 \mu \mathrm{m}$ [100] [101].

\subsubsection{Phase Transformation through Cyclic Heat Treatment}

Grain size refinement of steel, by temperature cycling can be done by repeated alpha-gamma phase transformations [102] [103]. One of the effective methods of the previous austenite refinement is refinement by temperature cycling, i.e., by cyclical repeated heating and cooling of steel. Refinement of steel microstructure by temperature cycling can be achieved by a cooling rate that provide diffusional transformations of austenite to pearlite, or by rates that provide transformations of austenite to bainite, or diffusion-less transformation to martensite [104]-[106].

\subsubsection{Cyclic Quenching Method (Repetitive Rapid Heating and Quenching)}

In previous works, the effect of heating rate on the refinement of steel austenite using a mixture of bainitic ferrite and retained austenite as the starting material were studied. During conventional continuous heating rate, as ranged from $2^{\circ} \mathrm{C} / \mathrm{s}$ to $100^{\circ} \mathrm{C} / \mathrm{s}$ which is related to a moderate superheating, would allow the austenite grains to direct grow from the previous retained austenite present in the initial microstructure, along the ferrite plate. In this case, the austenite will inevitably grow in an acicular morphology until the original austenite grain structure is recovered without request for nucleation of new austenite grain, resulting in the so-called memory effect and little grain refinement [107]. Some other early works [108] [109] also reported the similar observations. However, when a very slow continuous heating is imposed and correspondingly a limited superheating achieved though, 
the retained austenite decomposition into the cementite or carbide can occur in an initial bainitic or martensitic steel, as in the 2.25Cr-1Mo steel for example [110], on early heating stage. This will destroy the memory effect and lead to new austenite nucleation at prior austenite grain boundaries and the precipitates on the following austenitization heating.

On the other hand, a high degree of superheating, as a result of extremely rapid heating to an elevated austenitisation temperature, will significantly increase both the driving force for reverse $\alpha \rightarrow \gamma$ reaction and atom mobility. This make it possible for some new austenite grains to nucleate at all possible sites, including the prior austenite grain boundaries, the adjacent ferrite plate interfaces and even inside the plates, even if the retained austenite film will thicken simultaneously. The austenite will then grow at a high nucleation ratio and develop an equiaxed and ultrafine-grained morphology. This suggests that the austenite grain can be effectively refined when extremely rapid cyclic $\alpha \rightarrow \gamma \rightarrow \alpha$ phase transformation occurs in a mixture of bainitic ferrite and retained austenite under a high superheating situation.

In earlier work done by Wang et al. [110], they were studied the effect of extremely high degree of super heating on the refinement of steel austenite. They stated that, An extremely high degree of superheating for the reverse $\alpha \rightarrow \gamma$ transformation, which was successfully performed in a initial microstructure composed of bainitic ferrite and retained austenite as a result of extremely rapid resistance heating up to an elevated austenitization temperature, can prevent restoration of the previous coarse-grained austenite and lead to the formation of an ultrafine structure during the subsequent rapid cooling.

\subsection{Production Ultrafine Steels by Advanced Thermomechanical Processes}

Recent researches involving metallic materials can lead to technological innovations [111]. Both advanced thermomechanical processes and severe plastic deformation strategies have been developed to obtain ultrafine ferrite grain with size close to $1 \mu \mathrm{m}$ in low-carbon low-alloy steels [37]. Advanced thermomechanical processes involving modification to conventional large-scale processes can be optimized to operate in deformation conditions where they beneficially exploit solid-solid reactions such as recrystallization, precipitation, and phase transformation. Ultrafine grain size has been obtained in steels through deformation near or in the intercritical region by exploiting strain-induced dynamic transformation [112]-[114]. Ferrite dynamic recrystallization can be exploited straining in warm condition inside the ferrite domain [115] [116]. Also, ultrafine or nanocrystalline structures has been achieved by warm or cold deformation of martensite starting microstructure [117]-[119].

Two types of procedures are used to deform austenite: conventional or controlled thermomechanical processing [120]. The former consists of multi-deformation schedules aimed at changing the shape, while the second also aims to control the microstructural evolution. Controlled thermomechanical processing has been successfully industrialized in modern steel mills and can be defined as disciplined deformation schedules under continuous cooling and controlled conditions, aimed at attaining fine-grained microstructures [121]-[123]. This kind of processing can be separated in four different stages, as the temperature decreases. Figure 8 is a sche-

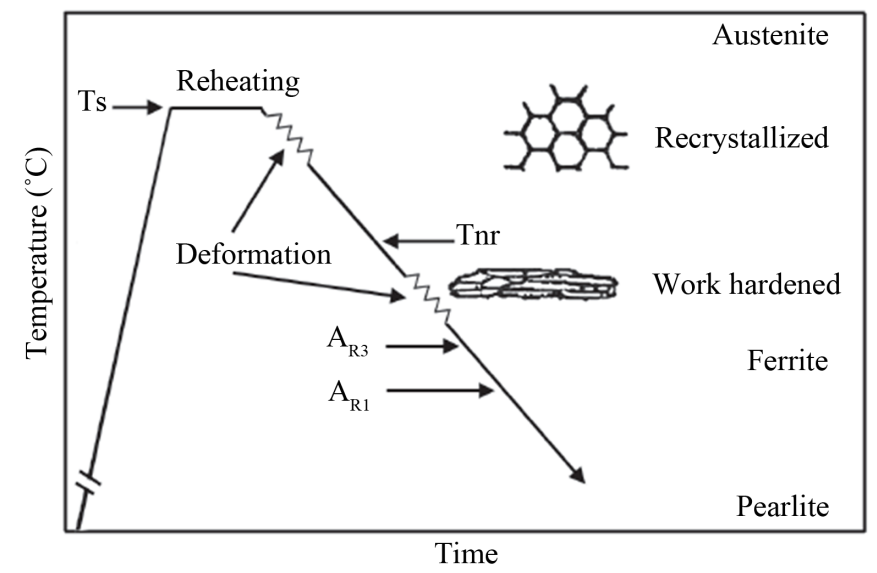

Figure 8. Schematic representation of the thermomechanical treatment for microalloyed steel, indicating the critical temperatures [126]. 
matic representation of the thermomechanical treatment for microalloyed steel, indicating the critical temperatures $\left(T_{s}, T_{n}, A_{R 3}\right.$, and $\left.A_{R 1}\right)$. In the first stage, grains coarsened by soaking at temperatures above Ts are refined by the repetition of deformations and recrystallizations at high temperatures. The second stage takes place under conditions in which recrystallization is no longer completed during inter pass times due to strain-induced precipitation [124] [125], i.e., below the non recrystallization temperature $\left(\mathrm{T}_{\mathrm{nr}}\right)$. Grains in this stage have a pancake-like shape and dislocation substructures are created inside the grains.

In the third stage, deformation takes place in the phase transition region, i.e., in the temperature range between the start of ferrite formation $\left(A_{R 3}\right)$ and the end of ferrite transformation $\left(A_{R 1}\right)$. Ferrite nucleates within and at grain boundaries. In this stage, austenite continues to deform and the transformed ferrite begins to be strained. In the fourth stage, a variety of microstructures can be obtained during cooling, depending on the cooling rate and the stage in which the deformation was interrupted. After the first deformation stage, when the material is air-cooled, the ferrite grains are relatively large due to grain growth during cooling. After the second stage, the grains are smaller. In the third stage, increasing the cooling rate causes the grains to become finer and substructural dislocation occurs inside the strained ferrite grains. During conventional thermomechanical processing, the multi-deformation schedule is similar to that of the first stage, where the recrystallization kinetics is very fast. Thus, static recrystallization occurs during inter pass times and no strain accumulates from one pass to another. It is well-established that the start temperature of ferrite formation $\left(A_{R 3}\right)$ and the end temperature of this transformation $\left(A_{R 1}\right)$ depend on the cooling rate. These temperatures decrease as the cooling rate is increased. When higher cooling rates are imposed, austenite is present at temperatures below that of equilibrium between the phases $\left(A_{e 3}\right.$ and $\left.A_{e 1}\right)$. Thus, it is possible to deform unstable austenite [37]-[116]. Upon deformation, strain-induced dynamic phase transformation (austenite to ferrite) can take place. New ferrite grains and transformed ferrite during cooling are strained together with austenite and continuous dynamic recrystallization of ferrite can occur. This technique has been used to produce ferrite grain sizes as fine as $2-5 \mu \mathrm{m}$ via recrystallization-controlled rolling or by conventional rolling followed by accelerated cooling [127].

\subsubsection{Recrystallization of Austenite during Hot Deformation}

An important mechanism that is widely used for grain refinement in steels is dynamic recrystallization during hot deformation [128]. This technique has been used to produce ferrite grain sizes as fine as $2-5 \mu \mathrm{m}$ via recrystallization-controlled rolling or by conventional rolling followed by accelerated cooling. In recrystallizationcontrolled rolling fine precipitates restrict austenite grain growth after deformation. Recrystallization controlled rolling is often used in conjunction with accelerated cooling and micro-alloying in order to effectively refine the grain size. Accelerated cooling is used to increase the cooling rate through the transformation zone in order to decrease the transformation temperature. In principle, a lower transformation temperature results in a higher ferrite nucleation rate due to a higher under cooling, and a decreased growth rate. Conventional controlled rolling has been implemented in many commercial operations through the addition of microalloying elements especially strong carbide/nitride formers elements. The addition of small amounts ( $>0.1 \mathrm{wt} \%)$ of strong carbide/nitride formers elements such as $\mathrm{Nb}, \mathrm{Ti}, \mathrm{V}$, and $\mathrm{Zr}$, with $\mathrm{Al}$ also normally present, to the austenite ("'microalloying”') is extremely important in commercial low alloy steels. Their main role is to precipitate from austenite-forming carbides/nitrides or complex carbonitrides. The solubility of these elements is small, so that high austenitizing temperatures in excess of $1100^{\circ} \mathrm{C}$ are usually required. This increases the density of sites for ferrite nucleation. The lowest solubility product is that of TiN followed by NbC, TiC, and VN, with VC being by far the most soluble carbide. Precipitation processes from the austenite can be divided in three groups:

1) Precipitation from undeformed austenite: this can happen after reheating of the steel or during cooling from a high soaking temperature. The carbides/nitrides formed in this way, with size $=20 \mathrm{~nm}$, are intended to restrain grain growth by pinning the grain boundaries.

2) Precipitation from deformed austenite: it is normally accepted that deformation significantly accelerates precipitation. In turn, this precipitation can delay the onset of austenite recrystallization that is invaluable for the controlled rolling of the austenite.

3) Precipitation during austenite-ferrite transformation: if enough alloying element remains in solid solution after high-temperature processing, carbide/nitride precipitation can occur during the austenite-ferrite transformation. These precipitates form at the austenite-ferrite transformation front resulting in precipitates arranged in parallel planes, which is often called interphase precipitation. 


\subsubsection{The Martensite Thermomechanical Treatment}

Martensite treatment is one of the known thermo-mechanical processes that can be used for the grain refinement of metastable austenitic stainless steels [129]. The as-cast specimens were first homogenized and then hot forged in order to prepare a suitable microstructure for the subsequent martensite treatment. This treatment may be consisted of single [130] [131] or repetitive [132] [134] stages of cold rolling followed by reversion annealing. In single stage, cold rolling was carried out with the reductions of $10 \%$ - $95 \%$ followed by annealing at temperature of $850^{\circ} \mathrm{C}$ for $15-1800 \mathrm{~s}$, as shown in Figure 9. This process results indicated that the specimen was reversion-annealed at $850^{\circ} \mathrm{C}$ for $30 \mathrm{~s}$ exhibited the smallest average austenite grain size of $65 \mathrm{~nm}$ with more than $86 \%$ austenite [130]. In repetitive martensite thermomechanical treatment, the first stage was consisted of cold rolling to $70 \%$ thickness reduction followed by annealing at $850^{\circ} \mathrm{C}$ for short annealing durations (60 second), while the second stage was comprised of cold rolling to $60 \%$ thickness reduction followed by annealing at $850^{\circ} \mathrm{C}$ up to 60 second, as shown in Figure 10. The smallest grain size of $80 \pm 10 \mathrm{~nm}$ with a microstructure consisted of austenite and small amount of retained martensite was achieved by secondary annealing for $30 \mathrm{~s}$. Increasing the annealing time to 60 second led to the formation of fully austenitic microstructure but the grain size of about $260 \pm$ $40 \mathrm{~nm}$. This microstructure possessed the yield strength of $1 \mathrm{GPa}$ and the total elongation of 30\% [132]. Table 3 and Table 4 show the single/ repetitive martensite thermomechanical treatment for different ultrafine grain austenitic stainless steel.

Table 3. Effects of different processing parameters on mechanical properties of 301 nano-ultrafine steel [133].

\begin{tabular}{|c|c|c|c|c|c|c|c|c|}
\hline Processing conditions & Steel & Structure & $\begin{array}{l}\text { Average } \\
\text { grain size }\end{array}$ & $\begin{array}{l}\text { UTS } \\
\text { (MPa) }\end{array}$ & $\begin{array}{l}\text { Yield strength } \\
\text { (MPa) }\end{array}$ & $\begin{array}{c}\text { Elongation } \\
\text { (\%) }\end{array}$ & $\begin{array}{l}\text { Hardness } \\
\text { (HV) }\end{array}$ & $\varepsilon_{\mathrm{c}}$ \\
\hline $\begin{array}{c}35 \% \mathrm{CR} \text { at }-10^{\circ} \mathrm{C}+750^{\circ} \mathrm{C} / 10 \mathrm{~min}+60 \mathrm{CR} \\
\text { at }-10^{\circ} \mathrm{C}+850^{\circ} \mathrm{C} / 1 \mathrm{~min}\end{array}$ & 301 & $95 \% \gamma$ & $70 \mathrm{~nm}$ & - & 1970 & - & 603 & 0.5 \\
\hline $62 \% \mathrm{CR}$ at $25^{\circ} \mathrm{C}+800^{\circ} \mathrm{C} / 1 \mathrm{~s}$ & 301LN & $\alpha+\gamma$ & $520 \mathrm{~nm}$ & - & 850 & 45 & 260 & - \\
\hline $90 \% \mathrm{CR} 600^{\circ} \mathrm{C} / 30 \mathrm{~min}$ & 301 & $15 \% \gamma$ & $280 \mathrm{~nm}$ & - & 1209 & - & 370 & - \\
\hline $90 \% \mathrm{CR} 750^{\circ} \mathrm{C} / 30 \mathrm{~min}$ & 301 & $95 \% \gamma$ & $1.7 \mu \mathrm{m}$ & - & 539 & - & 165 & - \\
\hline $90 \% \mathrm{CR} 900^{\circ} \mathrm{C} / 30 \mathrm{~min}$ & 301 & $80 \% \gamma$ & $5.8 \mu \mathrm{m}$ & - & 490 & - & 150 & - \\
\hline $90 \% \mathrm{CR}$ at $-196^{\circ} \mathrm{C}+750^{\circ} \mathrm{C} / 3 \mathrm{~min}$ & 301 & $95 \% \gamma$ & $2.5 \mu \mathrm{m}$ & - & - & - & 330 & 0.9 \\
\hline Coarse grained & 301 & $\gamma$ & $15 \mu \mathrm{m}$ & - & - & - & 220 & - \\
\hline $63 \% \mathrm{CR}+800^{\circ} \mathrm{C} / 1 \mathrm{~s}$ & 301LN & $93 \% \gamma$ & $540 \mathrm{~nm}$ & 1070 & 700 & 35 & 215 & - \\
\hline $63 \% \mathrm{CR}+800^{\circ} \mathrm{C} / 10 \mathrm{~s}$ & 301LN & $93 \% \gamma$ & $1 \mu \mathrm{m}$ & 1027 & 630 & 40 & 192 & - \\
\hline $60 \% \mathrm{CR}+800^{\circ} \mathrm{C} / 1 \mathrm{~s}$ & 301 & $\alpha+\gamma$ & $570 \mathrm{~nm}$ & 1042 & 704 & 35 & 216 & 1 \\
\hline $95 \% \mathrm{CR}$ at $-10^{\circ} \mathrm{C}+800^{\circ} \mathrm{C} / 10 \mathrm{~s}$ & 301 & $95 \% \gamma$ & $250 \mathrm{~nm}$ & 1470 & 966 & 36 & 422 & 0.5 \\
\hline
\end{tabular}

Table 4. Mechanical properties of 201L stainless steel at different stages of the repetitive thermo-mechanical process at room temperature [130].

\begin{tabular}{cccccc}
\hline Processing conditions $^{\mathrm{a}}$ & Average grain size & UTS (MPa) & Yield strength (MPa) & Elongation (\%) & Hardness (HV) \\
\hline SA at $1100^{\circ} \mathrm{C}$ for $150 \mathrm{~min}$ & $27 \mu \mathrm{m}$ & 1030 & 330 & 48 & 230 \\
$95 \% \mathrm{CR}$ & - & 1950 & - & 4 & 546 \\
$95 \% \mathrm{CR}+850^{\circ} \mathrm{C} / 30 \mathrm{~s}$ & $65 \mathrm{~nm}$ & 1780 & 1485 & 33 & 393 \\
$95 \% \mathrm{CR}+850^{\circ} \mathrm{C} / 180 \mathrm{~s}$ & $140 \mathrm{~nm}$ & 1710 & 1075 & 37 & 291 \\
$95 \% \mathrm{CR}+850^{\circ} \mathrm{C} / 600 \mathrm{~s}$ & $810 \mathrm{~nm}$ & 1420 & 870 & 34 & 262 \\
$95 \% \mathrm{CR}+850^{\circ} \mathrm{C} / 1800 \mathrm{~s}$ & $1.4 \mu \mathrm{m}$ & 1160 & 780 & 25 & 241 \\
\hline
\end{tabular}

${ }^{\mathrm{a} S A}$ : solution annealing; CR: cold rolling. 


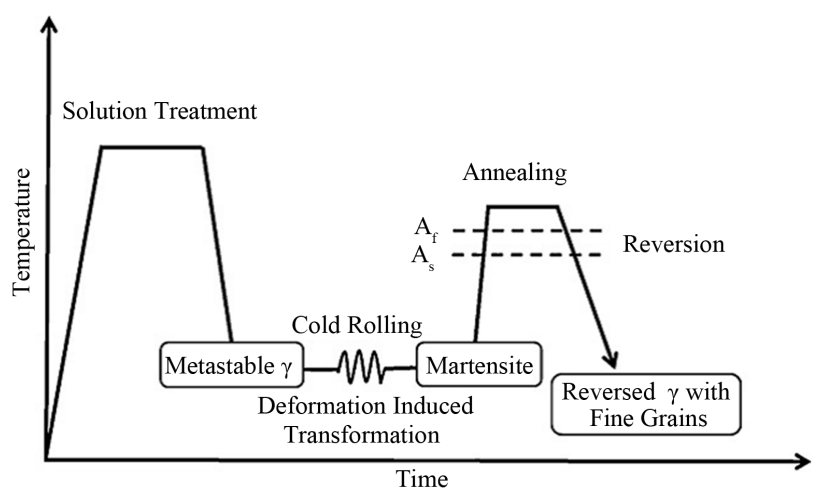

Figure 9. Schematic illustration of the thermomechanical process to obtain the nano grained structure in a $201 \mathrm{~L}$ stainless steel, $A_{s}$ and $A_{r}$ are the reverse transformation start and finish temperatures, respectively [130].

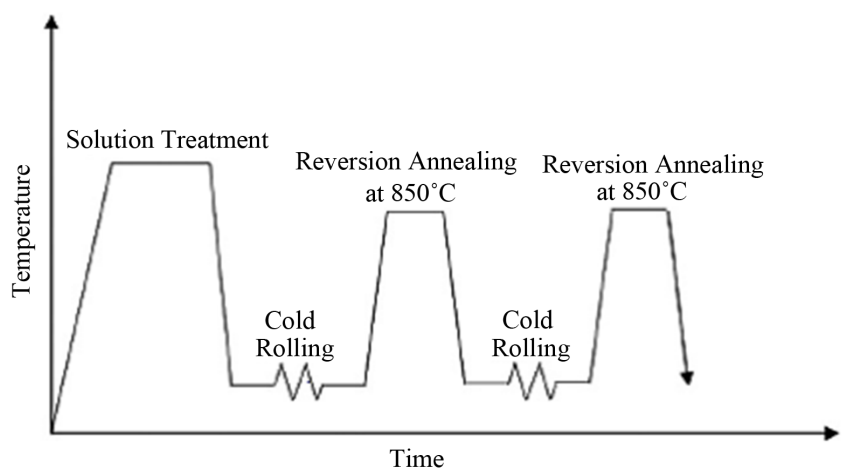

Figure 10. Schematic illustration of the repetitive thermomechanical process used to obtain nan/ultrafine grain structure in 201 stainless steel [132].

\subsubsection{Strain-Induced Ferrite Transformation}

Refinement of ferrite grains is a promising way to simultaneously improve both the tensile strength and toughness of steels [135]. Up to now, several different thermomechanical controlled processing (TMCP) routes have been conducted in steel industry to refine ferrite grains [136]-[141]. However, the grain refinement during TMCP is limited to $5 \mu \mathrm{m}$ [142] [143]. In the last decade, researchers have developed new thermo-mechanical processes to produce fine ferrite grains in the range of 1 - $3 \mu \mathrm{m}$ [144]-[146]. Among these approaches, ultra fine ferrite (UFF) formation through dynamic strain induced transformation of austenite to ferrite (DSIT) is a simple and most effective way [143] [144]. DSIT includes transformation of austenite to ferrite during rather than after deformation. It has been found that plastic strain increases the austenite to ferrite transformation temperature $\left(A_{R 3}\right)$ [147]. Therefore, if steel is deformed at temperatures just above $A_{R 3}$, the transformation temperature increases and reaches to deformation temperature provided that the sufficient amount of plastic strain can be imposed on austenite phase. In these conditions, ferrite phase is dynamically formed during deformation process. The critical strain in the range of 0.1 to 0.8 is required for initiation of DSIT [147]. The principles of DSIT are shown in Figure 11. The critical temperature for DSIT is usually just above the $A_{R 3}$ temperature. It has also been demonstrated that DSIT can occur if deformation applied in the austenite meta-stable temperature range between $\mathrm{Ae}_{3}$ and $\mathrm{A}_{\mathrm{R} 3}$ [148]. All the dynamic evolving behaviors of microstructure at lower deformation temperature range between $\mathrm{Ae}_{3}$ and $\mathrm{A}_{\mathrm{R} 3}$ were similar to that at $\mathrm{A}_{\mathrm{R} 3}$. The volume fraction of ferrite increased with increasing the amount of deformation, and most of the strain-induced ferrite were found to nucleate on the boundaries of ultrafine austenite grains, including a lot of them preferentially selected the corner as their nucleation sites. The reason should be mostly attributed to the change of carbon diffusion behavior due to the refinement of austenite grains. 


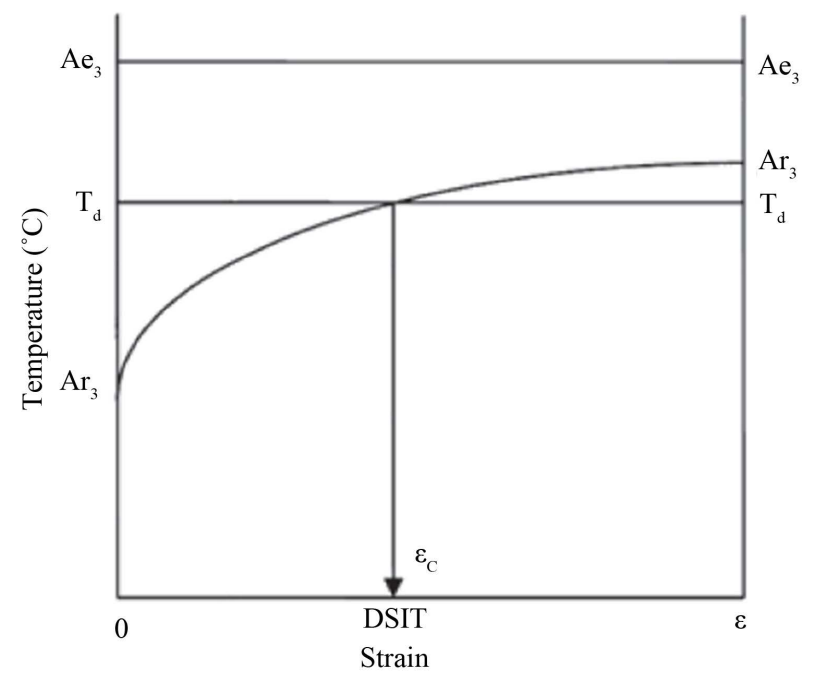

Figure 11. Principles of dynamic strain induced transformation during deformation at constant temperature [148].

\subsubsection{Large-Strain Warm Deformation}

In recent years, a variety of methods have been developed to produce ultrafine-grained (UFG) materials with a ferrite grain size of around $1 \mu \mathrm{m}$ [149] [150]. Many investigators [37] [38] [96] used large-strain warm deformation as most important thermomechanical technique to produce ultrafine grained steel.

Large-strain deformation processing schedules for production ultrafine grained steel are outlined in Figure 12. It consists of $3 \mathrm{~min}$ of reaustenitization at $912^{\circ} \mathrm{C}$ and a single-pass deformation at $860^{\circ} \mathrm{C}$ applying a logarithmic strain of $\varepsilon=0.3$ at a strain rate of $10 \mathrm{~s}^{-1}$ above the recrystallization temperature. In the conventional hot rolling route (Figure 12(a)), the sample is then air cooled to room temperature to obtain a conventional ferrite-pearlite starting microstructure with ferrite grain size around $12 \mu \mathrm{m}$. Grain refinement is achieved by subsequent largestrain warm deformation at $700^{\circ} \mathrm{C}$ (the fine grained (FG) route, Figure 12 (b)) and at $550^{\circ} \mathrm{C}$ (the UFG route, Figure 12(c)), respectively. A total strain of 1.6 is realized by a four-step flat compression series, each step exerting a strain of 0.4 at a strain rate of $10 \mathrm{~s}^{-1}$. The deformation temperature controls the degree of grain refinement. At $700^{\circ} \mathrm{C}$, a fine polygonal ferrite matrix with globular cementite and fine pearlite colonies is formed. At $550^{\circ} \mathrm{C}$, continuous grain subdivision and pronounced recovery lead to slightly elongated ferrite grains with a grain size of around $1 \mu \mathrm{m}$ [151]. After warm deformation, specimens were annealed for $2 \mathrm{~h}$ at the respective deformation temperature to simulate coiling at elevated temperatures, and then air cooled to room temperature.

On the other hand, previous works illustrate that; to control the finished microstructure, large-strain induced deformation process may be followed by inter-critical annealing to produce dual phase steel [25]. To obtain the final dual-phase microstructure, all specimens were subjected to inter-critical annealing followed by quenching in order to transform all austenite into martensite/bainite/pearlite depend on cooling rate of quenching media.

Plain carbon-manganese steel was subjected under the previous treatment by Calcagnotto et al. [152]. They concluded that, after inter-critical annealing at $730^{\circ} \mathrm{C}$ followed by water quenching, the microstructure obtained in case of hot deformation consists of a ferrite matrix with a grain size of $12.4 \mu \mathrm{m}$ and $31.3 \mathrm{vol} \%$ martensite, the latter occurring partly as isolated islands, partly as aligned bands. By applying multi-pass warm deformation at $700^{\circ} \mathrm{C}$ (fine grained route) and at $550^{\circ} \mathrm{C}$ (ultrafine grained route) between hot deformation and intercritical annealing, the ferrite grain size is reduced to 2.4 and $1.2 \mu \mathrm{m}$, respectively. The martensite fraction is $30.1 \mathrm{vol} \%$ in the fine grained steel and $29.8 \mathrm{vol} \%$ in the ultrafine grained steel. Exemplary micrographs are shown in Figure 13.

\subsubsection{Multistage and Single-Stage High-Speed Compression}

Figure 14 shows the thermal processing history in the multistage and single-stage high-speed compression tests, which were based on the Super Short interval Multi-pass Rolling (SSMR) process. The work pieces were gradually heated at a rate of $10^{\circ} \mathrm{C} / \mathrm{s}$ from room temperature to $1000^{\circ} \mathrm{C}$, maintained at the this temperature for $120 \mathrm{~s}$, 


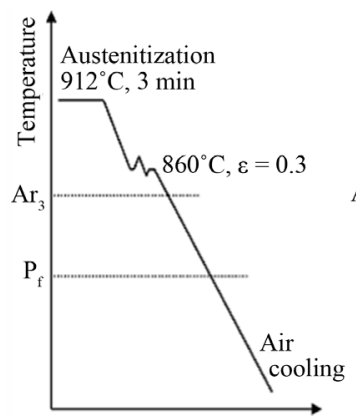

(a)

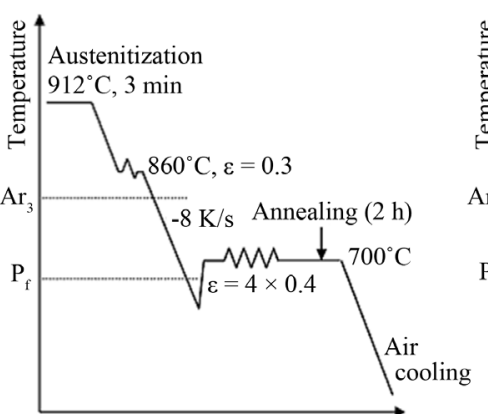

(b)

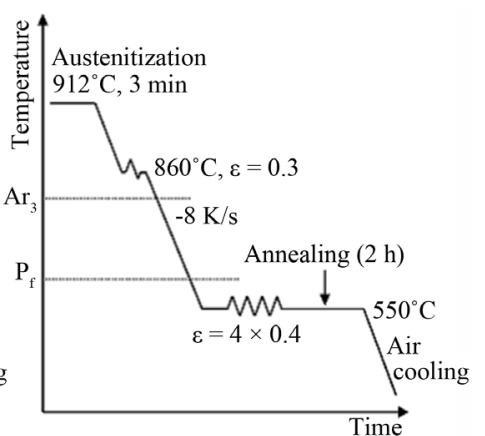

(c)

Figure 12. thermomechanical processing routes to produce different grain size in a hot deformation simulator. All treatment are followed by an intercritical annealing at $730^{\circ} \mathrm{C}$ for $3 \mathrm{~min}$ and subsequent quenching to obtain the final ferrite/martensite daul-phase microstructur. $\mathrm{Ar}_{3}$ : non-equilbruim transformation start temperature; $\mathrm{P}_{\mathrm{f}}$ : pearlite transformation finish temperature; $\varepsilon$ : logarithmic starin [152]. (a) Coarse grain (CG) route; (b) Fine grain (FG) route; (c) Ultrafine grain (UFG) route.
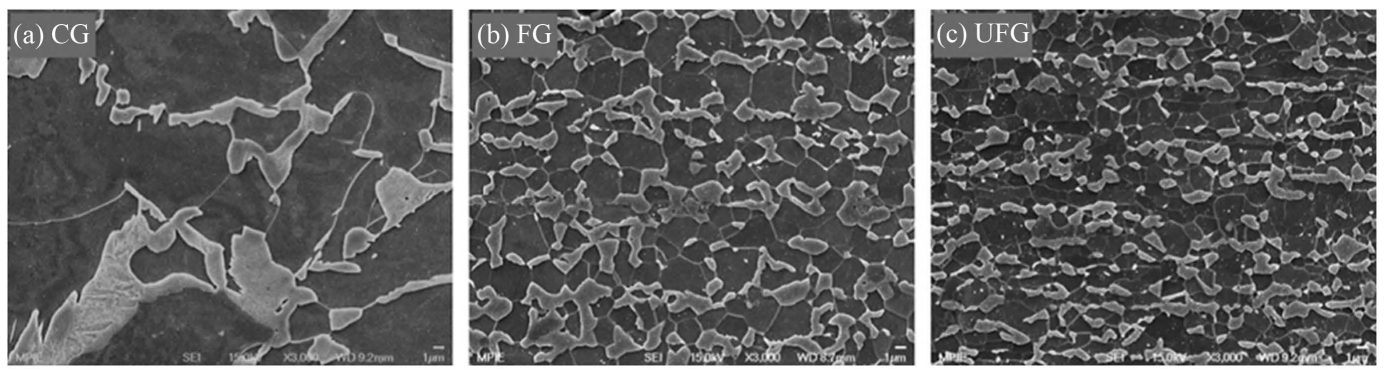

Figure 13. Microstructures of the (a) Conventional material (12.4 $\mu \mathrm{m}$ ferrite grain size); (b) Fine grained material ( $2.4 \mu \mathrm{m}$ ferrite grain size) and (c) ultrafine grained material (1.2 $\mu \mathrm{m}$ ferrite grain size) produced by the processing routes illustrated in Figure 10 plus intercritical annealing for $3 \mathrm{~min}$ at $730^{\circ} \mathrm{C}$ in a salt bath, followed by water quenching [152].

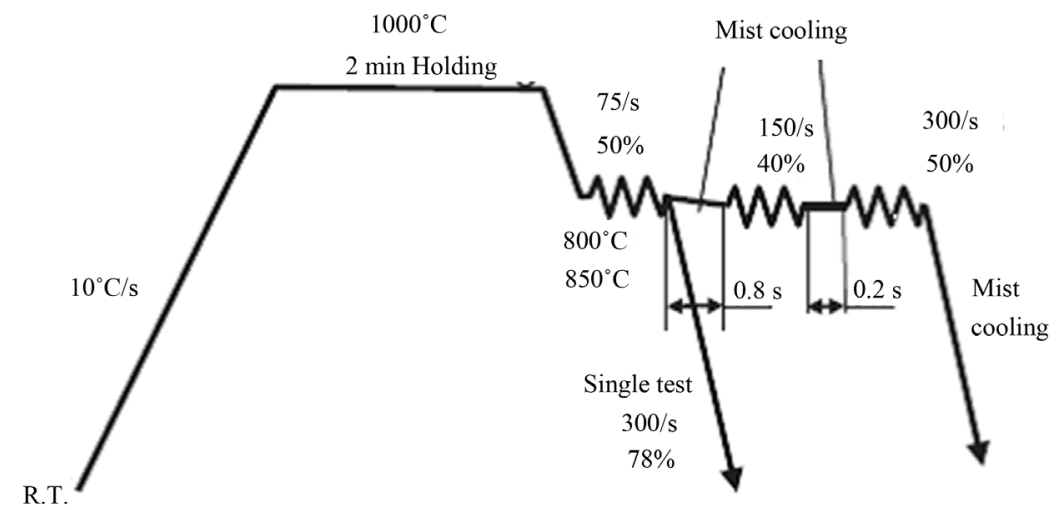

Figure 14. Thermal processing history in multistage and single-stage compression tests [154].

and then cooled at a rate of $50^{\circ} \mathrm{C} / \mathrm{s}$ to the testing temperature of $800^{\circ} \mathrm{C}$ or $850^{\circ} \mathrm{C}$. The austenite grain size before compression was about $30 \mu \mathrm{m}$ [153]. Before compression, there was a holding time of 5 second at the testing temperature to minimize the temperature distribution inside the work piece. The axial reductions of the different stages were $50 \%, 40 \%$, and $50 \%$ and the corresponding strain rates of the different stages were $75 / \mathrm{s}, 150 / \mathrm{s}$, and $300 /$ s, respectively. Severe plastic deformation at a temperature of approximately $\mathrm{Ae}_{3}$ is effective for producing ultrafine-grained plain steel because the accumulated strain can immediately induce a ferrite transformation. However, owing to the heat generation associated with severe deformation, the processing temperature easily 
rises to above $\mathrm{Ae}_{3}$. Consequently, it was necessary to remove the heat, and in the test process, the test pieces were cooled by mist spray between stages. A single-stage high speed compression test was also conducted. The heating pattern in the single-stage test was almost the same as that in the multistage compression test, but the testing temperature was slightly reduced to $760^{\circ} \mathrm{C}$. The axial reduction was $78 \%$ and the strain rate was $300 / \mathrm{s}$. This is because severe single stage compression generates considerable heat, and thus the test must be started earlier at a lower temperature to produce a stable ferrite structure.

\subsubsection{Rapid Cooling and Short Interval Multi-Pass Hot Rolling}

Toshiro et al. [155] discover a noble grain refinement method to attain ferrite grain size of $1 \mu \mathrm{m}$ in plain C-Mn steel by multi-pass hot rolling in a stable austenite temperature region. $0.1 \% \mathrm{C}-1 \% \mathrm{Mn}$ and $0.16 \% \mathrm{C}-0.7 \% \mathrm{Mn}$ steels were finish-rolled at about $\mathrm{Ae}_{3}$ and then rapidly cooled. Special emphases have been placed on the interval, $\Delta t$, between the finish of rolling and the start of water spray cooling of more than $1000^{\circ} \mathrm{C} \cdot \mathrm{s}^{-1}$ in cooling rate and the interval between the last two rolling passes. By reducing $\Delta t$ from 0.5 to $0.05 \mathrm{~s}$ alone, the grain sizes near the sheet surface and in the central region were markedly reduced to 1.3 and $2.2 \mu \mathrm{m}$ respectively. By reducing $\Delta t$ and the rolling pass interval together, a further reduction in grain size was then achieved. Consequently, the steel sheet in which the ultrafine grain structure of about $1 \mu \mathrm{m}$ in grain size penetrated from the sheet surface to the depth of a quarter of the sheet thickness and the grain size in the central region was well below $2 \mu \mathrm{m}$ was obtained. The transformation to the ultrafine ferrite is considered to be static and from deformed austenite $(\gamma)$.

The principal of rapid cooling and short interval multi-pass hot rolling is schematically represented in Figure 15. It consists of three rolling stands designated as F1 to F3 and water-cooling devices. The cooling device after F3 was designed to attain a large cooling rate over $1000^{\circ} \mathrm{C} \cdot \mathrm{s}^{-1}$ for the samples under investigation and to control the intervening time period $\Delta t$ between the last rolling pass and the beginning of the rapid cooling. The $\Delta t$ in this experiment is specifically defined as the period between the instance of the exit from the last rolling and the instance at which high-pressure water jets first make contact with samples. The cooling devices between the rolling stands were used to suppress adiabatic deformation heating when it was necessary to maintain sample temperature.

\subsection{Concept of "SSMR" Process}

To make the short interval multi-pass rolling process function well, reduction per pass, inter-pass time, number of passes and rolling temperature should be optimized. Rolling temperature affects the rolling load as well as the reduction per pass. The lower the material temperature is, the larger the rolling load becomes. In addition, if the temperature falls below the ferrite transformation temperature before the final pass, the microstructure of the rolled strip is supposed to contain deformed ferrite grains or abnormally grown grains, which are not preferable for mechanical properties of the strip. Therefore the rolling in the stable austenite temperature region was searched for the new process. In order to shorten the inter-pass time, the rolling stands must be placed close each other and rolling speed must be fast. However, when the rolling speed increases, the heat generation in rolling becomes large. For the purpose of the effective strain accumulation, excessive temperature rise should be avoided because the restoration of the strain proceeds fast in high temperature. Therefore the rapid cooling right after each rolling pass is necessary to compensate the generated heat. Immediate cooling after rolling is also required for inducing ferrite transformation and for restraining the grain growth after the transformation. The basic

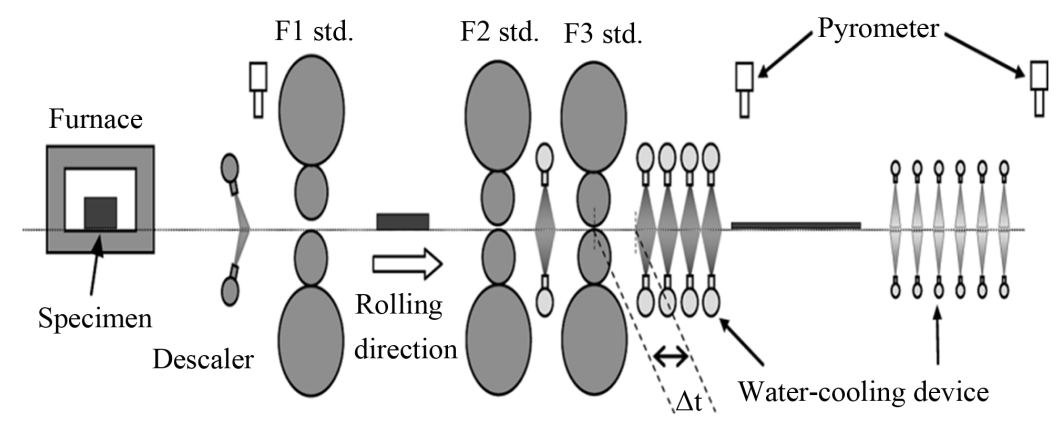

Figure 15. Schematic representation of experimental hot-rolling simulator [156]. 
concept of the newly proposed process is as follows. In downstream stands of hot finishing mill, more than two stands including the final one are equipped at extremely short distance. At those stands high speed and moderately large reduction rolling of $40 \%-50 \%$ per pass is performed. Strip temperature is controlled around $\mathrm{Ae}_{3}$, the para-equilibrium transformation temperature from austenite to ferrite, by inter-pass cooling. Then the strip is cooled down to appropriate temperature immediately. Authors named this process "Super Short interval Multipass Rolling (SSMR) process”.

\subsection{Production Ultrafine Steels by Severe Plastic Deformation Techniques}

Severe plastic deformation (SPD) techniques [157]-[159] impose large accumulated plastic strains at room or elevated temperatures, e.g. mainly in the temperature regime of warm deformation. Many different severe plastic deformation (SPD) processing techniques have been proposed, developed and evaluated. These techniques include equal-channel angular pressing (ECAP) [160]-[162], high-pressure torsion (HPT) [163]-[165], multi-directional forging [166]-[168], twist extrusion [169] [170], cyclic-extrusion-compression [171] [172], reciprocating extrusion [173] [174], repetitive corrugation and straightening (RCS) [175] [176], constrained groove pressing (CGP) [177], cylinder covered compression (CCC) [178], accumulative roll-bonding (ARB) [179] [180], friction stir processing (FSP) [181] [182] and submerged friction stir processing (SFSP) [183]. All of these procedures are capable of introducing large plastic straining and significant microstructural refinement in bulk crystalline solids. Some of these techniques, such as ECAP, HPT, multi-directional forging and ARB, are already well-established methods for producing UFG materials where, depending upon the crystal structure, the processed microstructures have grain sizes lying typically within the range of $\approx 70-500 \mathrm{~nm}$. The other techniques are currently under development for this purpose.

\subsubsection{Equal-Channel Angular Pressing}

Equal-channel angular pressing imposes large plastic strains on massive billets via a pure shear strain state. The approach was developed by Segal et al. in the early 1980s [184]. Its goal was to introduce intense plastic strain into materials without changing the cross-sectional area of the deformed billets. Owing to this characteristic, repeated deformation is possible. At the beginning of the 1990s this method was further developed and applied as a severe plastic deformation method for the processing of microstructures with submicron grain sizes [185]. The equal channel angular pressing method was mainly applied for nonferrous alloys (e.g. Al and Mg alloys) and some low carbon steels. The finest ferrite grain size obtained by use of this method is reportedly about $0.2 \mu \mathrm{m}$ [186] [187].

The ECAP technique was invented as a method for the shape-maintaining plastic deformation of bulk materials in [188] and for the first time has been shown to be applicable for the formation of an ultra-fine grained structure in metals and alloys in [189]. The method utilizes a die containing two channels of equal cross sections intersecting at an angle $2 \Phi$, which normally varies in the range $90^{\circ}-135^{\circ}$ (Figure 16). In the vicinity of the plane of intersection of these channels material undergoes severe plastic deformation, which is mainly of simple shear character. On passing the two channels a sample maintains its shape except for small portions at the ends (Figure 3). There have been done many analyses of the mechanics of deformation during ECAP to understand

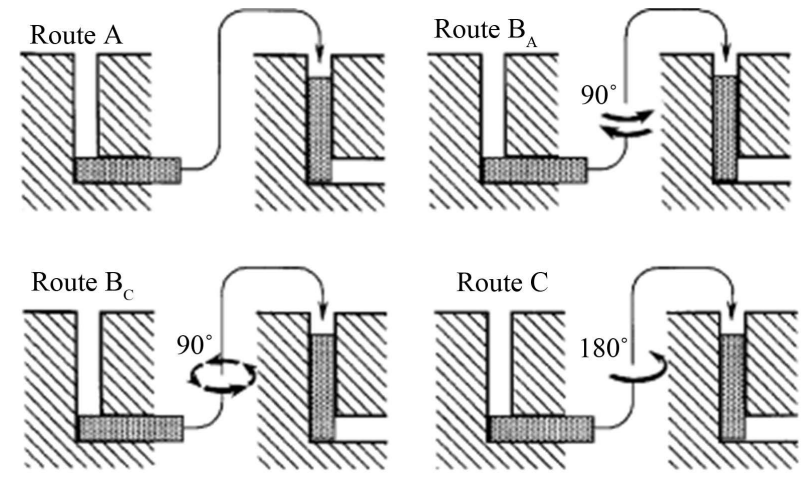

(a)

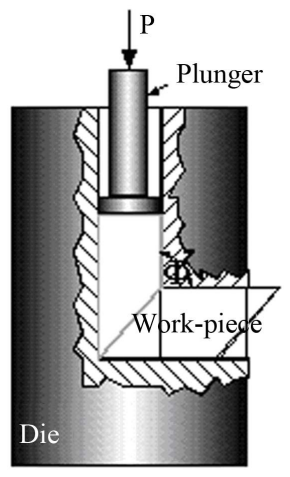

(b)

Figure 16. Schematic view of equal channel angular pressing [190]. 
the exact character of plastic strain during ECAP, its dependence on the location of material elements with respect to the channel walls and to evaluate the accumulated strain [190]-[193]. The simplest approximation is the model of simple shear according to which materials is subject to simple shear strain of $\varepsilon=2 / \sqrt{ } 3 \cot (\Phi / 2)$ singularly at the plane of channels' intersection [190]. For $2 \Phi=90^{\circ}$ the highest strain per pass equal to $\varepsilon=1.15$ is achieved. Dies with such an angle are used for pure metals and easily deformable alloys. For hard-to-deform materials strain is imposed at elevated temperatures and/or with the channels' intersection angle $2 \Phi>90^{\circ}$.

To accumulate very large strains sample can be forced to pass through the die several times. Strain path can be easily changed by turning the sample around its longitudinal axis between subsequent passes. Four standard routes have been established referred to as A, BA, BC, and C [190] [193] [194]. A sample is rotated around its axis to an angle of $0^{\circ}, 90^{\circ}$, and $180^{\circ}$ for the routes $\mathrm{A}, \mathrm{B}$, and C, respectively. When using route $\mathrm{BA}$, consecutive $90^{\circ}$ rotations have opposite senses, while in route $\mathrm{BC}$ the sample is rotated in the same direction.

Parameters of the die and deformation route can be chosen for any material to meet the following main requirements: Formation of an UFG structure with mainly high-angle grain boundaries, the absence of macroscopic damages and cracks in the samples, Microstructural homogeneity in the most volume of the samples, and Formation of equiaxed grains. In some cases using back pressure helps to meet these requirements.

The original ECAP is a discontinuous process and as such has a low production efficiency and high cost. It is considered as a basic way to understand the principles of SPD fabrication of nano-materials that then can be used in further developments aimed at scaling up of the process and production of low-cost nanomaterials in large quantities.

One of numerous ECAP-based continuous SPD methods is the ECAP-Conform process developed at IPAM [195]. The ECAP-Conform set up is schematically illustrated in Figure 17. A rotating shaft in the center contains a groove, into which the work-piece is fed. The work-piece is driven forward by frictional forces on the three contact interfaces with the groove, which makes the work-piece rotate with the shaft. The work-piece is constrained to the groove by a stationary constraint die. The stationary constraint die also stops the work-piece and forces it to turn an angle by shear as in a regular ECAP process. The angle is about $90^{\circ}$, which is the most commonly used channel intersection angle in ECAP. This set up effectively makes ECAP continuous. Other ECAP parameters (die angle, strain rate, etc.) can also be used. Our preliminary results have shown that the ECAP-Conform process can effectively refine grains of coarse-grained $\mathrm{Al}$ and improve its mechanical properties in a way similar to the conventional ECAP.

\subsubsection{Accumulative Roll Bonding}

Accumulative roll bonding essentially involves repeated application of conventional rolling. This approach has been suggested to possess the potential for mass production [196] [197]. While rolling is an attractive deformation process for continuous production of bulk sheets, the total reduction in thickness, i.e. the accumulated strain,

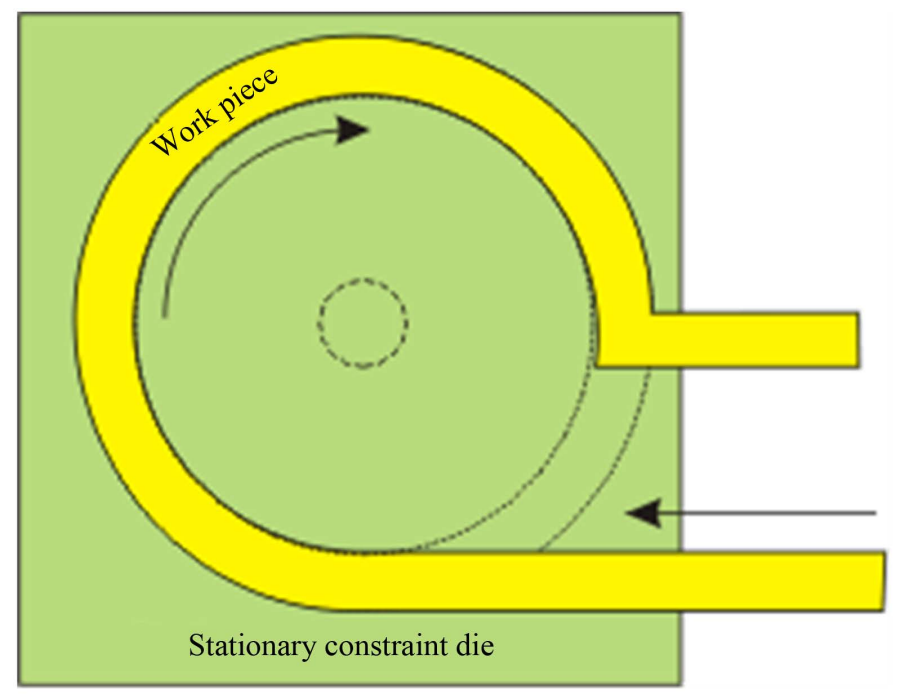

Figure 17. Schematic view of ECAP-Conform set-up [195]. 
which can be achieved by this method, is limited because of the decrease in the strip thickness with increasing rolling reduction. In order to obtain bulk material, rolled sheets are stacked and then bonded together during rolling [198]. Hence, the process involves simultaneous bonding and deformation. In the accumulative roll bonding method, the rolled material is cut, stacked to the initial thickness and rolled again. Owing to this approach, multiple repetitions are possible to achieve huge strains as shown in Figure 18. A natural limit of this approach lies in the increase in strength and the gradually reduced surface quality of the roll-bonded sheets.

\subsubsection{High Pressure Torsion}

High pressure torsion (HPT) technique is based on the use of Bridgeman anvil-type device. The possibility of the formation of a nano-crystalline structure by this method was first demonstrated in [200] [201]. A diskshaped sample is put between two anvils and subjected to a high pressure of 2.5 GPa (Figure 19). Rotation of one of the anvils forces the sample to deform by torsion. Up to five rotations of the anvil are usually enough to form a homogeneous microstructure with the grain size typically about $100 \mathrm{~nm}$, in some metals and alloys with high melting temperature as small as $50 \mathrm{~nm}$. This method enables the preparation of disc-shaped samples with diameter up to $20 \mathrm{~mm}$ and thickness about $0.2 \mathrm{~mm}$, which are good for fundamental studies of the structure-property relationships for nano-materials.

\subsubsection{Bi-Directional Large Strain Deformation}

Bi-directional compression can be used to introduce large plastic strains in steels. It combines severe plastic deformation (large strain) and thermomechanical processing (phase transformation and controlled cooling can be exploited). Compression is realized by alternate forging in two perpendicular directions. Elongation in the third direction is usually not restricted.

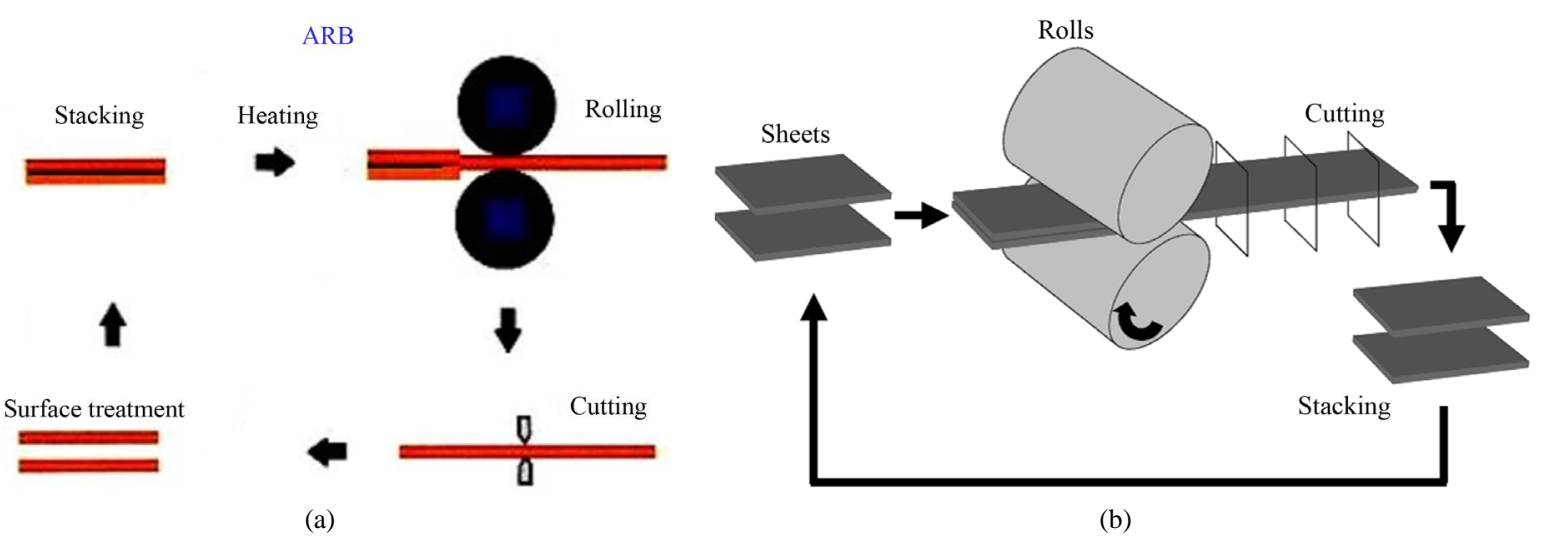

Figure 18. Schematic diagram showing ARB process [199]. (a) Two dimensions; (b) Three dimensions.

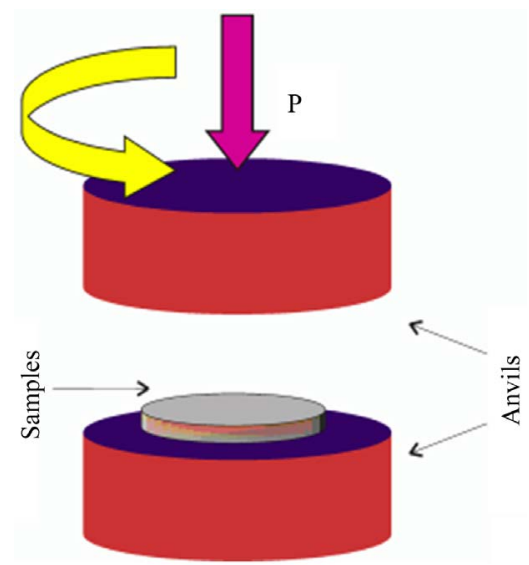

Figure 19. Schematic rendering of high pressure torsion [201]. 


\subsubsection{Multi-Axially Forged Austenite}

In the multidirectional forging (MDF) method, the samples were compressed with a changing loading direction of $90^{\circ}$ pass-by-pass (i.e., $\mathrm{z}$ to $\mathrm{y}$ to $\mathrm{x}$ to $\mathrm{z}$.) (Figure 20). The aspect ratio of the samples was almost unchanged during repeated MDF with a pass strain of $\Delta \varepsilon=0.4$.

\section{1) Dynamic Recrystallization (DRX)}

Production of ultrafine grained or nano-grained steel by multiaxially forged austenite was reported by Hauang et al. [203] by means of deformation at temperature which dynamic recrystallization (DRX) was dominated (below 0.5 melting temperature of the material). However, it was recently reported that continuous dynamic recrystallization (DRX) could take place and the ultra grain refinement to submicro-size or nano-size level was achieved [204]-[206] within a lower temperature range of austenite state under a severe plastic deformation such as Equal Channal Angular Pressing, Accumulative Roll Bonding, etc.

The main thrust of Huang et al. [203] work, is principally concerned with elucidating the microstructural evolution and the continuous dynamic recrystallization (DRX) mechanism of multi-axially forged austenite.

The evolution of continuous DRX during multiaxial forging can be summarized as a process in Figure 21. When initial grains are deformed in some direction, deformed bands will be produced along a certain direction in deformed grains by slip shear. Once the deformation direction changes, other deformed bands will also formed along other directions, in this way, deformed bands will cross each other, by which an austenite grain

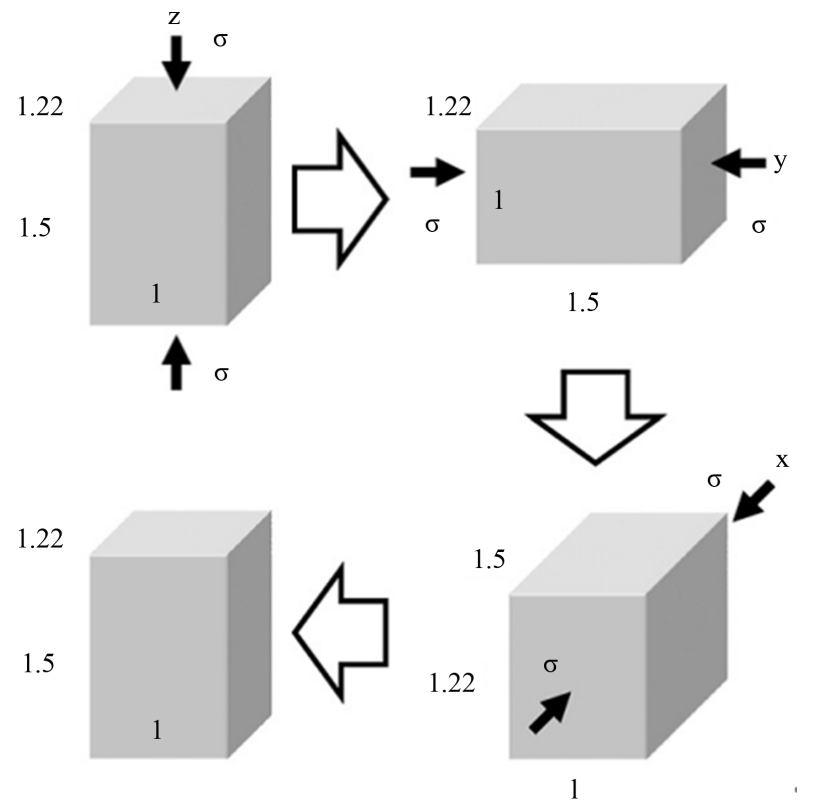

Figure 20. Schematic illustration of the process of multidirectional forging (MDF) with loading stress $\sigma$. The indexed numbers give the aspect ratio of the sample [202].

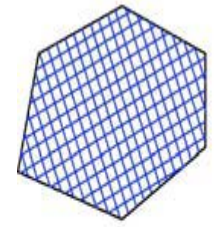

(a)

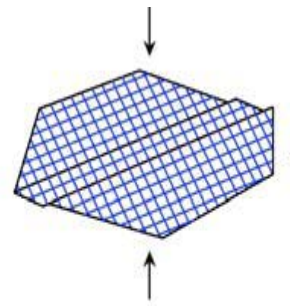

(b)

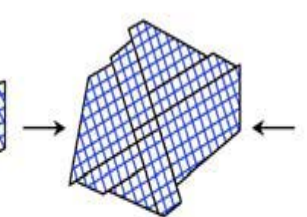

(c)

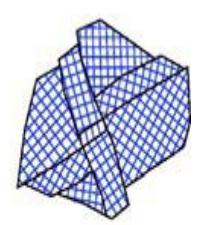

(d)

Figure 21. The evolution mechanism of continuous dynamic recrystallization during multiaxial forging (a) initial grain; (b) after the first pass; (c) after the second pass with deformation direction rotated $90^{\circ}$; (d) subgrains angled in the subsequent passes [203]. 
can be subdivided into several subgrains. And these subgrains will be gradually angled to new independent grains and its boundaries transformed into big angle boundaries in subsequent deformation passes.

\section{2) Static Recrystallization}

Multi-axial forging or multidirectional forging (MDF) is an effective method to produce ultrafine grained steel. The ultrafine ferrite grains with sizes of about $1.2 \mu \mathrm{m}$ obtained (from initial ferrite grains with sizes of about $38 \mu \mathrm{m}$ ) via MDF at room temperature followed by post deformation annealing at $500^{\circ} \mathrm{C}$ for $1 \mathrm{~min}$ as proposed by Soleymani et al. [207].

The main feature of the microstructure changed during MDF at room temperature is the ferrite grains pancaking. After MDF up to strain of 0.8, the grains are elongated along the transverse press direction. With increasing accumulative strain, more work hardened grains were formed after 4th pass of MDF and the grains aspect ratio (the ratio of the grains dimension in the longitudinal direction to that in the transverse direction) increased. The microstructure was completely replaced by highly pan-caked grains when the accumulative strain was 2.6. Multidirectional deformation can develop the micro-shear bands in various directions due to the change of deformation axes from pass to pass [208]. At the temperature of $500^{\circ} \mathrm{C}$, the grain refinement mechanism recognized as static recrystallization. The microstructure evolution process is that the new grains are formed by nucleating within deformed grains. Then they grow and consume the deformed microstructure until the material is completely recrystallized.

\subsubsection{Constrained Groove Pressing}

In terms of using severe plastic deformation to produce nanostructure sheets [209]-[211], two major severe plastic deformation techniques, which are mostly employed, are accumulative roll bonding [212] [213] and constrained groove pressing [214]. The constrained groove pressing, introduced by Shin et al. [214], involves repetitive corrugating and flattening stages. During constrained groove pressing, the work piece is subjected to cyclic shear deformation by utilizing asymmetrically grooved dies and flat dies. The constrained groove pressing process is schematically shown in Figure 22. In this technique, the gap between the upper die and lower die is identical to the sample thickness and therefore the inclined part of the sample, located in the groove, is subjected to pure shear deformation [215]. By imposing more constrained groove pressing passes, the higher strains are introduced to the work piece. The work piece subjected to severe plastic deformation by applying three passes of constrained groove pressing which resulted in the total strain of 3.48. This led to ultrafine grain low carbon steel having the grains of 260 - $270 \mathrm{~nm}$. Recently, many works are carried out to study the mechanical properties and microstructural evolutions of different materials such as low carbon steel, aluminum and copper subjected to constrained groove pressing. According to these studies [216] [217], it is reported that the constrained groove pressing can effectively enhance the mechanical properties of sheet metals. The treatments applied to ultra-fine grain steel is summarized in Table 5.

In order to produce the ultra-fine grain samples, the constrained groove pressing was used. The work piece was subjected to severe plastic deformation by applying three passes of constrained groove pressing which resulted in the total strain of 3.48. This led to ultrafine grain low carbon steel having the grains of $260-270 \mathrm{~nm}$. According to the past works [213] [216] [217], each constrained groove pressing pass imposes the strain of about 1.16. In the first step, the flat sheet becomes corrugated which results in a 0.58 effective strain in deformed regions. Whereas, in the second step, the flat dies are used to flatten the corrugated sheet by imposing an extra 0.58 strain to the previously deformed sections [215]-[217]. This is defined as one cycle of constrained

Table 5. The treatments applied to ultrafine grain and coarse samples [218].

\begin{tabular}{ccc}
\hline Steps & Coarse grain specimen & Ultrafine grain specimen \\
1 & Solid solution traetment $\left(850^{\circ} \mathrm{C} / 1 \mathrm{~h}\right)$ & Solid solution traetment $\left(850^{\circ} \mathrm{C} / 1 \mathrm{~h}\right)$ \\
2 & Water quenching & Water quenching \\
3 & Pre-straining $(4 \%, 6 \%$, and $8 \%)$ & Producing UFG microstructure by CGP \\
5 & Baking $\left(250^{\circ} \mathrm{C}\right.$ and $250^{\circ} \mathrm{C}$ for 20 min $)$ & Pre-straining $(4 \%, 6 \%$, and $8 \%)$ \\
6 & Tensile testing at room temperature & Baking $\left(250^{\circ} \mathrm{C}\right.$ and $250^{\circ} \mathrm{C}$ for 20 min) \\
\end{tabular}




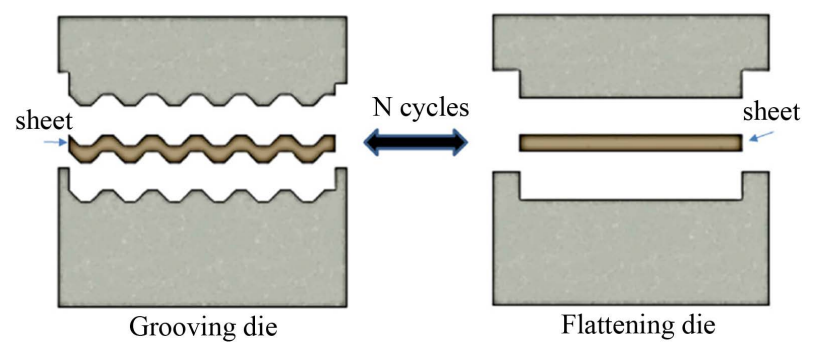

(a)

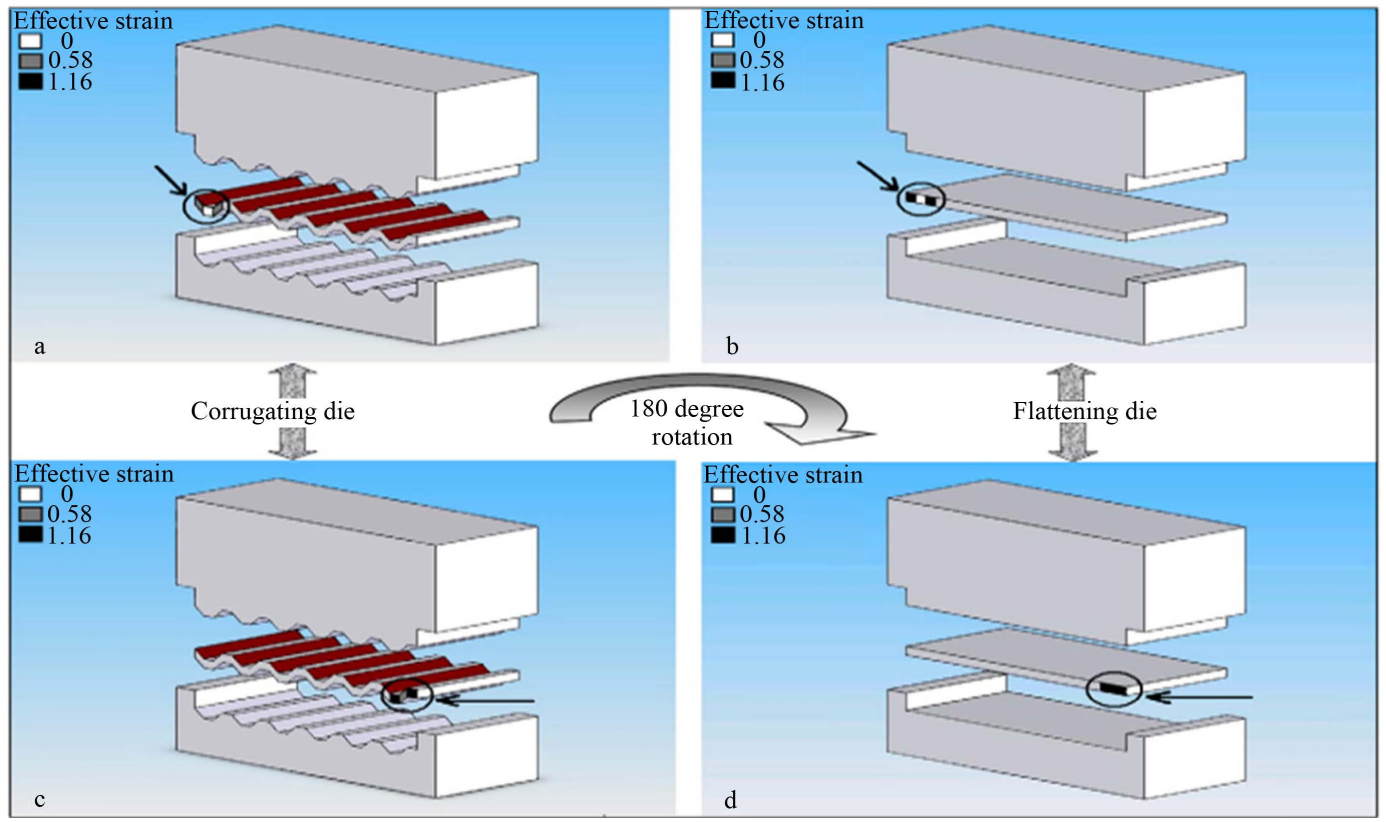

(b)

Figure 22. The schematic of dies used in constrained groove pressing process [218] [219]. (a) Two dimensions; (b) three dimensions.

groove pressing. After straightening, the specimen is rotated $180^{\circ}$ around the axis perpendicular to the plane of the sheet and then the second cycle is employed. After the second pass, another effective strain of 1.16 is introduced in the specimen [213]-[218].

\subsubsection{Warm Caliber Rolling}

Warm caliber rolling process is shown schematically in Figure 23. Shiro et al. [219] proposed that, caliber rolling has been used with relatively successful for UFG production. Earlier work done by Shiro et al. [219] for C-Mn steels (C15 and C60 steels) were heated up to $823 \mathrm{~K}$ and subsequently rolled by 12 passes from $40 \mathrm{~mm}$ square to a final of $13 \mathrm{~mm}$ square. The material of the C30 steel also was heated up to $823 \mathrm{~K}$ and subsequently rolled by 21 passes from $80 \mathrm{~mm}$ square to a final of $18 \mathrm{~mm}$ square. All calibers except the second last one were square type caliber and the second last one was oval type one. Immediately after rolling, rolled rods were water quenched [220] [221].

Kimura et al. [223] [224] have recently developed a warm caliber rolling process of tempered martensitic structures for medium-carbon low-alloy steels as a method to obtain ultrafine elongated grain (UFEG) structures, and found out enhanced impact toughness of the low-alloy steels at a yield strength $\left(\sigma_{y}\right)$ of $1400 \mathrm{MPa}$ or more.

Kimura et al. [225] concern especially for production ultrafine steel with following chemical composition, $0.39 \% \mathrm{C}, 1.98 \% \mathrm{Si}, 1.04 \% \mathrm{Cr}, 1.05 \% \mathrm{Mo}, 0.21 \% \mathrm{Mn}, 0.001 \% \mathrm{P},<0.001 \% \mathrm{~S}, 0.041 \% \mathrm{Al}, 0.002 \% \mathrm{~N},<0.005 \% \mathrm{O}$ and the balance Fe was used in this study. A $100 \mathrm{~kg}$ ingot was prepared by vacuum melting and casting, homogenized at $1200^{\circ} \mathrm{C}$, and then hot-rolled to a plate with a thickness of $4 \mathrm{~cm}$. A $12 \mathrm{~cm} \times 4 \mathrm{~cm} \times 4 \mathrm{~cm}$ block was cut 


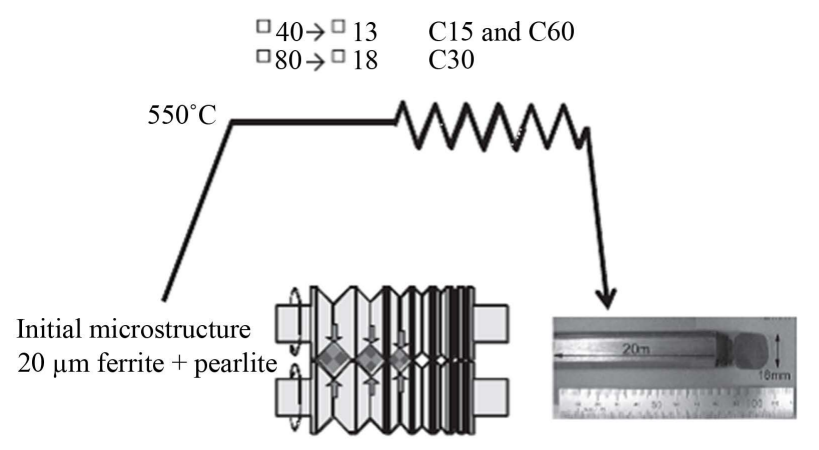

Figure 23. Schematic drawing of warm multi-pass caliber rolling to obtain ultrafine grained structure [222].

out of the plate, solution-treated at $1200^{\circ} \mathrm{C}$ for $1 \mathrm{~h}$ and then hot-rolled to a squared bar with a cross section area of $9 \mathrm{~cm}^{2}$, followed by water quenching. The quenched bars were tempered at $500^{\circ} \mathrm{C}$ for $1 \mathrm{~h}$ and then subjected to multi-pass caliber rolling to squared bars with a cross section of $2 \mathrm{~cm}^{2}$, followed by air cooling (temp-formed (TF) samples). The total reduction in area through the multi-pass rolling was $77 \%$ in 9 passes. Note that the samples were held for $5 \mathrm{~min}$ in a furnace after every three passes during the rolling and passed through twice for the final groove to control the cross sectional shape of the bars. For reference, parts of the quenched bars were tempered at $500^{\circ} \mathrm{C}$ for $1 \mathrm{~h}$ and then air cooled (QT sample).

Table 6 summarizes the common techniques to produce ultrafine grained steels and the ferrite grain sizes obtained. To obtain ultrafine grains using SPD methods, the accumulated plastic strains are required to be of the order of 3 - 4 for ECAP and be of the order of 5 - 6 for ARB process. To obtain ultrafine grains using advanced thermomechanical process methods, the accumulated plastic strain is required to be of the order of 1 - 3.6. Compared with SPD methods, the advanced thermomechanical process methods are generally less effective in producing ultrafine grains, but ATP methods are more adaptable to large scale production.

\section{Application of Ultrafine Grained Steels}

One of many advantages claimed for small grain size is that of dynamic deformation at high strain rate which are very important for the passengers' safety in the case of car collisions. However, ultrafine-grained (UFG) steels [198] [226] are expected to be used in the future as structural materials, including automobile body applications, because of their superior mechanical properties.

It is important to note also that the grain size has a strong influence on the local flow behavior during micro-forming and it is believed to be the limiting factor that dictates the minimum size for the production of geometrical features [227]. This means in practice that nano-crystalline materials exhibit the best formability in micro-imprinting and the use of ultrafine-grained materials may improve the flow behavior and the filling quality since size effects, such as process scatter and uneven shape evolution, are significantly reduced in comparison with the conventional coarse-grained materials. Processing by SPD has been used successfully for processing in micro-forming applications such as production of micro-gears and for production of net-shaped micro-electro-mechanical system (MEMS) components [228].

Ultrahigh strength wire can have many applications that demand exceptional tensile strength. In terms of quantity, two most important applications for ultrahigh strength steel wire are in the automotive tire reinforcement [229] and in the cable wire for suspension bridges [230]. In addition to the application in tires and bridges, ultrahigh strength wire can serve as springs, wire rope, and reinforcement in a wide range of composite structures, such as pre-stressed concrete structures. The application of ultrahigh strength wire in the composite industry is largely un-explored because the wire was not available before, but the application potential is expected to be enormous. It is highly recommended to conduct exploratory studies to verify the physical-mechanical properties, manufacturing procedural, and cost-saving advantages of ultrahigh strength wire reinforced composites.

There is a continued and increasing demand to transport oil and gas by pipelines at high operating pressures in the attempt to increase the capacity. This requires the use of ultrahigh strength steels. Furthermore, increasing the strength of the pipeline steel allows wall thickness to be significantly reduced with consequent reduction in weight. Thus, a major goal within the steel industry is to develop ultrahigh strength microalloyed pipeline steels 
Table 6. Summary of different techniques reported to produce ultrafine grained steels [37].

\begin{tabular}{|c|c|c|c|c|c|c|}
\hline Technique & Steels & Steel composition (wt\%) & $\begin{array}{c}\text { Ferrite grain } \\
\text { size achieved } \\
(\%)\end{array}$ & $\begin{array}{l}\text { Log, strain } \\
\text { imposed } \\
\text { (\%) }\end{array}$ & $\begin{array}{l}\text { Deformation } \\
\text { temperature } \\
\text { (K) }\end{array}$ & $\begin{array}{c}\text { Heat treatment } \\
\text { after } \\
\text { deformation }\end{array}$ \\
\hline \multirow{4}{*}{ ECAP } & $\begin{array}{c}\text { Plain low carbon } \\
\text { steel }\end{array}$ & $0.08 \mathrm{C}-0.42 \mathrm{Mn}-0.18 \mathrm{Si}$ & 0.2 & 3.0 & 293 & AC \\
\hline & $\begin{array}{c}\text { Plain low carbon } \\
\text { steel }\end{array}$ & $0.15 \mathrm{C}-1.1 \mathrm{Mn}-0.25 \mathrm{Si}$ & 0.3 in thickness & 4.0 & 623 & AC \\
\hline & $\begin{array}{l}\text { Ti-V low carbon } \\
\text { steel }\end{array}$ & $0.1 \mathrm{C}-1.59 \mathrm{Mn}-0.29 \mathrm{Si}-0.02 \mathrm{Ti}-0.05 \mathrm{~V}$ & $\sim 0.3$ thickness & 1.0 & 573 & AC \\
\hline & $\begin{array}{l}\text { Ferrite-austenite } \\
\text { dual phase steel }\end{array}$ & $0.15 \mathrm{C}-1.06 \mathrm{Mn}-0.25 \mathrm{Si}$ & 0.8 & 4.0 & 773 & $\begin{array}{c}1003 \mathrm{~K} \times \\
10 \mathrm{~min} W \mathrm{~W}\end{array}$ \\
\hline ARB & Ti-added IF steel & $0.003 \mathrm{C}-0.15 \mathrm{Mn}<0.01 \mathrm{Si}-0.049 \mathrm{Ti}$ & 0.4 & 5.6 & 773 & WC \\
\hline HPT & $\begin{array}{c}\text { Plain low carbon } \\
\text { steel }\end{array}$ & $\sim 0.7 \mathrm{C} \sim 1.0 \mathrm{Mn} \sim 0.3 \mathrm{Si}$ & 0.01 & $\begin{array}{l}\text { Shear than } 300 \text {, } \\
\text { log strain } 0.45\end{array}$ & 293 & $\mathrm{AC}$ \\
\hline $\begin{array}{l}\text { DRX* during hot } \\
\text { deformation }\end{array}$ & Micro-alloyed steel & $0.11 \mathrm{C}-1.45 \mathrm{Mn}-0.34 \mathrm{Si}-0.068 \mathrm{Nb}$ & $2-5$ & $\begin{array}{c}\text { Final rolling } \\
2.3-3.6\end{array}$ & $1153-1033$ & $\mathrm{AC}$ \\
\hline $\begin{array}{l}\text { Strain-induced } \\
\text { ferrite transformation }\end{array}$ & $\begin{array}{c}\text { Plain low carbon } \\
\text { steel }\end{array}$ & $0.06 \mathrm{C}-0.59 \mathrm{Mn}$ & $\begin{array}{c}1.0 \\
\text { (strip surface) }\end{array}$ & 0.36 & 1053 & AC \\
\hline $\begin{array}{l}\text { Deformation in the } \\
\text { inter-critical region }\end{array}$ & $\begin{array}{c}\text { Plain low carbon } \\
\text { steel }\end{array}$ & $0.17 \mathrm{C}-1.32 \mathrm{Mn}-0.44 \mathrm{Si}-0.15 \mathrm{Nb}$ & 2.1 & 2.3 & 973 & WQ \\
\hline $\begin{array}{l}\text { Warm rolling in the } \\
\text { ferrite region }\end{array}$ & Ti-added IF steel & 0.003C-0.15Mn-0.025Si-0.065Ti & $1-3$ & $\begin{array}{l}\text { Final rolling } \\
\sim 0.55 \times 5\end{array}$ & Below A ${ }_{\mathrm{r} 1}^{*}$ & WQ \\
\hline $\begin{array}{l}\text { DRX }^{*} \text { of ferrite } \\
\text { during warm } \\
\text { deformation }\end{array}$ & $\begin{array}{l}\text { Ultra-low carbon } \\
\text { steel }\end{array}$ & $0.0016 \mathrm{C}-0.1 \mathrm{Si}-0.03 \mathrm{Mn}$ & - & 4.0 & $\begin{array}{c}723 \text { - } 823 \\
\text { (lower than } \\
\left.\mathrm{A}^{*}{ }_{\mathrm{c} 1}\right) 823\end{array}$ & WQ \\
\hline $\begin{array}{l}\text { Pronounced } \\
\text { recovery of ferrite } \\
\text { during warm } \\
\text { deformation } \\
\text { and annealing }\end{array}$ & $\begin{array}{l}\text { Plain medium } \\
\text { carbon steel }\end{array}$ & $0.22 \mathrm{C}-0.21 \mathrm{Si}-0.74 \mathrm{Mn}$ & 1.3 & $\begin{array}{l}1.6 \text { at strain } \\
\text { rate of } 0.01 \mathrm{~s}^{-1}\end{array}$ & 823 & $\begin{array}{l}823 \mathrm{~K} \times \\
120 \mathrm{~min}\end{array}$ \\
\hline $\begin{array}{l}\text { Cold deformation } \\
\text { and annealing of } \\
\text { martensitic steel }\end{array}$ & Martensitic steel & $0.13 \mathrm{C}-0.37 \mathrm{Mn}-0.01 \mathrm{Si}$ & 0.18 & 0.8 & 293 & $\begin{array}{l}773 \mathrm{~K} \times \\
30 \mathrm{~min}\end{array}$ \\
\hline
\end{tabular}

Abbreviation: $\mathrm{DRX}^{*}$, dynamic recrystallization; $\mathrm{A}^{*} \mathrm{r} 1$, austenite to pearlite transformation temperature during cooling; $\mathrm{A}_{\mathrm{C} 1}^{*}$, pearlite to austenite transformation temperature during heating; ECAP, equal channel angular pressing; ARB, accumulative roll bonding; HPT, high pressure torsion; AC, air cooling; WC, water cooling; WQ, water quench.

with high toughness and formability. High toughness is important to reduce stress-induced cracking, while formability is important from the view point of pipe-bowing. Thus, high strength in conjunction with high toughness and formability are important requirements of the pipeline industry for transporting natural gas and crude oil over a long distance at high pressures [231]-[233]. Other characteristics that are required include resistance to hydrogen induced blister cracking in sour service environment [234] [235], stress corrosion cracking resistance, especially in $\mathrm{H}_{2} \mathrm{~S}$ environment [236], and fatigue resistance [237] [238]. In the aforementioned regard, it is important that the microstructure of the pipeline steel provides a combination of aforementioned properties.

Finally, it should be noted that considerable attention is now focused on the development of ultrafine-grained materials for use in specific applications [239]. For example, magnesium alloys are under consideration for use in hydrogen storage and ultrafine-grained titanium is an excellent candidate material for use in dental and surgical implants [240]. Descriptions of these developments are beyond the scope of this review, but nevertheless these topics provide exciting challenges for new and meaningful research that will have scientific rigor and yet provide valuable information for the future use of these materials in technological applications.

\section{Contribution of Steel Technology Department}

Steel Technology Department, CMRDI staff makes a great effort for studying the strengthening of steel through different methods such as microalloying [241]-[248], strengthening by solid solution elements [249] [250] for 
example N, C and Mn, interrupted accelerated cooling [251], cold drawing [252] [253], well design rolling schedule [254], reheating and finishing temperature [255] [256], and heat treatment [257].

Steel Technology Department staff published a lot of publications in role of microalloying in carbon manganese steel to produce high strength low alloy steels. In previous work [237]-[244], they studied the contribution of $\mathrm{V}, \mathrm{V}+\mathrm{N}, \mathrm{V}+\mathrm{Ti}$ combined with extra $\mathrm{C}$ and/or Mn in strengthening of such steel. The results of these works demonstrated that, the strengthening potential of vanadium seems to be due to precipitation strengthening rather than grain refinement effect. Both carbon and manganese in combination with vanadium showed a significant effect on increasing the precipitation strengthening. By study effect of vanadium as alloying element combined with nitrogen [246] [249] on microstructure and strength of low carbon steels with different manganese contents the results show that, vanadium microalloying effectively increased the strength of steels through solely precipitation strengthening or both precipitation strengthening and grain refining effect. The effectiveness of vanadium was greatly enhanced by increasing the nitrogen content. The grain refinement of vanadium-nitrogen microalloying seems to be due to inhibition of austenite grain growth as a result of precipitation of vanadium nitride in austenite during forging. Precipitation strengthening of these steels is achieved by precipitation of vanadium carbide and nitride in ferrite or bainite. Nitrogen enhanced the precipitation strengthening of vanadium microalloyed steels which could be attributed to the finer vanadium nitride dispersion precipitates compared with vanadium carbide. Up to $70 \%$ of the total nitrogen content of steel precipitates as vanadium nitride which could be achieved with $\mathrm{V} / \mathrm{N}$ ratio of about 6 - 7. Microalloying of low carbon-manganese steels $(0.1 \% \mathrm{C}$ and $1.8 \% \mathrm{Mn})$ with $0.15 \%$ vanadium and $0.025 \%$ nitrogen was found to be effective in attaining high levels of yield and ultimate tensile strengths of 835 and $940 \mathrm{MPa}$, respectively in the forging condition. On other work [252] [253], Ultra-high strength high-carbon wire rod steels have been produced using vanadium-microalloying technique instead of the conventional expensive and environment polluting lead patenting treatment. The experimental results show that, the strength increment attained in the hot rolled steels due to vanadium additions is maintained in the cold drawn wire. By using this technique, high tensile strength levels of 1550 - 1600 MPa were attained either by cold drawing of $0.17 \% \mathrm{~V}$ microalloyed high-carbon steel to $45 \%$ - $47 \%$ reduction or by cold drawing of $0.20 \% \mathrm{~V}$ microalloyed high-carbon steel to $25 \%-30 \%$ reduction. They concluded that, a combination of vanadium microalloying and accelerated cooling [251], resulted in additional strength increment due to refining of microstructure and increasing the precipitation strengthening component. In spite of the decrease in the amount of vanadium precipitates due to the increase in cooling rate, it is suggested that an increase in precipitation strengthening due to refining of these precipitates by accelerated cooling more than offsets the loss of precipitation strengthening due to decreasing the precipitates fraction. It was concluded that microalloying addition increase the strength of steel through different methods such as grain refinement, solid solution strengthening and precipitation strengthening [241]-[243]. Also the previous work demonstrate that microalloying addition improve both strength and toughness of steels [241] [258]-[260]. Investigation done by steel technology staff found that [261], in hot rolled V-and Ti-microalloyed steels, transmission electron microscopy revealed several types of non-metallic inclusions and precipitates, the most effective on grain refinement and strength increment are the very fine precipitates.

\section{Future Prospects of Ultrafine Grained Steels}

The following suggestions can be made for future work:

1) To complete the study the effect of mircro-alloying elements on refining the microstructure;

2) To study the effect of rare earth metal on refining the microstructure of special steel e.g. high speed tool steel, maraging steel and so on;

3) To use mechanical vibration and ultrasound for production of high speed tool steel with ultrafine and well distributed carbides;

4) To use mechanical vibration and ultrasound for production ultra-fine C-Mn steel with and without microalloying additions;

5) To use electroslag refining technology for production ultrafine steel single phase with micro-alloying additions;

6) To use electroslag refining technology equipped with electrical magnetic field for production ultrafine single phase steel;

7) To use severe plastic deformation methods for production ultrafine maraging steels;

8) To use severe plastic deformation combined with thermomechanical treatment for production high nitrogen steel especially meta-stable austenitic steels. 


\section{Conclusion}

The review reveals that the grain refinement by different strategies of ultrafine grained structure can lead to a unique combination of strength and ductility in different kinds of advanced steels. Such superior mechanical properties are highly desirable in the development of advanced steel for the next generation. However, the achievement of these properties is associated with further treatment to create specific microstructure that is responsible to improve the ductility of the advanced steel. Depending on the process boundary conditions, either a change of chemical composition, i.e. microalloying, or change of process, i.e. from conventional heat treatment to thermomechanical treatment, severe plastic deformation or a combination of any two processes can be selected. Thus, higher strength with equivalent or higher ductility can be obtained.

\section{Acknowledgements}

May ALLAH shower his mercy and forgiveness on the souls of my teachers and supervisors: My father Ahmed Mohamed Halfa, Prof. Dr. Kamal Mohamed Abd-Rabu El-Fawakhry, Mahmoud Farag El-Demerdash. I am indebted to Prof. Dr. Mamdouh Mahmoud Eissa, for his supervision and continuous guidance through all my work. I would like to express my thanks and gratitude to Prof. Dr. Taha Mohamed Taha Mattar, Head of Metal division, CMRDI, and Prof. Hoda Salama El-Faramawy, Head of Steel Technology Department. I gratefully acknowledge the pleasant atmosphere and support from all of my colleagues at the metal Division, Steel Technology Department of CMRDI.

\section{References}

[1] Misra, R., Nathani, H., Hartmann, J. and Siciliano, F. (2005) Microstructural Evolution in a New 770 MPa Hot Rolled Nb-Ti Microalloyed Steel. Materials Science and Engineering A, 394, 339-352. http://dx.doi.org/10.1016/j.msea.2004.11.041

[2] Zajac, S., Komenda, J., Morris, P., Matera, S. and Penalba Diaz, F. (2003) Quantitative Structure-Property Relationships for Complex Bainitic Microstructure. RFCS Final Report, European Commission, Luxembourg.

[3] Charleux, M., Poole,WJ., Militzer, M. and Deschamps, A.(2001) Precipitation Behavior and Its Effect on Strengthening of an HSLA-Nb/Ti Steel. Metallurgical and Materials Transactions A, 32, 1635-1647. http://dx.doi.org/10.1007/s11661-001-0142-6

[4] Foreman, J.E. and Makin, A.J. (1967) Dislocation Movement through Random Arrays of Obstacles. Canadian Journal of Physics, 45, 7-12. http://dx.doi.org/10.1139/p67-044

[5] Thermo-Calc, Ver, P. and Thermo-Calc, A.B. (2002) article. Royal Institute of Technology, Stockholm.

[6] Gladman, T. (1997) The Physical Metallurgy of Microalloyed Steels. The Institute of Materials, London, United Kingdom.

[7] Syarif, J., Nakashima, K., Tsuchiyama, T. and Setsuo, T. (2007) Effect of Solute Copper on Yield Strength in Dislocation-Strengthened Steels. Iron and Steel Institute of Japan (ISIJ) International, 47, 340-345. http://dx.doi.org/10.2355/isijinternational.47.340

[8] Siwecki, T., Blaz, L. and Petterson, S. (2000) Improving Properties in V-Nb Microalloyed Steels Modified with Mo. HSLA Steels 2000, Xi'an, China, 30 October-2 November, 2000, Beijing, 504-510.

[9] Misra, R., Weatherley, G., Hartmann, J. and Boucek, A. (2001) Ultrahigh Strength Hot Rolled Microalloyed Steels: Microstructural Aspects of Development. Materials Science Technology, 17, 1119-1129. http://dx.doi.org/10.1179/026708301101511040

[10] Kelly, A. and Nicholson, R.B. (1971) Strengthening Methods in Crystals. Applied Science Publishers Ltd., London, United Kingdom.

[11] Zajac, S., Lagneborg, R. and Siwecki, T. (1995) The Role of Nitrogen in Microalloyed Steels. Proceedings of the International Conference on “Microalloying 95”, Pittsburgh, 11-14 June 1995, 321-340.

[12] Lagneborg, R., Siwecki, T., Zajac, S. and Hutchinson, B. (1999) The Role of Vanadium in Microalloyed Steel. Scandinavian Journal of Metallurgy, 28, 186-241.

[13] Baker, R.G. and Nutting, J. (1969) The Tempering of Cr-Mo-V-W and Mo-V Steel Precipitation Processes in Steels. ISI Report, 64, 1-12.

[14] Kunitake, T. (1967) On the Yield Strength of Quenched and Tempered Structures of Low-Carbon, Low Alloy Steels. Transaction of the Iron and Steel Institute of Japan, 7, 254-262. 
[15] Bhadeshi, H. (2001) Bainite in Steels. IOM Communication Ltd., London.

[16] Takahashi, M. and Bhadeshia, H. (1990) Model for Transition from Upper to Lower Bainite. Materials Science and Technology, 6, 592-603. http://dx.doi.org/10.1179/mst.1990.6.7.592

[17] Wang, J. and Zwaag, S. (1990) Stabilization Mechanisms of Retained Austenite in Transformation-Induced Plasticity Steel. Metallurgical and Materials Transactions A, 21, 1527-1539.

[18] Hulka, K. and Heisterkamp, F. (1993) Low Carbon Steels the Key to Economic Constructions. International Symposium on Low-Carbon Steels for the 90’s, Pittsburgh, 18-21 October 1993, 211-218.

[19] Morrison, W. (2000) Past and Future Development of HSLA Steels. HSLA Steels 2000, Xi'an, China, Beijing, 30 October-2 November 2000, 11-19.

[20] ssKrauss, G. and Thompson, S. (1995) Ferritic Microstructures in Continuously Cooled Low- and Ultralow-Carbon Steels. Iron and Steel Institute of Japan (ISIJ) International, 35, 937-945. http://dx.doi.org/10.2355/isijinternational.35.937

[21] Morrison, W. (1996) The Effect of Grain Size on the Stress-strain Relationship in Low Carbon Steel. Transactions of American Society for Metals, 59, 824-846.

[22] Shin, D., Park, J., Chang, S., Lee, Y. and Park, K. (2002) Ultrafine Grained Low Carbon Steels Fabricated by Equal Channel Angular Pressing. Iron and Steel Institute of Japan (ISIJ) International, 42, 1490-1496. http://dx.doi.org/10.2355/isijinternational.42.1490

[23] Fukuda, Y., Oh-Ishi, K., Horita, Z. and Langdon, T. (2002) Processing of a Low-Carbon Steel by Equal-Channel Angular Pressing. Acta Materialia, 50, 1359-1368. http://dx.doi.org/10.1016/S1359-6454(01)00441-4

[24] Son,Y., Lee, Y., Park, K., Lee, C. and Shin, D. (2005) Ultrafine Grained Ferrite-Martensite Dual Phase Steels Fabricated via Equal Channel Angular Pressing: Micro-Structure and Tensile Properties. Acta Materialia, 53, 3125-3134. http://dx.doi.org/10.1016/j.actamat.2005.02.015

[25] Park, K., Han, S., Ahn, B., Shin, D., Lee, Y. and Um, K. (2004) Ultrafine Grained Dual Phase Steel Fabricated by Equal Channel Angular Pressing and Subsequent Intercritical Annealing. Scripta Materialia, 51, 909-913. http://dx.doi.org/10.1016/j.scriptamat.2004.06.017

[26] Kim, W., Kim, J., Choo, W., Hong, S. and Lee, J. (2001) Large Strain Hardening in Ti-V Carbon Steel Processed by Equal Channel Angular Pressing. Materials Letters, 51, 177-182. http://dx.doi.org/10.1016/S0167-577X(01)00320-2

[27] Shin, D., Seo, C., Kim, J., Park, K. and Choo, W. (2000) Microstructures and Mechanical Properties of Equal-Channel Angular Pressed Low Carbon Steel. Scripta Materialia, 42, 695-699.

http://dx.doi.org/10.1016/S1359-6462(99)00422-4

[28] Liu, M., Shi, B., Wang, C., Ji, S., Cai, X. and Song, H. (2003) Normal Hall-Petch Behavior of Mild Steel with Submicron Grains. Materials Letters, 57, 2798-2802. http://dx.doi.org/10.1016/S0167-577X(02)01377-0

[29] Song, R. (2005) Microstructure and Mechanical Properties of Ultrafine Grained C-Mn Steels. Shaker Verlag GmbH, Aachen.

[30] Brozzo, P., Buzzichelli, A., Mascanzoni, A. and Mirabile, G. (1977) Microstructure and Cleavage Resistance of Low Carbon Bainitic Steels. Metal Science, 11, 123-130. http://dx.doi.org/10.1179/msc.1977.11.4.123

[31] Tomita, Y. and Okabayashi, K. (1986) Effect of Microstructure on Strength and Toughness of Heat-Treated Low Alloy Structural Steels. Metallurgical Transactions A, 17, 1203-1209. http://dx.doi.org/10.1007/BF02665319

[32] Lazarova, R., Petrov, R.H., Gaydarova, V., Davidkov, A., Alexeev, A. and Manchev, M. (2011) Microstructure and Mechanical Properties of P265GH Cast Steel after Modification with TiCN Particles. Materials \& Design, 32, 27342741. http://dx.doi.org/10.1016/j.matdes.2011.01.024

[33] Rasouli, D., Khameneh Asl, S., Akbarzadeh, A. and Daneshi, G. (2009) Optimization of Mechanical Properties of a Micro Alloyed Steel. Materials \& Design, 30, 2167-2172. http://dx.doi.org/10.1016/j.matdes.2008.08.024

[34] Zhao, M., Yang, K. and Shan, Y. (2003) Comparison on Strength and Toughness Behaviors of Microalloyed Pipeline Steels with Acicular Ferrite and Ultrafine Ferrite. Material Letters, 57, 1496-1500. http://dx.doi.org/10.1016/S0167-577X(02)01013-3

[35] Zhao, M., Shan, Y. and Yang, K. (2004) Effect of Aging Treatment on Mechanical Property and $\mathrm{H}_{2} \mathrm{~S}$ Resistant Behavior of Acicular Ferrite Pipeline Steels. Acta Metallurgica Sinica, 40, 948-954. http://www.ams.org.cn/CN/Y2004/V40/I9/948

[36] Tóth, L., Rossmanith , H.P. and Siewert, T.A. (2002) Historical Background and Development of the Charpy Test. European Structural Integrity Society: From Charpy To Present Impact Testing, 30, 3-19.

http://dx.doi.org/10.1016/S1566-1369(02)80002-4 
[37] Zhao, M., Li, J., Zeng, T., Hunag, X., Zhao, Y. and Atrens, A. (2011) The Ductile to Brittle Transition for C-Mn Steel with an Ultrafine Grain Ferrite/Cementite Microstructure. Materials Science and Engineering A, 528, 7228-7237. http://dx.doi.org/10.1016/j.msea.2011.06.005

[38] Hanamura, T., Yin, F.X. and Nagai, K. (2004) Ductile-Brittle Transition Temperature of Ultrafine Ferrite/Cementite Microstructure in a Low Carbon Steel Controlled by Effective Grain Size. Iron and Steel Institute of Japan (ISIJ) International, 44, 610-617. http://dx.doi.org/10.2355/isijinternational.44.610

[39] Song, R., Ponge, D., Raabe, D., Speer, J. and Matlock, D. (2006) Overview of Processing, Microstructure and Mechanical Properties of Ultrafine Grained bcc Steels. Materials Science and Engineering A, 441, 1-17. http://dx.doi.org/10.1016/j.msea.2006.08.095

[40] Song, R., Ponge, D. and Raabe, D. (2005) Mechanical Properties of an Ultrafine Grained C-Mn Steel Processed by Warm Deformation and Annealing. Acta Materialia, 53, 4881-4892. http://dx.doi.org/10.1016/j.actamat.2005.07.009

[41] Kimura, Y., Inoue, T., Yin, F. and Tsuzaki. K. (2008) Inverse Temperature Dependence of Toughness in an Ultrafine Grain-Structure Steel. Science, 320, 1057-1060. http://dx.doi.org/10.1126/science.1156084

[42] National Highway Traffic Safety Administration (2007) DOT HS 810 863. www.nhtsa.gov .

[43] Euro NCAP (1998) Development of the European New Car Assessment. http://www.euroncap.com/files/Development-of-Euro-NCAP-1998---0-7498ffa2-36b6-4328-8b6e-f44fe5d35563.pdf

[44] Kim, S., Kim, G. and Chin, K. (2008) Development of High Manganese TWIP Steel with 980 MPa Tensile Strength. Proceeding of the International. Conference on New Developments in Advanced High-Strength Sheet Steels, AIST. Orlando, 15-18 June 2008, 249-256.

[45] Boron Extrication (2009) XC60 Body Structure. http://boronextrication.com/2009/08/2009-xc60-body-structure/.

[46] Shim, J., Cho, H., Chung, S., Shim, J. and Lee, D. (1999) Nucleation of Intragranular Ferrite at $\mathrm{Ti}_{2} \mathrm{O}_{3}$ Particle in Low Carbon Steel. Acta Materialia, 47, 2751-2760. http://dx.doi.org/10.1016/S1359-6454(99)00114-7

[47] Calcagnotto, M., Adachi,Y. Ronge, D. and Raabe, D. (2011) Deformation and Fracture Mechanisms in Fine- and Ultrafine-Grained Ferrite/Martensite Dual-Phase Steels and the Effect of Aging. Acta Materialia, 59, 658-670. http://dx.doi.org/10.1016/j.actamat.2010.10.002

[48] Song, R., Ponge, D., Raabe, D. Speer, J. and Matlock, D. (2006) Overview of Processing, Microstructure and Mechanical Properties of Ultrafine Grained BCC Steels. Materials Science and Engineering A, 441, 1-17. http://dx.doi.org/10.1016/j.msea.2006.08.095

[49] Song, R., Ponge, D. and Raabe, D. (2005) Mechanical Properties of an Ultrafine Grained C-Mn Steel Processed by Warm Deformation and Annealing. Acta Materialia, 53, 4881-4892. http://dx.doi.org/10.1016/j.actamat.2005.07.009

[50] Funakawa, Y., Shiozaki, T., Tomita, K., Yamamoto, T. and Maeda, E. (2004) Development of High Strength HotRolled Sheet Steel Consisting of Ferrite and Nanometer-Sized Carbides. Iron and Steel Institute of Japan (ISIJ) International, 44, 1945-1951. http://dx.doi.org/10.2355/isijinternational.44.1945

[51] Fernández, J., Illescas, S. and Guilemany, J. (2007) Effect of Microalloying Elements on the Austenitic Grain Growth in a Low Carbon HSLA steel. Materials Letters, 61, 2389-2392. http://dx.doi.org/10.1016/j.matlet.2006.09.021

[52] Medina, S. and Hernanden, C. (1995) Static Recrystallization of Austenite and Strain Induced Precipitation Kinetics in Titanium Microalloyed Steels. Acta Metallurgica, 42, 3945-3951. http://dx.doi.org/10.1016/0956-7151(94)90172-4

[53] Elwazri, A., Wanjara, P. and Yue, S. (2003) Dynamic Recrystallization of Austenite in Microalloyed High Carbon Steels. Materials Science and Engineering A, 339, 209-215. http://dx.doi.org/10.1016/S0921-5093(02)00164-8

[54] Fernández, A., Uranga, P., López, B. and Rodriguez-Ibabe, J. (2003) Dynamic Recrystallization Behavior Covering a Wide Austenite Grain Size Range in Nb and Nb-Ti Microalloyed Steels. Materials Science and Engineering A, 361, 367-376. http://dx.doi.org/10.1016/S0921-5093(03)00562-8

[55] Liang. X., Sun, X. and Liu. Q. (2006) Study of Dynamic Recrystallization of Low Carbon Steel in Thin Slab Continuous Rolling Process. Acta Metallurgica Sinica, 19, 265-270. http://dx.doi.org/10.1016/S1006-7191(06)60054-9

[56] Pickering, F. (1990) Some Beneficial Effects of Nitrogen in Steel. In: Korchynsky, M., Gorczyca, S. and Blicharski, M., Eds., Proceedings of International Symposium Microalloyed Vanadium Steels, Cracow, 24-26 April 1990, 33-62.

[57] Korczynsky, M. (1988) Microalloying and Thermo-Mechanical Treatment. In: DeArdo, A.J., Ed., Proceedings of International Symposium Processing, Microstructure and Properties of HSLA Steels, Pittsburgh, 1-3 September 1988, 169-201.

[58] Pickering, F. (1985) Vanadium as a Hardenability and Temperability Additive in Quenched and Tempered Steels. In: Gray, J.M., et al., Eds., Proceedings of an International Conference on HSLA Steels 85, Beijing, 4-8 November 1985, 305-324. 
[59] Renata, S., Henryk, A. and Anna, A. (2006) Effect of Nitrogen and Vanadium on Austenite Grain Growth Kinetics of a Low Alloy Steel. Materials Characterization, 56, 340-347. http://dx.doi.org/10.1016/j.matchar.2005.09.012

[60] Melloy, G., Slimmon, P. and Podgursky, P. (1973) Optimization the Boron Effect. Metallurgical and Materials Transactions A, 4, 2279-2289. http://dx.doi.org/10.1007/BF02669367

[61] Matlock, D., Krauss, G. and Speer, J. (2005) New Microalloyed Steel Applications for the Automotive Sector. Materials Science Forum, 500-501, 87-96. http://dx.doi.org/10.4028/www.scientific.net/MSF.500-501.87

[62] Klinkenberg, C. and Jansto, J. (2006) International Conference on New Development in Ferrous and Forged Products. TMS, Winter Park, CO., Colorado.

[63] Ebrahimi, G., Javdani, M. and Arabshahi, H. (2010) Effect of Thermo-Mechanical Parameters on Microstructure and Mechanical Properties of Microalloyed Steels. Brazilian Journal of Physics, 40, 454-458. http://dx.doi.org/10.1590/S0103-97332010000400017

[64] Ghosh, P., Ray, R.K., Ghosh, C. and Bhattacharjee, D. (2008) Comparative Study of Precipitation Behavior and Texture Formation in Continuously Annealed $\mathrm{Ti}$ and $\mathrm{Ti}+\mathrm{Nb}$ Added Interstitial-Free High-Strength Steels. Scripta Materialia, 58, 939-942. http://dx.doi.org/10.1016/j.scriptamat.2008.01.056

[65] Hong, S., Jun, H., Kang, K. and Park, C. (2003) Evolution of Precipitates in the Nb-Ti-V Microalloyed HSLA Steels during Reheating. Scripta Materialia, 48, 1201-1206. http://dx.doi.org/10.1016/S1359-6462(02)00567-5

[66] Ghosh, P., Ghosh, C., Ray, R. and Bhattacharjee, D. (2008) Precipitation Behavior and Texture Formation at Different Stages of Processing in an Interstitial Free High Strength Steel. Scripta Materialia, 59, 276-268. http://dx.doi.org/10.1016/j.scriptamat.2008.03.044

[67] Adamczyk, J., Kalinowska-Ozgowicz, E., Ozgowicz, W. and Wusatowski, R. (1995) Interaction of Carbonitrides V(C, N) Undissolved in Austenite on the Structure and Mechanical Properties of Microalloyed V-N Steels. Journal of Materials Processing Technology, 53, 23-32. http://dx.doi.org/10.1016/0924-0136(95)01958-H

[68] Matsuo, S., Ando, T. and Grant, N. (2000) Grain Refinement and Stabilization in Spray-Formed AISI 1020 Steel. Materials Science and Engineering A, 288, 34-41. http://dx.doi.org/10.1016/S0921-5093(00)00881-9

[69] Tomita, Y. and Okabayashi, K. (1986) Effect of Microstructure on Strength and Toughness of Heat-Treated Low Alloy Structural Steels, Metallurgical and Materials Transactions A, 17, 1203-1209.

[70] Lazarova, R., Petrov, R.H., Gaydarova, V., Davidkov, A., Alexeev, A., Manchev, M., and Manolov, M. (2011) Microstructure and Mechanical Properties of P265GH Cast Steel after Modification with TiCN Particles. Materials \& Design, 32, 2734-2741. http://dx.doi.org/10.1016/j.matdes.2011.01.024

[71] Rasouli, D., Khameneh Asl, S.H., Akbarzadeh, A. and Daneshi, G.H. (2009) Optimization of Mechanical Properties of a Microalloyed Steel. Materials \& Design, 30, 2167-2172. http://dx.doi.org/10.1016/j.matdes.2008.08.024

[72] Andrade, H., Akben, M. and Jonas, J. (1983) Effect of Molybdenum, Niobium, and Vanadium on Static Recovery and Recrystallization and on Solute Strengthening in Microalloyed Steels. Metallurgical and Materials Transactions A, 14, 1967-1977. http://dx.doi.org/10.1007/BF02662364

[73] Craven, A., He, K., Garvie, L. and Baker, T. (2000) Complex Heterogeneous Precipitation in Titanium-Niobium Microalloyed Al-Killed HSLA Steels-I. (Ti, Nb) (C, N) Particles. Acta Materialia, 48, 3857-3868. http://dx.doi.org/10.1016/S1359-6454(00)00194-4

[74] Charleux, M., Poole, W., Militzer, M. and Deschamps, A. (2001) Precipitation Behavior and Its Effect on Strengthening of an HSLA-Nb/Ti Steel. Metallurgical and Materials Transactions A, 32, 1635-1647. http://dx.doi.org/10.1007/s11661-001-0142-6

[75] Xu, G., Gan, X., Ma, G., Luo, F. and Zou, H. (2010) The Development of Ti-Alloyed High Strength Microalloy Steel. Materials \& Design, 31, 2891-2896. http://dx.doi.org/10.1016/j.matdes.2009.12.032

[76] Jia, Z., Misra,R., O’Malley, R. and Jansto, SJ. (2011) Fine-Scale Precipitation and Mechanical Properties of Thin Slab Processed Titanium-Niobium Bearing High Strength Steels. Materials Science and Engineering A, 528, 7077-7083. http://dx.doi.org/10.1016/j.msea.2011.05.073

[77] Farahat, A. and El-Bitar, T. (2010) Effect of Nb, Ti and Cold Deformation on Microstructure and Mechanical Properties of Austenitic Stainless Steels. Materials Science and Engineering A, 527, 3662-3669. http://dx.doi.org/10.1016/j.msea.2010.02.064

[78] Soto, R., Saikaly, W., Bano, X., Issartel, C., Rigaut, G. and Charai, A. (1999) Statistical and Theoretical Analysis of Precipitates in Dual-Phase Steels Microalloyed with Titanium and Their Effect on Mechanical Properties. Acta Materialia, 47, 3475-3481. http://dx.doi.org/10.1016/S1359-6454(99)00190-1

[79] Regone, W., Jorge, A. and Balancin, O. (2003) Evidence of Strain-Induced Precipitation of $\mathrm{Ti}_{4} \mathrm{C}_{2} \mathrm{~S}_{2}$ during Hot Deformation of Ti-Only Stabilized IF Steel. Scripta Materialia, 48, 773-778. http://dx.doi.org/10.1016/S1359-6462(02)00532-8 
[80] Zener, C. and Smith, C. (1948) Grains, Phases and Interfaces: Interpretation of Microstructures. Transaction metallurgy Society of AIME, 175, 15-51.

[81] He, K. and Baker, T. (1993) The Effects of Small Ti Additions on the Mechanical Properties and the Microstructures of Controlled Niobium-Bearing HSLA Plate. Materials Science and Engineering A, 169, 53-65. http://dx.doi.org/10.1016/0921-5093(93)90598-9

[82] Moon, J., Kim, S., Lee, J. and Lee, C. (2007) Limiting Austenite Grain Size of TiN-Containing Steel Considering the Critical Particle Size. Scripta Materialia, 56, 1083-1086. http://dx.doi.org/10.1016/j.scriptamat.2007.02.025

[83] Wu, K., Zhang, L., He, X., Shang, C., Yang, S. and Wang, X. (2006) Micro Mechanical Properties and Stability of Acicular Ferrite in a Low Carbon Microalloyed Steel. Acta Metallurgica Sinica, 42, 19-22.

[84] Poths, R., Higginson, R. and Palmiere, E. (2001) Complex Precipitation Behaviour in a Microalloyed Plate Steel. Scripta Materialia, 44, 147-151. http://dx.doi.org/10.1016/S1359-6462(00)00617-5

[85] Suikkanen, P., Kömi, J. and Karjalainen, L. (2005) Processing Low and Ultra-Low Carbon Bainitic Steels with Excellent Property Combinations. Proceedings of the International Conference on Microalloying for New Steel Processes and Applications. Donostia-San Sebastian, 7-9 September, 2005, 535-542.

[86] Asahi, H., Hara, T. and Sugiyama, M. (2004) Metallurgical Design of Ultra-High Strength Steels for Gas Pipelines. International Journal of Offshore and Polar Engineering, 14, 11-17.

[87] Wang, M. and He, X. (2002) Effect of Boron Addition on Structure and Properties of. Low Carbon Bainitic Steels. Iron and Steel Institute of Japan (ISIJ) International, 42, S38-S46.

[88] Misra, R., Tenneti, K., Weatherly, G. and Tither, G. (2003) Microstructure and Texture of Hot-Rolled Cb-Ti and V-Cb Microalloyed Steels with Differences in Formability and Toughness. Metallurgical and Materials Transactions A, 34, 2341-2351. http://dx.doi.org/10.1007/s11661-003-0297-4

[89] Babbit, M., Valette, P. and Riguat, G. (1991) Development of a New Bainitic Steel With Very High Yield Strength at SOLLAC. In: DeArdo, A.J. (Ed.), Processing Microstructure and Properties of Microalloyed and Other Modern High Strength Low Alloy Steels. Iron and Steel Society, 3-6 June 1991, Pittsburgh, 281-288.

[90] Ochi, T., Takahashi, T. and Takada, H. (1988) Improvement of the Toughness of Hot Forged Products through Intragranular Ferrite Formation. Proceedings of 30th Mecahnical Working and Steel Proceing Conference, 23-27 October 1988, Dearborn, 65-72.

[91] Wang, K., Wang, L. and Cui, W. (2006) Effect of V and V-N Microalloying on Deformation-Induced Ferrite Transformation in Low Carbon Steels. Journal of Materials Science \& Technology, 22, 159-163. (in Chinese). http://www.jmst.org/EN/Y2006/V22/I02/159

[92] Zhao, S., Wang, Q., Pant, U., Zhang, C., Su, H., Yang, C., Yan, Z. and Zhang, Y. (2007) Fundamental Evaluations on Microstructure and Mechanical Properties of On-Line Normalizing Processed V-N Microalloyed N80 Class Oil Casings. Journal of Iron and Steel Research International, 14, 227-233. http://dx.doi.org/10.1016/S1006-706X(08)60084-9

[93] Ollilainen, V., Kasprzak, W. and Holappa, L. (2003) The Effect of Silicon, Vanadium and Nitrogen on the Microstructure and Hardness of Air Cooled Medium Carbon Low Alloy Steels. Journal of Materials Processing Technology, 134, 405-412. http://dx.doi.org/10.1016/S0924-0136(02)01131-7

[94] Adamczyk, J. (2006) Development of the Microalloyed Constructional Steels. Journal of Achievements in Materials and Manufacturing Engineering, 14, 9-20

[95] Wei, H., Liu, G., Zhao, H. and Zhang, M. (2014) Effect of Carbon Content on Hot Deformation Behaviors of Vanadium Microalloyed Steels. Materials Science and Engineering A, 596, 112-120. http://dx.doi.org/10.1016/j.msea.2013.12.063

[96] Sellars, C. and Whiteman, J. (1979) Recrystallization and Grain Growth in Hot Rolling. Metal Science, 13, $187-194$. http://dx.doi.org/10.1179/msc.1979.13.3-4.187

[97] Grange, RG. (1971) The Rapid Heat Treatment of Steel. Metallurgical Transactions, 2, 65-78. http://dx.doi.org/10.1007/BF02662639

[98] Kolesnik, B.P. (1964) Rapid Heat Treatment of Mn-Si Pipe Steel. Metal Science and Heat Treatment, 6, 100-104. http://dx.doi.org/10.1007/BF00655386

[99] Yao, J., Du, X. and Liu, X. (2009) Isothermal Growth Kinetics of Ultra-fine Austenite Grains in a Nb-V-Ti Microalloyed Steel. Journal of Materials Science \& Technology, 25, 615-618.

[100] Tokizane, M., Ameyama, K. and Takao, K. (1988) Ultra-Fine Austenite Grain Steel Produced by Thermomechanical Processing. Scripta Metallurgica, 22, 697-701. http://dx.doi.org/10.1016/S0036-9748(88)80185-6

[101] Furuhara, T., Kikumoto, K., Saito, H., Sekine, T., Ogawa, T., Morito, S. and Maki, T. (2008) Phase Transformation from Fine-Grained Austenite. Iron and Steel Institute of Japan (ISIJ) International, 48, 1038-1045. 
[102] Grange, R. (1966) Strengthening by Austenite Grain Refinement. Transaction of the American Society Metals, 1, 2629.

[103] Anashkin, A., Belov, A., Sokolov, A., Bogatov, A. and Smirnov, S. (1987) Heat Cycling of Carbon Steel Wire. Metal Science and Heat Treatment, 30, 93-97.

[104] Fedyukin, V. (1984) Thermal Cycling Treatment of Steels and Cast Irons. Leningrad State University, Leningrad.

[105] Koppehaal, T. (1972) A Thermal Processing for TRIP Steel. Metallurgical and Materials Transactions A, 3, 15491554. http://dx.doi.org/10.1007/BF02643045

[106] Konopleva, E., Éntin, R., Bayazitov, V. and Okoemov, Y. (1988) Thermal Cycling Treatment of Low-Carbon Steel with Hardening from Intercritical Temperature Range. Metal Science and Heat Treatment, 8, 617-620. http://dx.doi.org/10.1007/BF00778269

[107] Bhadeshia, H. (1992) Bainite in Steel. The Institute of Materials 1 Carlton House Terrace, London.

[108] Wada, T. and Eldis, G. (1982) Transformation Characteristic of 2.25Cr-1Mo Steel, Application of 2.25Cr-1Mo Steel for Thick-Wall Pressure Vessels. ASTM STP 755, American Society for Testing Materials, Philadelphia, 343-362.

[109] Kimmins, S. and Gooch, D. (1983) Austenite Memory Effect in 1Cr-1Mo-0.75 V (Ti, B) Steel. Materials Science and Technology, 17, 519-532.

[110] Wang, Q., Zhang, C., Xu, W., Zhao, J., Zhao, S. and Yanz, S. (2007) Refinement of Steel Austenite Grain Under an Extremely High Degree of Superheating. Journal of Iron and Steel Research International, 14, 161-166. http://dx.doi.org/10.1016/S1006-706X(08)60072-2

[111] Howe, A. (2009) Industry Perspective on Ultrafine Grained Steels. Journal of Materials Science \& Technology, 24, 815-819. http://dx.doi.org/10.1179/174328409X441247

[112] Niikura, N., Fujioka, M., Adachi, A., Matsukura, A., Yokota, T. and Shirota, Y. (2001) New Concepts for Ultrarefinement of Grain Size in Super Metal Project. JMPT 2001, 117, 141-146.

[113] Beladi, H., Kelly, G., Shokouhi, A. and Hodgson, P. (2004) The Evolution of Ultrafine Ferrite Formation through Dynamic Strain-Induced Transformation. Materials Science and Engineering A, 371, 343-352. http://dx.doi.org/10.1016/j.msea.2003.12.024

[114] Abdollah-Zadeh, A. and Eghbali, B (2007) Mechanism of Ferrite Grain Refinement during Warm Deformation of a Low Carbon Nb-Microalloyed Steel. Materials Science and Engineering A, 457, 219-225. http://dx.doi.org/10.1016/j.msea.2006.12.022

[115] Najafi-Zadeh, A., Jonas, J. and Yue, S. (1992) Grain Refinement by Dynamic Recrystallization during the Simulated Warm-Rolling of Interstitial Free Steels. Metallurgical and Materials Transactions A, 23, 2607-2617. http://dx.doi.org/10.1007/BF02658064

[116] Murty, S., Torizuka, S. and Nagai, K. (2005) Ferrite Grain Size Formed by Large Strain-High Deformation in a 0.15C Steel. Materials Transactions, 46, 2454-2460. http://dx.doi.org/10.2320/matertrans.46.2454

[117] Ueji, R., Tsuji, N., Minamino, Y. and Koizumi, Y. (2002) Ultra-Grain Refinement of Plain Low Carbon Steel by ColdRolling and Annealing of Martensite. Acta Materialia, 50, 4177-4189. http://dx.doi.org/10.1016/S1359-6454(02)00260-4

[118] Tsuji, N. and Maki, T. (2009) Enhanced Structural Refinement by Combining Phase Transformation and Plastic Deformation in Steels. Scripta Materialia, 60, 1044-1049. http://dx.doi.org/10.1016/j.scriptamat.2009.02.028

[119] Hase, K. and Tsuji, N. (2011) Effect of Initial Microstructure on Ultrafine Grain Formation through Warm Deformation in Medium-Carbon Steels. Scripta Materialia, 65, 404-407. http://dx.doi.org/10.1016/j.scriptamat.2011.05.018

[120] DeArdo, A. (1995) Modern Thermomechanical Processing of Microalloyed Steel: A Physical Metallurgy Perspective. Proceedings of Microalloying 95 Conference, Pittsburgh, 11-14 June 1995, 15-33.

[121] Tanaka, T. (1981) Controlled Rolling of Steel Plate and Strip. International Metals Revision, 26, 185-212. http://dx.doi.org/10.1179/imr.1981.26.1.185

[122] Jonas, J. and Sellars, C. (1992) Thermomechanical Processing. In: Charles, J.A., Greenwood, G.W. and Smith, G.S. Eds., Future Development of Metals and Ceramics, Woodhead Publishing Limited, Cambridge.

[123] Jonas, J. and Yue, S. (1990) Microstructural Evolution during Hot Rolling. Proceedings of the International Symposium on Mathematical Modeling of Hot Rolling of Steel, Hamilton, 26-29 August 1990, 99-118.

[124] Dutta, B., Palmiere, E.J. and Sellars, C.M. (2001) Modelling the Kinetics of Strain Induced Precipitation in Nb Microalloyed Steels. Acta Materialia, 49, 785-794. http://dx.doi.org/10.1016/S1359-6454(00)00389-X

[125] Dutta, B. and Palmiere, E.J. (2003) Effect of Prestrain and Deformation Temperature on the Recrystallization Behavior of Steels Microalloyed with Niobium. Metallurgical and Materials Transactions A, 34, 1237-1247. http://dx.doi.org/10.1007/s11661-003-0234-6 
[126] Alberto, M., Luiz, H. and Oscar, B. (2012) Ultra Grain Refinement during the Simulated Thermo-Mechanical Processing of Low Carbon Steel, The Journal of Materials Research and Technology, 1, 141-147. http://dx.doi.org/10.1016/S2238-7854(12)70025-X

[127] Speich, G., Demarest, V. and Miller, R. (1981) Formation of Austenite during Intercritical Annealing of Dual-Phase Steels. Metallurgical and Materials Transactions A, 12, 1419-1428. http://dx.doi.org/10.1007/BF02643686

[128] Oliveira, M., Jorge, J. and Balancin, O. (2004) Influence of Strain-Induced Nucleation on the Kinetics of Phase Transformation in a Forging Steel during Warm Working. Scripta Materialia, 50, 1157-1162. http://dx.doi.org/10.1016/j.scriptamat.2004.01.011

[129] Rezaee, A., Kermanpur, A., Najafizadeh, A. and Moallemi, M. (2011) Production of Nano/Ultrafine Grained AISI 201L Stainless Steel through Advanced Thermo-Mechanical Treatment. Materials Science and Engineering A, 528, 5025-5029. http://dx.doi.org/10.1016/j.msea.2011.02.093

[130] Farnoosh, F., Abbas, N., Kermanpur, K., Ali, H. and Roohallah. S. (2010) Production of Nano/Submicron Grained AISI 304L Stainless Steel through the Martensite Reversion Process. Materials Science and Engineering A, 527, 73347339. http://dx.doi.org/10.1016/j.msea.2010.08.002

[131] Moallemi, M., Kermanpur, A., Najafizadeh, A., Rezaee, A. and Samaei baghbadorani, H. (2012) Formation of Nano/Ultrafine Grain Structure in a 201 Stainless Steel Through the Repetitive Martensite Thermomechanical Treatment. Materials Letters, 89, 22-24. http://dx.doi.org/10.1016/j.matlet.2012.08.058

[132] Eskandari, M., Najafizadeh, A., Kermanpur, A. and Karimi, M. (2009) Potential Application of Nanocrystalline 301 Austenitic Stainless Steel in Lightweight Vehicle Structures. Materials and Design, 30, 3869-3872. http://dx.doi.org/10.1016/j.matdes.2009.03.043

[133] Momeni, A. and Abbasi, S. (2011) Repetitive Thermomechanical Processing towards Ultra Fine Grain Structure in 301, 304 and 304L Stainless Steels. The Journal of Materials Research and Technology, 27, 338-343. http://dx.doi.org/10.1016/S1005-0302(11)60071-6

[134] Pickering, F. (1978) Physical Metallurgy and the Design of Steels. Applied Science Publishers, London.

[135] Al-Hajeri, K. (2005) The Grain Coarsening and Subsequent Transformation of Austenite in the HSLA Steel during High Temperature Thermomechanical Processing. University of Pittsburgh, Pittsburgh, 15-16.

[136] Tanaka, T. (1995) Science and Technology of Hot Rolling Process of Steel. Proceedings of the International Conference on “Microalloying 95”, Pittsburgh, 11-14 June 1995, 165-181.

[137] Llewellyn, D. (1992) Steels: Metallurgy and Applications. Butterworth-Heinemann Reading, London.

[138] Cohen, C. and Hansen, S. (1985) On the Fundamentals of HSLA Steels, HSLA Steels. Metallurgy and Applications, Conference Proceeding, ASM International, Beijing, 4-8 November 1985, 61-71.

[139] Gray, J. and DeArdo, A. (1985) Austenite Conditioning Alternatives for Microalloyed Steels Products. HSLA Steels, Metallurgy and Applications, Conference Proceeding, ASM International, Beijing, 4-8 November 1985, 83-96.

[140] Palmiere, E., Garcia, C. and DeArdo, A. (1994) Compositional and Microstructural Changes Which Attend Reheating and Grain Coarsening in Steels Containing Niobium. Metallurgical and Materials Transactions A, 25, 277-286. http://dx.doi.org/10.1007/BF02647973

[141] Priestner, R. and Hodgson, P.D. (1992) Ferrite Grain Coarsening during Transformation of Thermomechanically Processed C-Mn-Nb Austenite. The Journal of Materials Research and Technology, 8, 849-854. http://dx.doi.org/10.1179/mst.1992.8.10.849

[142] Hodgson, P.D., Hickson, M.R. and Gibbs, R.K. (1998) The Production and Mechanical Properties of Ultrafine Ferrite. Materials Science Forum, 284-286, 63-72. http://dx.doi.org/10.4028/www.scientific.net/MSF.284-286.63

[143] Hurley, P.J., Muddle, B.C. and Hodgson, P.D. (2002) The Production of Ultrafine Ferrite during Hot Torsion Testing of a 0.11 wt pct C Steel. Metallurgical and Materials Transactions A, 33, 2985-2993. http://dx.doi.org/10.1007/s11661-002-0283-2

[144] Beladi, H., Kelly, G., Shokouhi, A. and Hodgson, P.D. (2004) The Evolution of Ultrafine Ferrite Formation through Dynamic Strain-Induced Transformation. Materials Science and Engineering A, 371, 343-352. http://dx.doi.org/10.1016/j.msea.2003.12.024

[145] Priestner, R. and Ibraheem, A.K. (2000) Processing of Steel for Ultrafine Ferrite Grain Structures. Journal of Materials Science \& Technology, 16, 1267-1272. http://dx.doi.org/10.1179/026708300101507497

[146] Azevedo, G., Barbosa, R., Pereloma, E.V. and Santos, D. B. (2005) Development of an Ultrafine Grained Ferrite in a Low C-Mn and Nb-Ti Microalloyed Steels after Warm Torsion and Intercritical Annealing. Materials Science and Engineering A, 402, 98-108. http://dx.doi.org/10.1016/j.msea.2005.04.026

[147] Beladi, H., Kelly, G., Shokouhi, A. and Hodgson, P. (2004) Effect of Thermomechanical Parameters on the Critical Strain for Ultrafine Ferrite Formation through Hot Torsion Testing. Materials Science and Engineering A, 367, 152- 
161. http://dx.doi.org/10.1016/j.msea.2003.09.095

[148] Yada, H., Li, C.M. and Yamagata, H. (2000) Dynamic $\gamma \rightarrow \alpha$ Transformation during Hot Deformation in Iron-NickelCarbon Alloys. Iron and Steel Institute of Japan (ISIJ) International, 40, 200-206. http://dx.doi.org/10.2355/isijinternational.40.200

[149] Chang, y., Kim, N. and Lee, C. (2007) Deformation Induced Ferrite Transformation in Microalloyed Steels: Theory and Application. Materials Science Forum, 561-565, 2491-2508.

[150] Matsumura, H. and Yada, Y. (1987) Evolution of Ultrafine-Grained Ferrite in Hot Successive Deformation. Transactions of the Iron and Steel Institute of Japan, 27, 492-498. http://dx.doi.org/10.2355/isijinternational1966.27.492

[151] Calcagnotto, M., Ponge, D. and Raabe, D. (2008) Ultrafine Grained Ferrite/Martensite Dual Phase Steel Fabricated by Large Strain Warm Deformation and Subsequent Intercritical Annealing. Iron and Steel Institute of Japan (ISIJ) International, 48, 1096-1101. http://dx.doi.org/10.2355/isijinternational.48.1096

[152] Calcagnotto, M., Ponge, D. and Raabe, D. (2010) Effect of Grain Refinement to $1 \mu \mathrm{m}$ on Strength and Toughness of Dual-phase Steels. Materials Science and Engineering A, 527, 7832-7840. http://dx.doi.org/10.1016/j.msea.2010.08.062

[153] Eduardo D., Akira, Y. and Jun, Y. (2014) Modeling Static and Dynamic Kinetics of Microstructure Evolution in Type 316 Stainless Steel. Steel Research International, 85, 1099-1108. http://dx.doi.org/10.1002/srin.201300173

[154] Akira, Y., Mamoru, I., Hisanao, K. and Jun, Y. (2012) Multistage and High-speed Compression Testing Machine for Obtaining Flow Stress and Microstructure Evolution in Hot Forming of Steels. Iron and Steel Institute of Japan (ISIJ) International, 52, 574-581. http://dx.doi.org/10.2355/isijinternational.52.574

[155] Toshiro, T., Norio, I. Kaori, M., Suguhiro, F., Mitsuru, Y., Masayuki, W., Manabu, E., Tamotsu, S., Youichi, H. and Yasutaka, O. (2008) Grain Refinement of C-Mn Steel to $1 \mu \mathrm{m}$ by Rapid Cooling and Short Interval Multi-Pass Hot Rolling in Stable Austenite Region. Iron and Steel Institute of Japan (ISIJ) International, 48, 1148-1157.

[156] Manabu, E., Suguhiro, F., Tamotsu, S., Youichi, H., Kaori, M., Masayuki, W., Toshiro, T., Norio, I., Mitsuru, Y. and Yasutaka, O. (2008) Super Short Interval Multi-Pass Rolling Process for Ultrafine-Grained Hot Strip. Iron and Steel Institute of Japan (ISIJ) International, 48, 1142-1147.

[157] Valiev, R., Sergueeva, A. and Mukherjee, A. (2003) The Effect of Annealing on Tensile Deformation Behavior of Nanostructure SPD Titanium. Scripta Materialia, 49, 669-674. http://dx.doi.org/10.1016/S1359-6462(03)00395-6

[158] Alexandrov, I. and Valiev, R. (2001) Developing of SPD Processing and Enhanced Properties in Bulk Nanostructured Metals. Scripta Materialia, 44, 1605-1608. http://dx.doi.org/10.1016/S1359-6462(01)00783-7

[159] Stolyarov, V., Zhu, Y., Lowe, T., Islamgaliev, R. and Valiev, R. (1999) A Two Step SPD Processing of UltrafineGrained Titanium. Nanostructred Materials, 11, 947-954. http://dx.doi.org/10.1016/S0965-9773(99)00384-0

[160] Valiev, R., Krasilnikov, N. and Tsenev, N. (1991) Plastic Deformation of Alloys with Submicro-Grained Structure. Materials Science and Engineering A, 137, 35-40. http://dx.doi.org/10.1016/0921-5093(91)90316-F

[161] Segal, V., Dobatkin, S. and Valiev, R. (editors) (2004) Equal-Channel Angular Pressing of Metallic Materials: Achievements and Trends. Thematic Issue, Part 1, Russian Metall, 1, 1-102. (translated from Metally 2004, no. 1, pp. 3-119).

[162] Brandon, D.G. (1966) The Structure of High-Angle Grain Boundaries Structure de Joints de Grains a Grands Angles. Acta Metallurgica, 14, 1479-1484. http://dx.doi.org/10.1016/0001-6160(66)90168-4

[163] Zhilyaev, A. and Langdon, T. (2008) Using High-Pressure Torsion for Metal Processing: Fundamentals and Applications. Progress in Materials Science, 53, 893-979. http://dx.doi.org/10.1016/j.pmatsci.2008.03.002

[164] Mishra, R.S. Valiev, R.Z. and A.K. Mukherjee, A.K. (1997) The Observation of Tensile Superplasticity in Nanocrystalline Materials. Nanostructured Materials, 9, 473-476. http://dx.doi.org/10.1016/S0965-9773(97)00103-7

[165] Zhilyaev, A., Nurislamova, G., Kim, B., Baro, M., Szpunar, J. and Langdon, T. (2003) Experimental Parameters Influencing Grain Refinement and Microstructural Evolution During High-Pressure Torsion. Acta Materialia, 51, 753765. http://dx.doi.org/10.1016/S1359-6454(02)00466-4

[166] Salishchev, G., Valiahmetov, O. and Galeev, R. (1993) Formation of Submicrocrystalline Structure in Titanium Alloy VT8 and Its Influence on Mechanical Properties. Journal of Materials Science, 28, 2898-2902. http://dx.doi.org/10.1007/BF00354692

[167] Sevillano, J., Houtte, P. and Aernoudt, E. (1980) Large Strain Work Hardening and Textures. Progress in Materials Science, 25, 69134. http://dx.doi.org/10.1016/0079-6425(80)90001-8

[168] Sitdikov, O., Sakai, T., Goloborodko, A., Miura, H. and Kaibyshev, R. (2004) Effect of Pass Strain on Grain Refinement in 7475 Al Alloy during Hot Multidirectional Forging. Materials Transactions, 45, 2232-2238. http://dx.doi.org/10.2320/matertrans.45.2232

[169] Beygelzimer, Y., Varyukhin, V., Orlov, D., Synkov, S., Spuskanyuk, A. and Pashinska,Y. (2004) Severe Plastic De- 
formation by Twist Extrusion. In: Zehetbauer, M.J. and Valiev, R.Z., Eds., Nanomaterials by Severe Plastic Deformation. Wiley-VCH Verlag, Weinheim, 511-516.

[170] Varyutkhin, V., Beygelzimer, Y., Synkov, S. and Orlov. D. (2006) Application of Twist Extrusion. Materials Science Forum, 503-504, 335-340.

[171] Bay, B., Hansen, N., Hughes, D.A. and Kuhlmann-Wilsdorf, D. (192) Overview No. 96 Evolution of f.c.c. Deformation Structures in Polyslip. Acta Metallurgica et Materialia, 40, 205-219. http://dx.doi.org/10.1016/0956-7151(92)90296-Q

[172] Richert, M., Liu, Q. and Hansen, N. (1999) Microstructural Evolution over a Large Strain Range in Aluminum Deformed by Cyclic-Extrusion Compression. Materials Science and Engineering A, 260, 275-283. http://dx.doi.org/10.1016/S0921-5093(98)00988-5

[173] Chu, H., Liu, K. and Yeh, J. (2000) Study of 6061- $\mathrm{Al}_{2} \mathrm{O}_{3 \mathrm{p}}$ Composites Produced by Reciprocating Extrusion. Metallurgical and Materials Transactions A, 31, 2587-2596. http://dx.doi.org/10.1007/s11661-000-0203-2

[174] Chu, H., Liu, K. and Yeh, J. (2001) Aging Behavior and Tensile Properties of 6061Al-0.3 $\mu$ m $\mathrm{Al}_{2} \mathrm{O}_{3 \mathrm{p}} \mathrm{Particle} \mathrm{Com-}$ posites Produced by Reciprocating Extrusion, Scripta Materialia, 45, 541-546. http://dx.doi.org/10.1016/S1359-6462(01)01055-7

[175] Huang, I., Zhu, Y., Jiang, H. and Lowe, T. (2001) Microstructures and Dislocation Configurations in Nanostructured Cu Processed by Repetitive Corrugation and Straightening, Acta Materialia, 49, 1497-1505. http://dx.doi.org/10.1016/S1359-6454(01)00069-6

[176] Zhu, Y., Jiang, H., Huang, J. and Lowe, T. (2001) A New Route to Bulk Nanostructured Metals. Metallurgical and Materials Transactions A, 32, 1559-1562. http://dx.doi.org/10.1007/s11661-001-0245-0

[177] Shin, D., Park, J., Kim, Y. and Park, K. (2002) Constrained Groove Pressing and Its Application to Grain Refinement of Aluminum. Materials Science and Engineering A, 328, 98-103. http://dx.doi.org/10.1016/S0921-5093(01)01665-3

[178] Zhao, X., Jing, T.F., Gao, Y.W., Zhou, J.F. and Wang, W. (2004) A New SPD Process for Spheroidal Cast Iron. Materials Letters, 58, 2335-2339. http://dx.doi.org/10.1016/j.matlet.2004.01.034

[179] Saito, Y., Tsuji, N., Utsunomiya, H., Sakai, T. and Hong, R.G. (1998) Ultra-Fine Grained Bulk Aluminum Produced by Accumulative Roll-Bonding (ARB) Process. Scripta Materialia, 39, 1221-1227. http://dx.doi.org/10.1016/S1359-6462(98)00302-9

[180] Saito, Y., Utsunomiya, H., Tsuji, N. and Sakai, T. (1999) Novel Ultra-High Straining Process for Bulk MaterialsDevelopment of the Accumulative Roll-bonding (ARB) Process. Acta Materialia, 47, 579-583. http://dx.doi.org/10.1016/S1359-6454(98)00365-6

[181] Rhodes, C., Mahoney, M., Bingel, W., Spurling, R. and Bampton, C. (1997) Effects of Friction Stir Welding on Microstructure of 7075 Aluminum. Scripta Materialia, 36, 69-75. http://dx.doi.org/10.1016/S1359-6462(96)00344-2

[182] Mishra, R., Ma, Z. and Charit, I. (2003) Friction Stir Processing: A Novel Technique for Fabrication of Surface Composite. Materials Science and Engineering A, 341, 307-310. http://dx.doi.org/10.1016/S0921-5093(02)00199-5

[183] Hofmann, D. and Vecchio, K. (2005) Submerged Friction Stir Processing (SFSP): An Improved Method for Creating Ultra-fine-grained Bulk Materials. Materials Science and Engineering A, 402, 234-241. http://dx.doi.org/10.1016/j.msea.2005.04.032

[184] Hofmann, D. and Vecchio, K. (2007) Thermal History Analysis of Friction Stir Processed and Submerged Friction Stir Processed Aluminum, Materials Science and Engineering A, 465, 165-175. http://dx.doi.org/10.1016/j.msea.2007.02.056

[185] Valiev, R., Krasilnikov, N. and Tsenev, N. (1991) Plastic Deformation of Alloys with Submicron-Grained Structure. Materials Science and Engineering A, 137, 35-40. http://dx.doi.org/10.1016/0921-5093(91)90316-F

[186] Fukuda, Y., Oh-Ishi, K., Horita, Z. and Langdon, T.G. (2002) Processing of a Low-Carbon Steel by Equal-channel Angular Pressing. Acta Materialia, 50, 1359-1368. http://dx.doi.org/10.1016/S1359-6454(01)00441-4

[187] Shin, D., Kim, B., Kim, Y. and Park, K. (2000) Microstructural Evolution in a Commercial Low Carbon Steel by Equal Channel Angular Pressing. Acta Materialia, 48, 2247-2256. http://dx.doi.org/10.1016/S1359-6454(00)00028-8

[188] Tóth, L. (2005) Modelling of Strain Hardening and Microstructural Evolution in Equal Channel Angular Extrusion. Computational Materials Science, 32, 568-576. http://dx.doi.org/10.1016/j.commatsci.2004.09.007

[189] Hansen, N. and Barlow, C.Y. (2014) 17-Plastic Deformation of Metals and Alloys. Physical Metallurgy (Fifth Edition), II, 1681-1764. http://dx.doi.org/10.1016/B978-0-444-53770-6.00017-4

[190] Segal, V. (1995) Equal Channel Angular Extrusion: From Macromechanics to Structure Formation. Materials Science and Engineering A, 271, 322-333. http://dx.doi.org/10.1016/S0921-5093(99)00248-8

[191] Tóth, I., Massion, R., Germain, L., Baik, S. and Suwas, S. (2003) Analysis of Texture Evolution in Equal Channel 
Angular Extrusion of Copper Using a New Flow Field. Acta Materialia, 52, 1885-1898. http://dx.doi.org/10.1016/j.actamat.2003.12.027

[192] Beyerlein, I. and Tome, C. (2004) Analytical Modeling of Material Flow in Equal Channel Angular Extrusion (ECAE). Materials Science and Engineering A, 380, 171-190. http://dx.doi.org/10.1016/j.msea.2004.03.063

[193] Valiev, R., Islamgaliev, R. and Alexandrov, I. (2000) Bulk Nanostructured Materials from Severe Plastic Deformation. Progress in Materials Science, 45, 103-189. http://dx.doi.org/10.1016/S0079-6425(99)00007-9

[194] Zhu, Y. and Langdon, T. (2004) Fundamentals of Nanostructured Materials by Severe Plastic Deformation. The Journal of the Minerals, Metals \& Materials Society (TMS), 56, 58-63. http://dx.doi.org/10.1007/s11837-004-0294-0

[195] Raab, G., Valiev, R., Lowe, T. and Zhu, Y. (2004) Continuous Processing of Ultrafine Grained Al by ECAP-Conform. Materials Science and Engineering A, 382, 30-34. http://dx.doi.org/10.1016/j.msea.2004.04.021

[196] Tsuji, N., Saito, Y., Lee, S. and Minamino, Y. (2003) ARB (Accumulative Roll-Bonding) and Other New Techniques to Produce Bulk Ultrafine Grained Materials. Advanced Engineering Materials, 5, 338-344. http://dx.doi.org/10.1002/adem.200310077

[197] Saito, Y., Utsunomiya, H., Tsuji, N. and Sakai, T. (1999) Novel Ultra-High Straining Process for Bulk MaterialsDevelopment of the Accumulative Roll-bonding (ARB) Process. Acta Materialia, 47, 579-583. http://dx.doi.org/10.1016/S1359-6454(98)00365-6

[198] Tsuji, I., Ito, Y., Saito, Y. and Minamino, Y. (2002) Strength and Ductility of Ultrafine Grained Aluminum and Iron Produced by ARB and Annealing, Scripta Materialia, 47, 893-899. http://dx.doi.org/10.1016/S1359-6462(02)00282-8

[199] Costa, A., Reis, L., Kestens, M. and Andrade, A. (2005) Ultra Grain Refinement and Hardening of IF-Steel during Accumulative Roll-bonding. Materials Science and Engineering A, 406, 279-285. http://dx.doi.org/10.1016/j.msea.2005.06.058

[200] Cao, Y., Wang, Y., Liao, X. Kawasaki, M., Ringer, S., Langdon, T.G. and Zhu. Y.T. (2014) Concurrent Microstructural Evolution of Ferrite and Austenite in a Duplex Stainless Steel Processed by High-Pressure Torsion. Acta Materialia, 63, 16-29. http://dx.doi.org/10.1016/j.actamat.2013.09.030

[201] Valiev, R., Korznikov, A. and Mulyukov, R. (1993) Structure and Properties of Ultrafine-Grained Materials Produced by Severe Plastic Deformation, Materials Science and Engineering A, 186, 141-148. http://dx.doi.org/10.1016/0921-5093(93)90717-S

[202] Nakao, Y. and Miura, H. (2011) Nano-Grain Evolution in Austenitic Stainless Steel during Multi-Directional Forging. Materials Science and Engineering A, 528, 1310-1317. http://dx.doi.org/10.1016/j.msea.2010.10.018

[203] Huang, J. and Xu, Z. (2006) Evolution Mechanism of Grain Refinement Based on Dynamic Recrystallization in Multiaxially Forged Austenite. Materials Letters, 60, 1854-1858.http://dx.doi.org/10.1016/j.matlet.2005.12.110

[204] Tsuji, N., Kitahara, H., Ueji, R. and Ueda, M. (2005) Crystallographic Analysis of Martensite in Steels by Means of EBSD. Proceedings of International Conference on Martensitic Transformations (ICOMAT 05), 14-17 June 2005, Shanghai. KEYNOTE lecture in the session E.

[205] Guthrie, R. and Jonas, J. (1993) ASM Handbook. 10th Edition, Vol. 1, American Society for Metals, Metals Park, 288-292.

[206] Tsuji, I., Ueji, R., Minamino, Y. and Saito, Y. (2002) A New and Simple Process to Obtain Nano-structured Bulk LowCarbon Steel with Superior Mechanical Property. Scrpita Materiala, 46, 305-310. http://dx.doi.org/10.1016/S1359-6462(01)01243-X

[207] Soleymani, V. and Eghbali, B. (2012) Grain Refinement in a Low Carbon Steel through Multidirectional Forging. Journal of Iron and Steel Research International, 19, 74-78. http://dx.doi.org/10.1016/S1006-706X(12)60155-1

[208] Shiro, T., Akio, O., Narayana, M., Murty, S.V.S. and Kotobu, N. (2006) Effect of Strain on the Microstructure and Mechanical Properties of Multi-Pass Warm Caliber Rolled Low Carbon Steel. Scripta Materialia, 54, 563-568. http://dx.doi.org/10.1016/j.scriptamat.2005.10.055

[209] Valiev, R. and Langdon, T. (2006) Principles of Equal-Channel Angular Pressing as a Processing Tool for Grain Refinement. Progress in Materials Science, 51, 881-981. http://dx.doi.org/10.1016/j.pmatsci.2006.02.003

[210] Ji, Y. and Park, J. (2009) Development of Severe Plastic Deformation by Various Asymmetric Rolling Processes. Materials Science and Engineering A, 499, 14-17. http://dx.doi.org/10.1016/j.msea.2007.11.099

[211] Alihosseini, H., Asle Zaeem, M. and Dehghani, K. (2012) A Cyclic Forward-Backward Extrusion Process as a Novel Severe Plastic Deformation for Production of Ultrafine Grains Materials. Materials Letters, 68, 204-208. http://dx.doi.org/10.1016/j.matlet.2011.10.037

[212] Saito, Y., Tsuji, N., Utsunomiya, H., Sakai, T. and Hong, R.G. (1998) Ultra-Fine Grained Bulk Aluminum Produced by Accumulative Roll-bonding (ARB) Process. Scripta Materialia, 39, 1221-1227. 
http://dx.doi.org/10.1016/S1359-6462(98)00302-9

[213] Shin, D., Park, J., Kim, Y. and Park, K. (2002) Constrained Groove Pressing and Its Application to Grain Refinement of Aluminum. Materials Science and Engineering A, 328, 98-103. http://dx.doi.org/10.1016/S0921-5093(01)01665-3

[214] Tsuji, I., Saito, Y., Utsunomiya, H. and Tanigawa, S. (1999) Ultra-Fine Grained Bulk Steel Produced by Accumulative Roll-Bonding (ARB) Process. Scripta Materialia, 40, 795-800. http://dx.doi.org/10.1016/S1359-6462(99)00015-9

[215] Krishnaiah, I., Chakkingal, U. and Venugopal, P. (2005) Production of Ultrafine Grain Sizes in Aluminium Sheets by Severe Plastic Deformation Using the Technique of Groove Pressing. Scripta Materialia, 52, 1229-1233. http://dx.doi.org/10.1016/j.scriptamat.2005.03.001

[216] Khodabakhshi, F., Kazeminezhad, M. and Kokabi, A.H. (2010) Constrained Groove Pressing of Low Carbon Steel: Nano-Structure and Mechanical Properties. Materials Science and Engineering A, 527, 4043-4049. http://dx.doi.org/10.1016/j.msea.2010.03.005

[217] Alihosseini, H. and Dehghani, K. (2012) Bake Hardening of Ultra-Fine Grained Low Carbon Steel Produced by Constrained Groove Pressing. Materials Science and Engineering A, 549, 157-162. http://dx.doi.org/10.1016/j.msea.2012.04.024

[218] Khodabakhshi, F., Kazeminezhad, M. and Kokabi, A.H. (2012) Resistance Spot Welding of Ultra-Fine Grained Steel Sheets Produced by Constrained Groove Pressing: Optimization and Characterization. Material Characterization, 69, 71-83. http://dx.doi.org/10.1016/j.matchar.2012.04.011

[219] Shiro, T., Matthias, K., Yoshiyuki, F. and Manfred, B. (2012) Effect of Tensile Strength and Microstructure on NotchFatigue Properties of Ultrafine-Grained Steels. Iron and Steel Institute of Japan (ISIJ) International, 52, 910-914. http://dx.doi.org/10.2355/isijinternational.52.910

[220] Ohmori, I., Torizuka, S., Nagai, K., Koseki N. and Kogo, Y. (2003) Transformations and Microstructures -Evolution of Ultrafine-Grained Ferrite Structure through Multi-Pass Warm Caliber-Rolling. Tetsu-To-Hagane/Journal of the Iron and Steel Institute of Japan, 89, 781-788.

[221] Murty, S. and Torizuka, S. (2008) Microstructure-Mechanical Properties Correlation in Ultrafine Grained Steels Processed by Large Strain Warm Deformation. Iron and Steel Institute of Japan (ISIJ) International, 48, 1088-1095. http://dx.doi.org/10.2355/isijinternational.48.1088

[222] Torizuka, S., Muramatsu, E., Murty, S. and Nagai, K. (2006) Microstructure Evolution and Strength-Reduction in Area Balance of Ultrafine-Grained Steels Processed by Warm Caliber Rolling. Scrpita Materiala, 55, 751-754. http://dx.doi.org/10.1016/j.scriptamat.2006.03.067

[223] Kimura, Y., Inoue, T., Yin, F. and Tsuzaki, K. (2008) Inverse Temperature Dependence of Toughness in an Ultrafine Grain-Structure Steel. Science, 320, 1057-1060.

[224] Kimura, Y., Inoue, T., Yin, F. and Tsuzaki, K. (2010) Delamination Toughening of Ultrafine Grain Structure Steels Processed through Tempforming at Elevated Temperatures. Iron and Steel Institute of Japan (ISIJ) International, 50, 152-161. http://dx.doi.org/10.2355/isijinternational.50.152

[225] Kimura, Y., Inoue, T. and Tsuzaki, K. (2013) Tempforming in Medium-Carbon Low-Alloy Steel. Journal of Alloys and Compounds, 577, S538-S542. http://dx.doi.org/10.1016/j.jallcom.2011.12.123

[226] Wu, Z., Ding, H., Li, H., Huang, M. and Cao, F. (2013) Microstructural Evolution and Strain Hardening Behavior during Plastic Deformation of Fe-12Mn-8Al-0.8C Steel. Materials Science and Engineering A, 584, 150-155. http://dx.doi.org/10.1016/j.msea.2013.07.023

[227] Kang, S., Na, Y., Park, K., Jeon, J., Son, S. and Lee, J. (2007) A Study on the Micro-Formability of Al 5083 Superplastic Alloy Using Micro-Forging Method. Materials Science and Engineering A, 449-451, 338-342. http://dx.doi.org/10.1016/j.msea.2006.01.166

[228] Langdon. T. (2013) Twenty-Five Years of Ultrafine-Grained Materials: Achieving Exceptional Properties through Grain Refinement, Acta Materialia, 61, 7035-7059. http://dx.doi.org/10.1016/j.actamat.2013.08.018

[229] Lesuer, D., Syn, C. and Sherby, O. (1996) Ultrahigh Carbon Steel for Automotive Applications. 1996 SAE International Congress \& Exposition, Detroit, 26-29 February 1996, 26-29.

[230] Elices, M. (2004) Influence of Residual Stresses in the Performance of Cold Drawing Pearlitic Wires. Journal of Materials Science, 39, 3889-3899. http://dx.doi.org/10.1023/B:JMSC.0000031470.31354.b5

[231] Zhao, M., Yang, K. and Shan, Y. (2002) The Effects of Thermo-Mechanical Control Process on Microstructures and Mechanical Properties of a Commercial Pipeline Steel. Materials Science and Engineering A, 335, 14-20. http://dx.doi.org/10.1016/S0921-5093(01)01904-9

[232] Bott, I., Teixeira, L. and Rios, R. (2005) High-Strength Steel Development for Pipelines. Metallurgical and Materials Transactions A, 36, 443-454.http://dx.doi.org/10.1007/s11661-005-0315-9

[233] Hillenbrand, I., Graf, I. and Kalwa, I. (2001) Development and Production of High Strength Pipeline Steels. Proceed- 
ings of the Conference Niobium, Orlando, 2-5, December 2001.

[234] Takahashi, I. and Iino, M. (1996) Thermomechanical Control Process as a Tool to Grain Refine the Low Manganesecontaining Steel for Sour Service Line Pipe. Iron and Steel Institute of Japan (ISIJ) International, 36, 235-240. http://dx.doi.org/10.2355/isijinternational.36.235

[235] Takahashi, A. and Iino, M. (1996) Microstructure Refinement by Cu Addition and Its Effect on Strengthening and Toughening of Sour Service Line Pipe. Iron and Steel Institute of Japan (ISIJ) International, 36, 241-245. http://dx.doi.org/10.2355/isijinternational.36.241

[236] Contreras, A., Albiter, A., Salazar, M. and Perez, R. (2005) Slow Strain Rate Corrosion and Fracture Characteristics of X-52 and X-70 Pipeline Steels. Materials Science and Engineering A, 407, 45-52. http://dx.doi.org/10.1016/j.msea.2005.07.028

[237] Kim, Y., Kim, S., Lim, Y. and Kim, N. (2002) Effect of Microstructure on the Yield Ratio and Low Temperature Toughness of Line-Pipe Steels. Iron and Steel Institute of Japan (ISIJ) International, 42, 1571-1577. http://dx.doi.org/10.2355/isijinternational.42.1571

[238] Zhong, Y., Xiao,F., Zhang, J., Shan, Y., Wang, W. and Yang, K. (2006) In Situ TEM Study of the Effect of M/A Films at Grain Boundaries on Crack Propagation in an Ultra-fine Acicular Ferrite Pipeline Steel. Acta Materialia, 54, 435443. http://dx.doi.org/10.1016/j.actamat.2005.09.015

[239] Skripnyuk, V., Rabkin, E., Estrin, Y. and Lapovok, R. (2004) The Effect of Ball Milling and Equal Channel Angular Pressing on the Hydrogen Absorption/Desorption Properties of Mg-4.95 wt\% Zn-0.71 wt\% Zr (ZK60) Alloy. Acta Materialia, 52, 405-414. http://dx.doi.org/10.1016/j.actamat.2003.09.025

[240] Latysh, V., Krallics, G.Y., Alexandrov, I. and Fodor. A. (2006) Application of Bulk Nanostructured Materials in Medicine. Current Applied Physics, 6, 262-266.http://dx.doi.org/10.1016/j.cap.2005.07.053

[241] Eissa, M. (1988) The Effect of Microalloying Additions and Hot Rolling Condition on the Mechanical Properties of High Strength Low Alloy Steels. Ph.D. Thesis, Faculty of Engineering, Cairo University, Egypt.

[242] Baraka, I., El-Fawakhry, K., Mishreky, M.L., Eissa, M. and Lamei, M.M. (1989) Effect of Titanium as Microalloying Element on the Mechanical Properties of High Strength Low Alloy Steel. 2nd International Conference on Mining and Metallurgical Engineering, Suez Canal University, 20-22 March 1989, 580-588.

[243] El-Fawakhry, K., Mishreky, M.L. and Eissa, M. (1990) Secondary Hardening of Vanadium and Titanium Microalloyed Steels. Scandinavian Journal of Metallurgy, 19, 33-38.

[244] Mekkawy, M.F., El-Fawakhry, K., Mishreky, M.L. and Eissa, M. (1990) Effect of Rolling Schedule on Mechanical Properties and Structure of V- and Ti-Microalloyed Steels. Scandinavian Journal of Metallurgy, 19, 82-84.

[245] Mekkawy, M.F., El-Fawakhry, K., Mishreky, M.L. and Eissa, M. (1990) Effect of Reheating Temperature on Microstructure and Strength of V- and Ti-microalloyed Steels. Scandinavian Journal of Metallurgy, 19, 236-245.

[246] Mekkawy, M.F., El-Fawakhry, K., Mishreky, M.L. and Eissa, M. (1990) Effect of Finish-rolling Temperature on Microstructure and Strength of V- and Ti-Microalloyed Steels. Scandinavian Journal of Metallurgy, 19, 246-256.

[247] Mekkawy, M.F., El-Fawakhry, K., Mishreky, M.L. and Eissa, M. (1990) Direct Quenching of Low Manganese Steels Microalloyed with Vanadium or Titanium. Transactions of the Iron and Steel Society (ISS), Iron and Steelmaker, October (1990), 75-83.

[248] Mekkawy, M.F., El-Fawakhry, K., Mishreky, M.L. and Eissa, M. (1990) Effect of Interrupted Accelerated Cooling on Mechanical Properties and Structure of V- and Ti-Microalloyed Steel Bars. Materials Science and Technology, 7, 2836. http://dx.doi.org/10.1179/mst.1991.7.1.28

[249] Eissa, M., El-Fawakhry, K., Mishreky, M.L. and Abd ElKarim, O. (1993) Production of Titanium Microalloyed Reinforcing Steel Bars in Open Hearth Furnaces. AMSE Transactions, 34, 1-15.

[250] Lamei, M.M. (1993) The Effect of Microalloying Elements on the Mechanical Properties of Low Carbon-Manganese Steel. Ph.D. Thesis, Faculty of Science, Cairo University, Egypt.

[251] Tawfik, I. (1993) Effect of Vanadium and Nitrogen on Mechanical Properties of Low Carbon Steels. M.Sc. Thesis, Faculty of Engineering, Cairo University, Egypt.

[252] Fathi, A. (1994) Microalloyed High Carbon Steel. M.Sc. Thesis, Faculty of Science, Helwan University, Egypt.

[253] Eissa, M., El-Fawakhry, K., El-Faramawy, H. and Fathy, A. (1996) Production of Ultra High Strength Wire Rod Steels by Vanadium Microalloying. Steel Research, 67, 100-105.

[254] Eissa, M., El-Fawakhry, K., El-Faramawy, H. and Fathy, A. (1996) Vanadium-Microalloyed High Carbon Steel. Transactions of Iron and Steel Society (ISS), Iron and Steelmaker, 23, 73-81

[255] Eissa, M., El-Fawakhry, K., Ahmed, M., El-Zommor, M. and Lamei, M.M. (1997) Development of Superior High Strength Low Impact Transition Temperature Steels Microalloyed with Vanadium and Nitrogen. Journal of Materials 
Science and Technology, 5, 3-19.

[256] Eissa, M., El-Fawakhry, K., Mishreky, M.L. Hussein, A.H. and Tawfik, A. (1998) Low Carbon Manganese Steels Microalloyed with Vanadium and Nitrogen. Steel Research, 69, 334-342.

[257] El-Fawakhry, K., Eissa, M. and Mishreky, M.L. (1998) Production of High Strength Steel for Prestressed Concrete Using Microalloying Technology. AISU 2nd International Symposium on "Electric Furnace”, Damascus, 18-20 Octorber 1998.

[258] Eissa, M. (1998) Influence of Base Composition on the Strength of Vanadium-Microalloyed Steel Bars. Steel Research, 69, 438-445.

[259] Eissa, M. and Mattar, T. (2002) Mechanical Properties Relationships in V- and Ti-Microalloyed Steels. Steel Research, 73, 403-408.

[260] Eissa, M., Abd El-Aziz, A., Ghaly, S., Halfa, H. and Saber, S. (2011) Effect of Microalloying Additions on the Microstructure and Mechanical Properties of Low Carbon Steel. Journal of Iron and Steel Research International, 18, 246251.

[261] Eissa, M., Mekkawy, F., El-Fawakhry, K. and Mishreky, M.L. (1991) Characterization of Precipitates in Vanadium and Titanium Microalloyed Steels. Iron and Steel Institute of Japan (ISIJ) International, 31, 1020-1025. http://dx.doi.org/10.2355/isijinternational.31.1020 
Scientific Research Publishing (SCIRP) is one of the largest Open Access journal publishers. It is currently publishing more than 200 open access, online, peer-reviewed journals covering a wide range of academic disciplines. SCIRP serves the worldwide academic communities and contributes to the progress and application of science with its publication.

Other selected journals from SCIRP are listed as below. Submit your manuscript to us via either submit@scirp.org or Online Submission Portal.
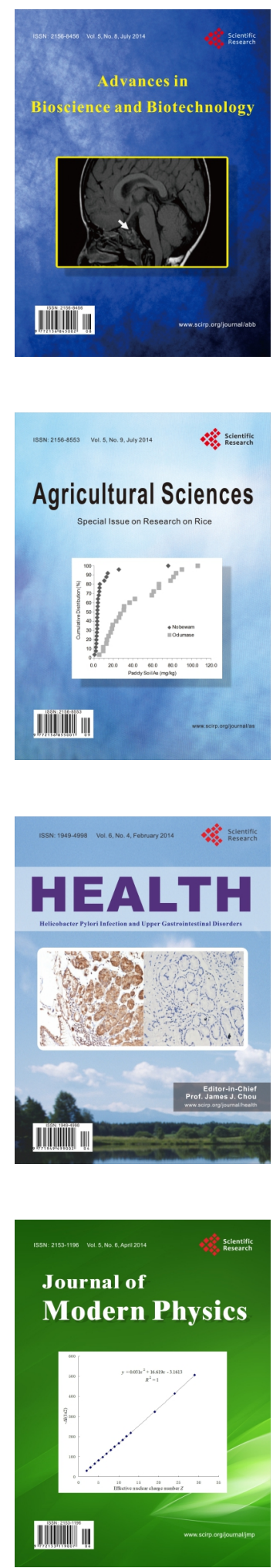
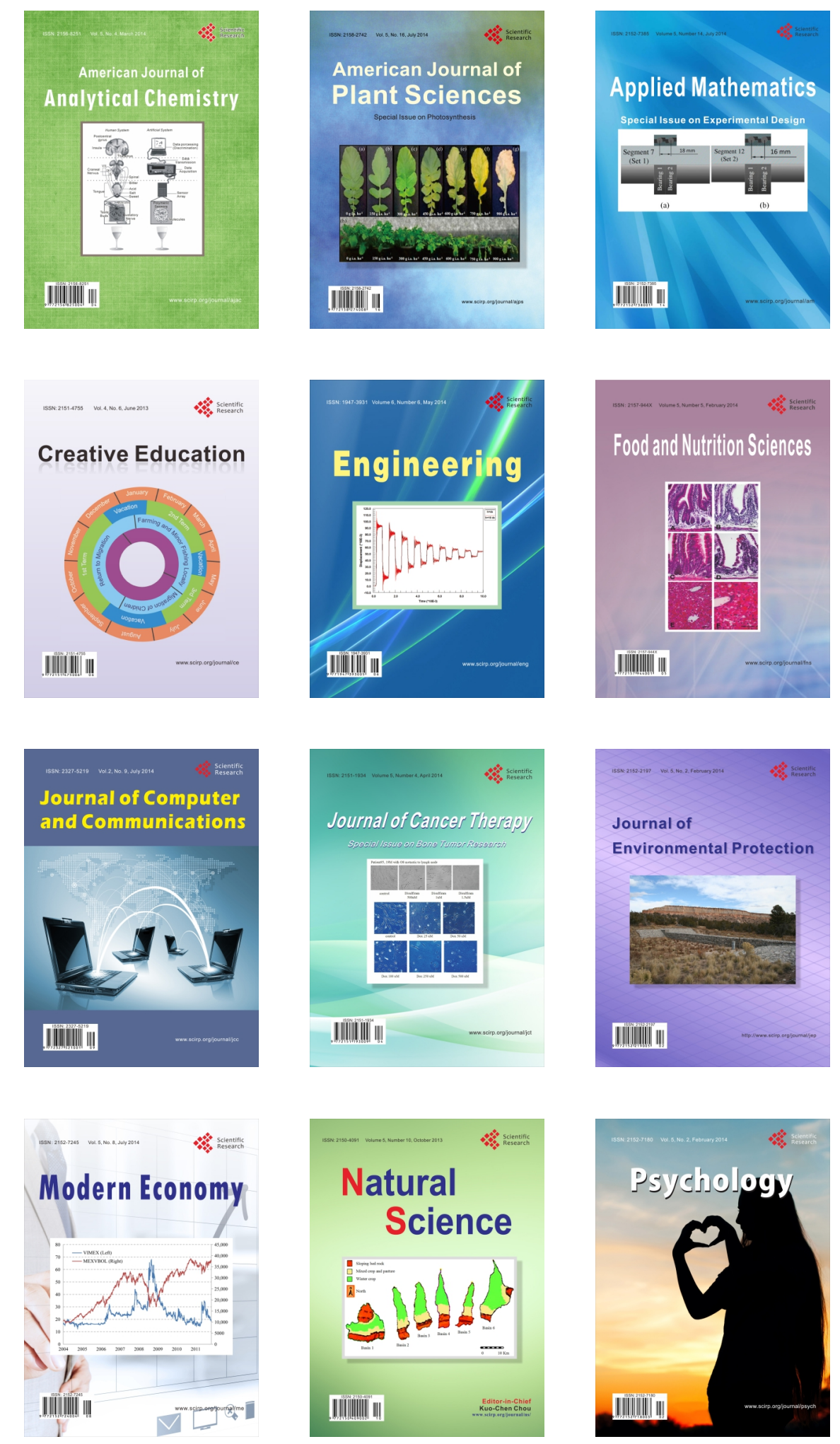